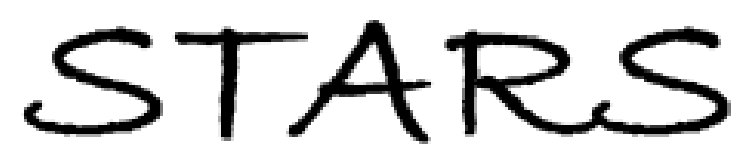

University of Central Florida

STARS

\title{
Assessing The Web-based Destination Marketing Activities: A Relationship Marketing Perspective
}

Liza Cobos

University of Central Florida

Part of the Hospitality Administration and Management Commons, and the Tourism and Travel Commons

Find similar works at: https://stars.library.ucf.edu/etd

University of Central Florida Libraries http://library.ucf.edu

This Masters Thesis (Open Access) is brought to you for free and open access by STARS. It has been accepted for inclusion in Electronic Theses and Dissertations, 2004-2019 by an authorized administrator of STARS. For more information, please contact STARS@ucf.edu.

\section{STARS Citation}

Cobos, Liza, "Assessing The Web-based Destination Marketing Activities: A Relationship Marketing Perspective" (2006). Electronic Theses and Dissertations, 2004-2019. 1099.

https://stars.library.ucf.edu/etd/1099

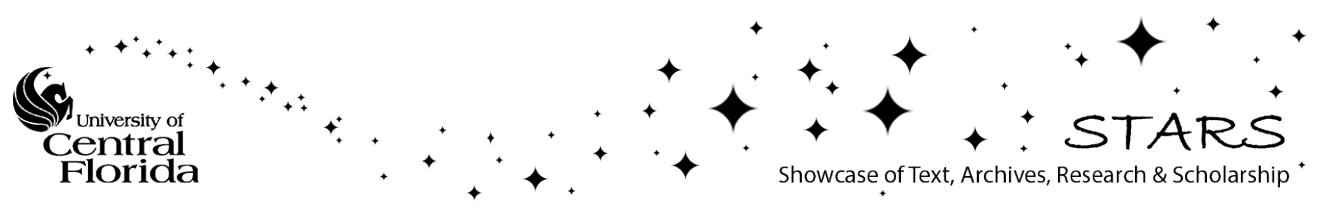




\title{
ASSESSING THE WEB-BASED DESTINATION MARKETING ACTIVITIES: A RELATIONSHIP MARKETING PERSPECTIVE
}

by

\section{LIZA M. COBOS}

B.B.A. Loyola University New Orleans, 2001

\author{
A thesis submitted in partial fulfillment of the requirements \\ for the degree of Master of Science in Tourism and Hospitality Management \\ in the Rosen College of Hospitality Management \\ at the University of Central Florida \\ Orlando, Florida
}

Fall Term

2006 
(C) 2006 Liza M. Cobos 


\begin{abstract}
Innovations in information technology have played an important role in the way business is conducted. Technology innovations have great impact on tourism destination marketing organizations such as convention and visitor bureaus, since they are highly dependent on information and timely distribution of it to the public. Information technology innovations such as the Internet allow CVBs to perform their marketing functions in a more efficient manner.

The implementation of web-based marketing functions is impacted by organizational characteristics that either foster or hinder their implementation (Thong, 1999; Tornatzky \& Fleischer, 1990; Wang \& Fesenmaier, 2006; Zhu \& Kraemer, 2005). Information technology innovations have been adopted by organizations in different levels of sophistication. Since the main function of a CVB is the promotion of a destination technologies that facilitate this process are important to this type of organization. Unfortunately, the marketing practice of American CVBs is still dominated by principles of mass marketing by communicating the same message to all consumers. As a result, the use of websites by American CVB has been limited to information provision functions and has lost opportunities to build relationship with customers through additional web-based marketing activities.

This study proposes that CVBs should use web-based marketing activities to attract and retain relationships with customers. This study provides two main contributions to the existing literature: a) examines web-based marketing functions from a relationship marketing perspective and b) examines the impact of organizational characteristics on the sophistication level of webbased marketing functions.
\end{abstract}


The use and effectiveness of web functions and its applications were examined. The results showed that the majority of the CVBs focus the use of their website to provide information. A standard multiple regression was used to investigate the impact of the organizational factors on the different web functions. The results of the regression show that size, financial resources and management team's technological expertise are the only factors that impact the level of web functions implemented by CVBs. 
For my dad, mom and sisters who have always encouraged me to reach for my dreams.

"The future belongs to those who believe in the beauty of their dreams" Eleanor Roosevelt 


\section{ACKNOWLEDGMENTS}

Many people have contributed to this project both directly by providing guidance and indirectly by providing support and encouragement. First, I would like to thank my committee members for providing me with guidance and support through this process. Dr. Youcheng Wang, my advisor and committee chair, thank you for encouraging me to do the thesis, for helping me focus my topic and for your continued guidance through this process without your constant support this would not be possible. Dr. Tammie Kaufman thank you for your support and kind words when they were most needed. Dr. Fevzi Okumus thank you for the probing questions, support and continuous feedback, as you know this has not been easy but your guidance was greatly appreciated. Also, I would like to thank other faculty members that even though they were not in charge of helping with this research project provided help and support, Dr. Denver Severt and Professor Kim Severt thank you for everything.

Second, thank you to the National Laboratory for allowing me to use the data for this research project. Lastly, I would like to thank my dad, mom, sisters and those of you who are almost my sisters without your continuous encouragement and loving support this would not be possible. To my friends in Orlando, Puerto Rico (Stackas) and other parts of the US and the world thank you for listening to my concerns and problems. Family and friends your encouragement and loving support has been greatly appreciated without all of you this would not be possible. Thank you all for believing in me! 


\section{TABLE OF CONTENTS}

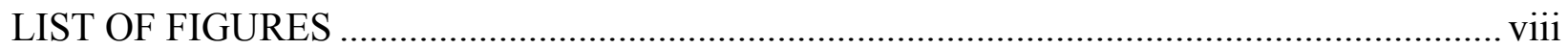

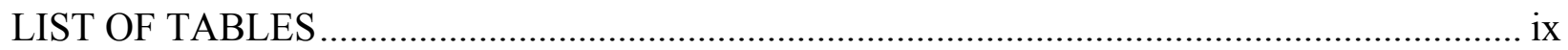

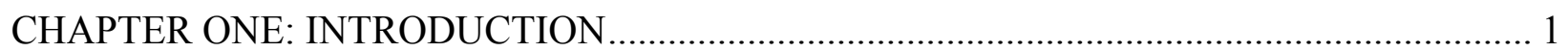

Significance of the Study ……………............................................................................ 7

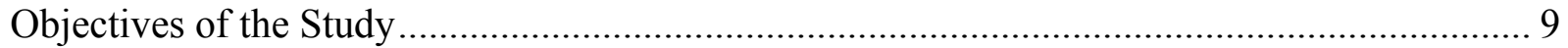

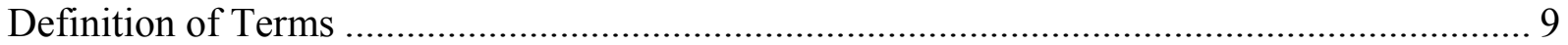

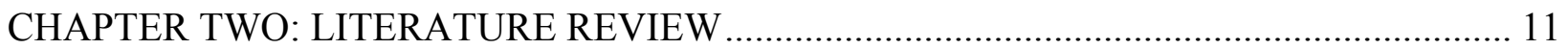

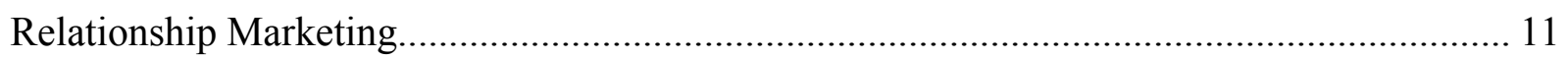

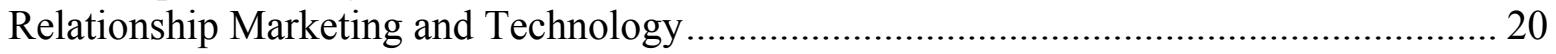

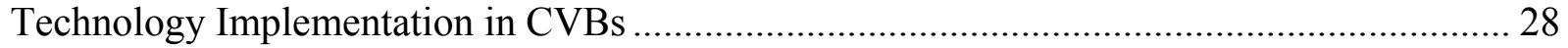

Stages of Web-based Technology Implementation .............................................................. 32

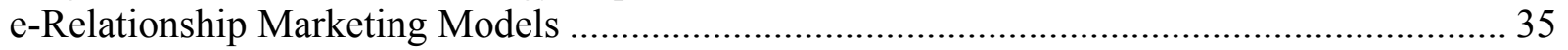

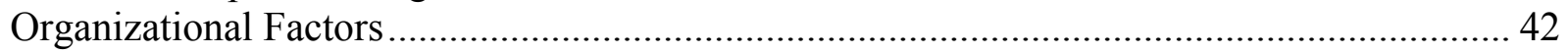

Impact of Organizational Factors........................................................................................ 43

DMOs Online Relationship Marketing Activities - Determinant Factors ………………..... 52

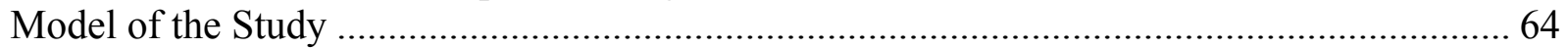

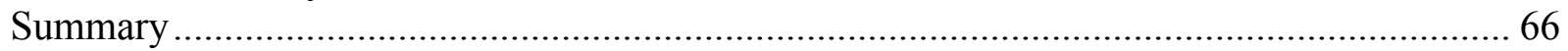

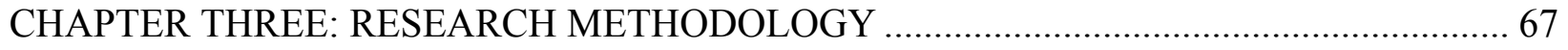

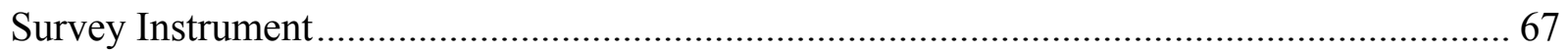

Sampling Frame and Data Collection.............................................................................. 68

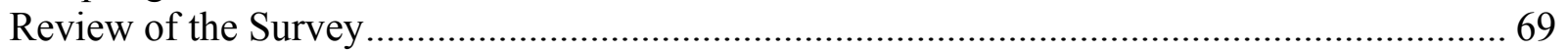

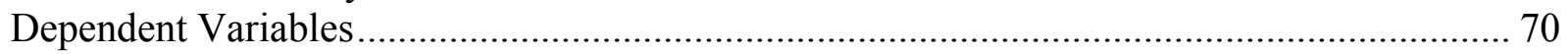

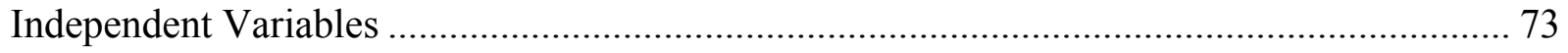

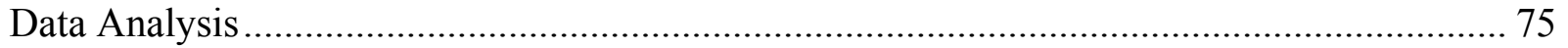

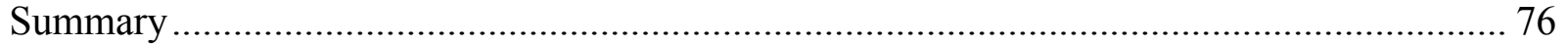

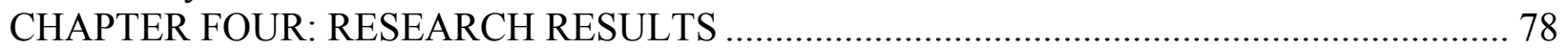

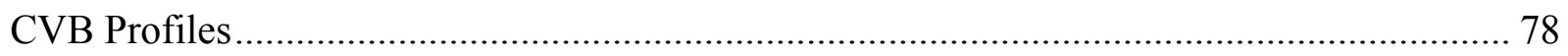

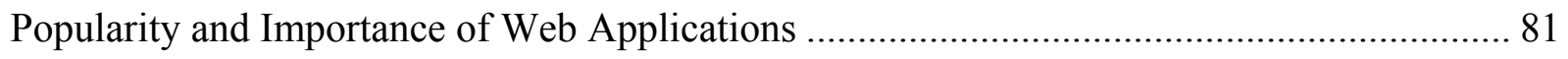

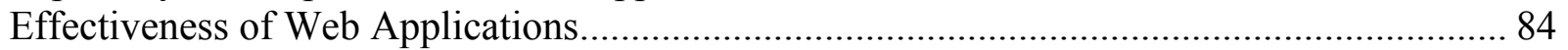

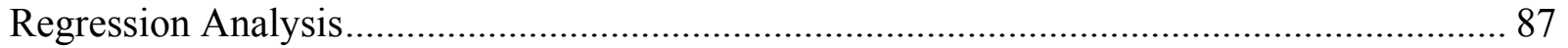

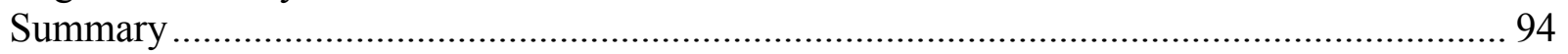

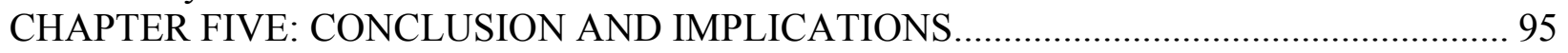

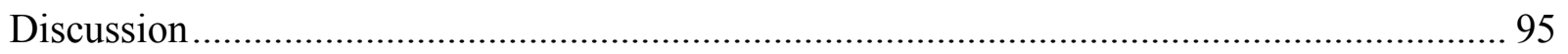

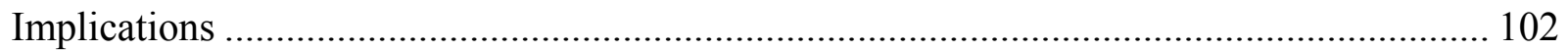

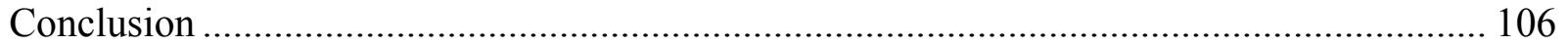

Limitations and Suggestions for Future Research ................................................................ 107

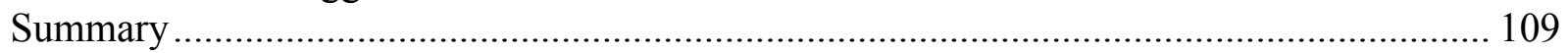

APPENDIX: NATIONAL SURVEY ON WEB MARKETING STRATEGIES ……................ 110

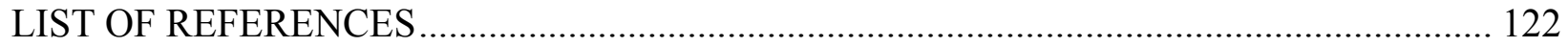




\section{LIST OF FIGURES}

Figure 1: Web-based technology implementation model .................................................. 33

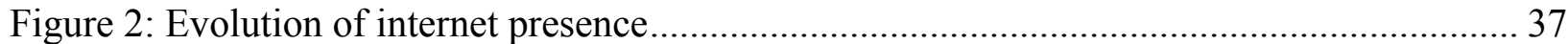

Figure 3: Proposed stages of web-based relationship marketing activities ............................... 39

Figure 4: Proposed conceptual model of DMOs web-based relationship marketing implementation and the impact of organizational factors ........................................... 53

Figure 5: Testing model for impact of organizational factors on DMOs web-based relationship

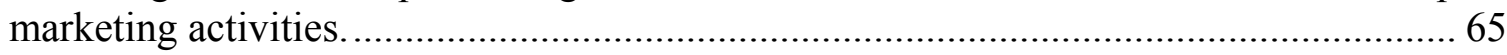

Figure 6: Effectiveness evaluation matrix for web marketing activities ................................ 72 


\section{LIST OF TABLES}

Table 1: Comparison between transaction and relationship marketing ................................... 14

Table 2: Theoretical models for innovation and technology adoption .................................. 47

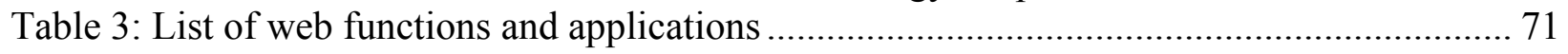

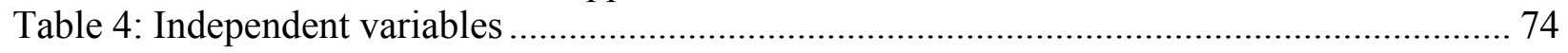

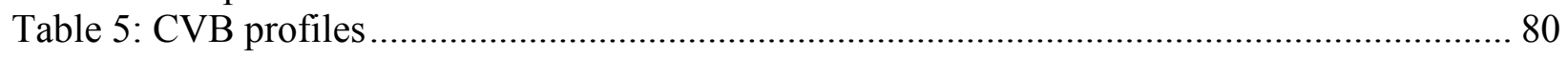

Table 6: Popularity and perceived importance of web technology application by functions ....... 83

Table 7: Assessment of effectiveness of web technology applications based on functions ......... 85

Table 8: Results of standard multiple regression analyses on the impact of organizational factors on the effectiveness and sophistication of web marketing functions............................. 93 


\section{CHAPTER ONE: INTRODUCTION}

Information technology plays an important role in the way business is conducted.

Organizations are forced to adjust and take advantage of the opportunities provided by information technology in order to stay competitive. Businesses that do not take advantage of the value that technology provides will run the risk of loosing customers and their competitive advantage (Sharma, 2002). Some of the functions that technology has impacted are information search, advertising, consumer buying patterns and behaviors (Hanson, 2000). On a global scale, all industries have been affected by the emergence and implementation of technological advances. The tourism industry is one of the most heavily impacted by technological changes due to the nature of the business which is efficiency focused and information sensitive (Gretzel, Yuan, \& Fesenmaier, 2000).

Advances in technology are to be closely monitored and implemented by destination marketing organizations (DMOs) such as convention and visitors bureaus (CVBs) to gain the most advantage of technology applications. Integration of information technology (IT) systems into the organizational structure of the DMO is an important key to success (Gretzel et al., 2000). In addition, technology has facilitated the relationship building process with customers by providing systems with the capabilities to obtain customer information and translate it into benefits for both the organization and the customer (Zineldin, 2000). The information gathered through technology allows organizations to customize products and services for the customer (Ahn, Kim, \& Han, 2003).

Web-based technology applications have helped CVBs perform their job more effectively and efficiently by distributing information to visitors at their convenience and assisting in information searches. In addition, internet technology enables CVBs to perform activities outside 
the scope of their organizational boundaries and perform service activities to better service customer needs (Yuan, Gretzel, \& Fesenmaier, 2003). CVBs can use their website for several functions from providing information like a brochure, assisting in customer's specific information searches through interactive searches, assisting a visitor in making a hotel reservation or creating a customized information search for the visitor (Hanson, 2000). Some examples of the impact the internet has had on CVBs include the opportunity for online advertising to be targeted to an audience and deliver advertisements that are customized to their needs, interest and taste (Gretzel et al., 2000). In addition, the internet has become an important communication tool for CVBs because what and how information is presented in its website has a great influence in the perceived image of the destination (Gretzel et al., 2000).

CVBs are private, not-for-profit organizations (Gartrell, 1988, p. 7) whose purpose is to make the destination a dynamic meeting place by attracting conventions, trade shows and visitor business to the area (Gartrell, 1988). The CVB is a community's single most important marketing organization, projecting an image for that destination into various targeted markets (Gartrell 1988, p. 6). Gartrell (1988) states that CVBs have one fundamental mission: to solicit and service conventions and other related group business and to engage in visitor promotions, which generate overnight stays for a destination, thereby enhancing and developing the economic fabric of the community (p. 10).

Based on this definition the goal of a CVB is to help promote and develop a destination through marketing activities using various media such as television commercials, print materials, and websites.

CVBs have the task of promoting a destination, its entertainment options and services to attract visitors to the area. A CVB's marketing objective is to generate new sources of revenue 
for their communities through destination marketing activities (Gartrell, 1998, p. 39). A CVB that is successful in this task will not experience direct financial benefits for its own organization since most CVBs are funded through membership dues, hotel room taxes, city, county or state taxes, grants, revenues from advertising programs and in kind gifts to the bureau (Gartrell, 1988). However, if CVBs successfully perform their job, businesses in the area will experience the financial benefits through increased business and revenues.

Customers face a variety of choices when buying a product or a service and for organizations to become profitable they need to focus on the customer's needs and wants. When an individual decides to make a leisure or business trip they have different options to facilitate the information search, decision and buying process for their travel arrangements. CVB is one of the many sources of information consumers can use to assist in their decision-making process. Since the goal of a CVB is to promote and attract visitors to the area by marketing the destination and its services it is important to pay close attention to its marketing practices. CVBs need to not only attract visitors but also create long lasting relationships to help retain existing customers. The ultimate goal of a CVB is to create a competitive advantage over other destinations and to promote the use of its services for the customers' future visits.

In the past decade the Internet has become a powerful marketing tool for organizations. Tourism related companies, like CVBs, have used websites as an information portal, transaction engine, and decision making tool for customers. The development of electronic commerce and its different functions offers new opportunities for collaboratively marketing tourism destinations (Palmer \& McCole, 2000). In the tourism industry, more specifically CVBs, the use of IT has been mainly focused on the use of the Internet as a tool to deliver information to the customer (Yuan, Gretzel \& Fesenmaier, 2006). 
The use of IT enables CVBs to promote a destination's tourism and services, and effectively communicate with customers (Yuan et al., 2006). IT currently utilized by CVBs is mainly focused on the business-consumer relationship with a focus on information provision (Palmer \& McCole, 2000). However, there is an increase in the use and importance of IT use within the organization to support administrative activities like marketing, finance and staff training (Yuan et. al., 2006). On the other hand, the business-business aspect of IT use has been limited to general information provision and exchange (Yuan. et al., 2006).

However, the same organizations that have utilized the IT to perform the transactions mentioned above have failed to exploit the full benefits of creating a relationship with their customers through web-based marketing strategies such as effectively providing information on products and services, e-commerce transaction functions, personalization/customization capabilities, and customer loyalty or retention programs (Bauer, Grether, \& Leach, 2002; Wang \& Fesenmaier, 2006). The focus on mass marketing efforts has made CVBs loose opportunities to attract and retain customers. More attention should be paid by CVBs to not only market the destination to prospective visitors but also to create relationships with visitors to help retain them. One main problem faced by CVBs is the limited use of the web. CVBs use websites as an information portal and not as a relationship building and retention tool (Wang \& Fesenmaier, 2006).

Since the main function of a CVB is to market a destination it is imperative to discuss marketing and its evolution from a relationship marketing perspective. Since the introduction by McCarthy (1960) of the marketing mix, the 4 Ps of marketing (price, product, place and promotion) has been viewed as a promotional technique for a product or a service with the main focus placed on the 4 Ps of marketing. An evolution of marketing strategies has occurred to 
reflect the changes in the customer needs and desires. Marketing has evolved from a transaction focused activity to a relationship building activity performed by most organizations to promote long and profitable business relationships.

The aim of relationship marketing is to create long lasting relationships with customers, provide a better customer experience and create greater customer satisfaction to build longlasting relationships (Kotler, Bowen, \& Makens, 2006). One way to accomplish a competitive advantage over other organizations is for the organization to create a mutually beneficial relationship with customers. Building this relationship helps create customer loyalty since the customer perceives that the firm appreciates and values the customer's commitment to the company.

Berry (1995) introduced the concept of relationship marketing as a different view to transaction marketing by focusing on the long-term approach to a marketing strategy. The business world realizes the importance of relationship marketing strategies when competition increases and product differentiation is not an easy factor to obtain (Grönroos, 1990). In addition, companies realized the price of obtaining new customers and the value of keeping existing ones. The focus of relationship marketing strategies is to develop and maintain enduring, long-term customer relationships (Gummesson, 1994). This is based on the premise that obtaining new customers costs five times more than keeping an existing customer (Bauer et al., 2002). Ahn et al. (2003) define relationship marketing as a "process designed to grasp features of customers and apply those features to marketing activities" (p. 324). As previously discussed, organizations need to take advantage of relationship marketing and implement activities that support relationship marketing efforts. Organizations that effectively implement information technology innovations that assist in customer attraction and retention will be successful in their relationship 
marketing efforts (Yuan \& Fesenmaier, 2000). In the tourism industry DMOs and CVBs should use these systems to better market their destinations, attract and retain customers. The decision to embrace relationship marketing and the activities that assist in this effort are influenced by the organizational (Wang \& Fesenmaier, 2006). An examination of the organizational characteristics will assist in the correct allocation of resources and successful implementation of web-based relationship marketing activities (Yuan et al., 2003; Wang \& Fesenmaier, 2006).

A review of the literature indicates that the implementation of the different web-based marketing activities within organizations depends on organizational characteristics like company culture, company size, financial resources, technological expertise and experience, organizational flexibility, and managerial support of new technological implementations (Goode \& Stevens, 2000; Gretzel et al., 2000; Scupola, 2003; Teo \& Tan, 1998; Thong, 1999; Tornatzky \& Fleischer, 1990; Wang \& Fesenmaier, 2006; Zhu \& Kraemer, 2005). A study conducted by Gretzel et al. (2000) on advertising strategies used by CVBs concluded that limited resources, lack of communication, lack of proper management, employees insufficient knowledge, legal regulations and restrictions, and ownership issues were the most important barriers to technology implementation and adaptation.

On the other hand, a study conducted by Yuan et al. (2003) found that CVBs need to focus their efforts to provide education and training programs for employees to increase their knowledge on new technology. In addition, the study found that management support is an important aspect needed within the CVB in order to successfully implement and use new technologies. On regards to other factors, Wang and Fesenmaier (2006) found that a successful web marketing strategy requires innovative organizational approaches and a favorable organizational technology environment. 
Taking a relationship marketing perspective, this research seeks to examine the webbased marketing systems of DMOs and determine the impact organizational characteristics have on the web-based marketing activities and degree of implementation of relationship marketing activities used by CVBs in the United States. The research is based on several models of relationship marketing, web-based relationship marketing and innovation adoption. First, Kotler et al.'s (2006) relationship marketing model is used to identify the basic levels of relationships between the company and the customer. Second, Hanson's (2000) web-based relationship marketing model or personalization continuum is used to explain the methods used by organizations to create relationships with customers through the web. Third, Tornatzky and Fleischer's (1990) technological, organizational and environmental (TOE) framework of technology adoption is used to explain the impact of organizational characteristics on technology adoption behavior.

Built on a relationship marketing framework, this study proposes that CVBs implement web-based relationship marketing activities in four stages (information, communication, transaction and assurance). These four stages demonstrate a hierarchical progression of technology sophistication and how CVBs use technology to handle customer relationships. The study also suggests that a CVBs' web-based activities are affected by organizational factors, particularly technological environment, organizational characteristics, and technological competence.

\section{Significance of the Study}

This study seeks to examine the web-based relationship marketing activities implemented by American CVBs and the organizational factors that influence their implementation. More 
specifically, this study hopes to contribute to the existing body of knowledge on influencing factors affecting the adoption of web-based marketing functions by investigating factors that affect a CVB's implementation and use of web-based functions as a method to build relationships with customers.

Research on web-marketing on the tourism industry has been mainly focused on the adoption or non-adoption of technology or on the number of web-based functions implemented by organizations. Furthermore, research in the industry has been focused on the impact of organizational characteristics on the implementation of innovations, like information technology and internet functions. However, research on the impact of organizational characteristics on CVBs web-based marketing strategies is very limited or mainly focused on the impact of the organizational characteristics on the web-based marketing functions from a system implementation perspective. IT research in the CVB arena includes the advertising strategies, the impact of organizational characteristics on extent of IT use and internet use, effective use of the Internet as an advertising strategy and impact of organizational characteristics on web-based marketing strategies (Dore \& Crouch, 2003; Gretzel et al., 2000; Yuan \& Fesenmaier, 2000; Yuan et al., 2006; Wang \& Fesenmaier, 2006). Furthermore, research on relationship building and retention practices through web marketing strategies has been limited. Consequently, the proposed research examines web-based marketing functions from a relationship marketing perspective.

First, the popularity (use) and importance of the web applications will be examined. Second, the applications under each function of the web-based marketing activities will be examined to determine the effectiveness of those functions. Third, this study will examine organizational factors that affect the use of web-based marketing activities and the level of the 
web-based marketing functions implemented by CVBs. Examining these factors will help explore the impact organizational factors have on the degree of web-based marketing functions used by CVBs and the level of effectiveness of those functions. This study will help shed light into factors affecting web marketing functions and will help CVBs examine their specific organizational factors in order to identify those factors that promote and hinder their success.

\section{Objectives of the Study}

The main purpose of this study is to examine the web-based marketing functions of American CVBs from a relationship marketing perspective. Furthermore, this study will investigate the impact of organizational characteristics on the web-based marketing activities implemented by CVBs. More specifically this study will:

1) Evaluate web-based marketing activities used by CVBs from a relationship marketing perspective.

2) Measure the effectiveness of web-based marketing activities implemented by CVBs.

3) Identify and determine the impact CVB's organizational characteristics have on the implementation of web-based marketing activities.

\section{$\underline{\text { Definition of Terms }}$}

Convention and Visitors Bureau (CVB): A city, state, or regional not-for-profit organization whose purpose is the marketing of the destination to different target markets (i.e. leisure travel, conventions, business travelers) to attract visitors to 
the area and assist in developing the local economy (Gartrell, 1988).

Destination Marketing Organization (DMO): An organization in charge of marketing a destination to enhance its image and attract visitors to the area to increase tourism.

Destination Marketing: The promotion of a destination and its services to attract potential visitors to the area. This is the main function and responsibility of a destination marketing organization such as a CVB.

Relationship marketing: The process of identifying and establishing, maintaining, enhancing, and when necessary terminating relationship with customers to meet the objectives of all parties involved, with the objective of creating mutually beneficial relationships and longer lasting relationship with customers (Berry, 1995; Grönroos, 1990; Kotler et al., 2006). 


\section{CHAPTER TWO: LITERATURE REVIEW}

The following discussion will provide an overview of the existing literature on relationship marketing, technology implementation and organizational characteristics, and web based marketing functions. Finally, the literature review will end with a description of the variables to be studied and the model developed for this study will be introduced and explained.

\section{Relationship Marketing}

Marketing practices and strategies have been influenced by the market environment. Throughout the decades an organization's marketing efforts have adjusted to reflect the consumer demands of the times. Marketing as it is known today was introduced around 1960s with the marketing mix and the four Ps of marketing (Grönroos, 1994). The marketing mix and

its four Ps (product, place, price and promotion) has become the universal marketing model and have had a big impact on the practice of marketing. However, this approach to marketing is mainly focused on the marketing of products (Payne, 1995; Zineldin, 2000). The marketing mix and the four P's have been the dominant theory on marketing for decades; however, a paradigm shift has occurred that focuses on the customer and the relationships that need to be formed to increase the profitability of the relationship; this concept is called relationship marketing (Grönroos, 1994).

For many years, marketing has been mainly focused on obtaining customers to complete transactions with no or limited emphasis in relationship building or customer retention. Transaction marketing is focused on the sale of products or services with minimal or no customer contact (Payne, 1995). Organizations implement mass marketing efforts to obtain the 
highest number of customers, complete transactions without focusing on relationship building or retention, and treat all customers the same (Berry, 1995; Grönroos, 1990; Stone, Woodcock \& Wilson; 1996). One of today's most used business strategies involves transforming firms to become customer focused while increasing revenue and profits margins (Kim, Suh \& Hwang, 2003). Since organizations are constantly looking at customization and personalization as methods to improve marketing efforts, most implement relationship marketing as a way to achieve this goal (Vesanen \& Raulas, 2006).

A shift in marketing strategies to relationship marketing focuses on interactive marketing as the dominant part of the marketing function (Grönroos, 1994; Zineldin, 2000). Improved marketing efforts translate to gained benefits in improved marketing and customer retention (Vesanen \& Raulas, 2006). A firm pursuing a relationship marketing strategy creates value for its customer through the customer interactions more than through the core product or service (Payne, 1995). Moreover, customer interactions provide the opportunity for the organization to create strong ties with the customer which provide added value to the customer (Grönroos, 1994; Zineldin, 2000).

The concept of relationship marketing was not on the mass marketing radar until the 1990s when organizations started to realize the importance of customer retention (O'Malley \& Mitussis, 2002). The deregulation experienced in many industries in the late 1970s and early 1980s helped develop marketing for the services arena (Berry \& Parasuraman, 1993). However, the importance of the customer was highlighted in the mid-1990s when marketing to protect the customer base became a vital strategy for survival (Berry, 1995). Moreover, the globalization of the business world and the increasing recognition of the importance of customer retention and customer relationships reinforced the trend of the change in marketing strategies (Grönroos, 
1994; Payne, 1995). The importance of relationship marketing has been highlighted by the nature of the service industry in which services are provided on a constant basis and relationship development between service provider and customer promotes and facilitates relationship marketing (Berry, 1995).

The idea of relationship marketing developed from a study on high-contact services markets (O'Malley \& Mitussis, 2002). The service market is highly dependent on the interactions that occur between individuals and the company. This frequent interaction promotes the creation of relationships between the parties involved (O'Malley \& Mitussis, 2002). As mentioned earlier, the shift from transaction to relationship marketing (Dwyer, Schurr, \& Oh, 1987) in consumer markets was driven by changes in the business environment and facilitated by technology (Sisoda \& Wolfe, 2000). In 1983 Berry introduced the first definition to relationship marketing as "attracting, maintaining, and - in multi-service organizations- enhancing customer relationships" (Berry, 1995, p. 236). See table 1 for comparison between transaction and relationship marketing. 


\section{Table 1: Comparison between transaction and relationship marketing}

\begin{tabular}{l|l}
\hline \multicolumn{1}{c|}{ Transaction Marketing } & \multicolumn{1}{c}{ Relationship Marketing } \\
\hline $\begin{array}{l}\text { Focus on a single sale } \\
\text { Orientation on products or services } \\
\text { features }\end{array}$ & Orientation to customer values \\
Short time scale & Long time scale \\
Little emphasis on customer service & High customer service emphasis \\
Limited customer commitment & $\begin{array}{l}\text { Goal is to increase customer } \\
\text { loyalty }\end{array}$ \\
$\begin{array}{l}\text { Moderate customer contact } \\
\text { Quality is primarily a concern of } \\
\text { production }\end{array}$ & High customer contact \\
\hline Source: Payne, 1995 & Quality is the concern of all \\
\hline
\end{tabular}

In the 1980s Berry (1995) introduced the concept of relationship marketing to demonstrate a different view to transaction marketing. To demonstrate the complexity of relationship marketing Berry states that there are different levels of relationship marketing implementation. An organization will have a higher potential for sustained competitive advantage if a higher level of relationship marketing is practiced (Berry, 1995).

Berry (1995) explains that there are three levels of relationship marketing and each has a different impact on an organization's competitive advantage. Level one of relationship marketing depends primarily on pricing strategies such as emphasizing on pricing incentives to secure customer's loyalty. Unfortunately, the potential to create a competitive advantage for the organization with this strategy is low because price is the most easily imitated element of the marketing mix.

Level two depends primarily on social bonds, which involves the personalization and customization of the relationship; however, an aggressive pricing strategy may still be a vital 
element of the marketing mix. Berry (1995) states that on regards to providing an organization with a competitive advantage, social bonds can provide the organization with customer loyalty when competitive differences are not strong.

Level three of relationship marketing is mostly dependent on providing structural solutions to important customer problems. Berry (1995, p. 240) states "when organizations can offer target customers value-adding benefits that are difficult or expensive to obtain elsewhere, they help create a strong foundation for maintaining and enhancing relationships". In addition to financial (level one) and social bonds (level two), the author proposes that services provided in level three give the organization a foundation for a strong and difficult strategy for competitors to copy, therefore providing the company with a strong competitive advantage. At level three, the solution to the customer's problem is implemented into the structure of the service deliver system rather than depending on the individual service provider's relationship building skills. This structural strategy connects the customer to the company rather than to the employee providing the service (Berry, 1995).

Grönroos (1990) was one of the first researchers to write about the impact of relationship marketing on the service industry. The author explains that the traditional approach to marketing frequently does not cover all the possible phases of relationships that may emerge at various stages of the customer relationship life cycle. Grönroos (1990) defines relationship marketing as:

Process of identifying and establishing, maintaining, enhancing, and when necessary terminating relationships with customers and other stakeholders, at a profit, so that the objectives of all parties involved are met, where this is done by a mutual giving and fulfillment of promises (p. 5). 
Gummesson (1994) proposes that relationship marketing is the birth of a new marketing strategy which is focused on the customer and not the transaction; this paradigm shift helps organizations profit from established customer relationships. Cross and Smith (1995) and Grönroos $(1990,1994)$ explained the importance of the new paradigm of marketing as a way of strengthening the intangible aspects of a relationship with a customer. Firms that practice relationship marketing hope to prevent competitive inroads, because intangible aspects, unlike tangible offerings, are not easily imitated by the competition.

To highlight the importance of the new paradigm Gummesson's study (1994) on making relationship marketing operational seeks to expand the 4 P's of the marketing mix by creating the 30 R's of relationship marketing (RM). The 30 R's of RM were created by Gummesson to help explain in detail all the possible relationships that may arise from customer interactions and transactions with service providers. The $30 \mathrm{R}$ 's that relate most closely to web-based relationship marketing, for the context of this research, are R13: the electronic relationship, and R25: the customer as a member. Only these two items of the relationship list will be discussed in detail. Electronic relationship (R13) helps highlight the importance of technological advances and the impact in relationship marketing. Gummesson describes R13 (the electronic relationship) as an important aspect of technology and web based functions since an ever increasing percentage of today's marketing takes place through systems based in IT (1994). On the other hand, Gummesson states that R25 (the customer as a member) refers to the activities an organization develops to create a long-term sustaining relationship, "it has become increasingly frequent to enlist customers as members of various marketing programmes" $(1994, \mathrm{p} .14)$. This relationship illustrates the paradigm shift researchers are proposing which focuses on marketing strategies that focus on individual customers and creating long-term relationships with these 
customers. The 30 R's proposed by Gummesson relate to all organizations including tourism and hospitality related companies. Like other hospitality organizations CVBs have been impacted by technological advances and increased competition. CVBs that are aware of all the relationships that may emerge from transactions and implement strategies to address these relationships will gain a competitive advantage over other CVBs. Firms, like CVBs, implement relationship marketing in different degrees as part of their overall marketing strategy.

Berry (1983) proposed that there are five elements for practicing relationship marketing. The first element is a core service needs to be developed which is the basis to build a customer relationship. The second element is the customization of the relationship to the individual customer, emphasizing that the core service provides extra benefits to the customer. The third element involves the pricing strategy which encourages customer loyalty. The fourth element involves marketing within the organization to promote the service for the workforce to provide the service to the customer.

Several researchers have proposed different models on the stages and functions to implement relationship marketing activities (Kim, Suh \& Hwang, 2003; Vesanen \& Raulas, 2006). However, the same basic elements and activities are found in the different models proposed, and all of which have the ultimate goal of customizing the service or product offering to retain customer. Kim, Suh and Hwang (2003) propose a four stage process to implement relationship marketing. First, data needs to be collected. Obtaining information from the customer through data mining functions facilitated by technology applications allows the organization to customize product/service offerings. Second, the information collected is integrated into the marketing process to help customize product/service offerings for the customer. The aim is to meet and exceed customer expectations to create loyal customers. Third, 
satisfactory long-term customer relationships can be created and established by providing customers effective and profitable service. Finally, business value can be achieved by establishing customer relationships (Kim, Suh \& Hwang, 2003).

A big part of a marketing effort is personalization which involves the process of gathering and analyzing customer data, customizing the marketing process and the targeting of marketing activities (Vesanen \& Raulas, 2006). Vesanen and Raulas (2006) developed a model that explains the personalization process that identifies the main elements and explains in detail the process. The authors propose that the model consists of four actions (interactions, processing, customization and delivery) and four elements (customer, customer data, customer profile and marketing output) that interconnect throughout the personalization process.

The process starts with the customer and their search for specific products or services. Following are the interactions with the customer, through web searches and purchases. These activities provide the organization with valuable information about the customer and their buying preferences and behavior. The customer data is collected through buyer-seller interactions or website visits which provide the organization with additional customer information. After the data is collected it is processed and transformed into customer profiles which highlight the customer preferences and allows for customers to be segmented into groups.

Organizations create customer profiles from the data collected through interactions or searches. These profiles are created to help the organization differentiate customer by their preferences. Customer profiles are then used by organizations to assist in the personalization process while creating a marketing output. The marketing output is the printed material, website, personalized price or product recommendation. Marketers can choose from different channels to transmit their customized message. This delivery promotes the customer to take action which 
creates a new interaction where new information will be obtained. Finally, delivery shows how the personalized marketing output effort reaches the customer to influence and assist the customer in their selection and buying process. Each new action allows for the personalization process to continue in a loop in which new data is gained with each interaction allowing personalization to continue and be fine tuned. Implementing a relationship marketing strategy has many benefits to both the customer and the firm.

Relationship marketing allows the service provider to gain more knowledge about the customer and their requirements and needs (Berry, 1995; Grönroos, 1994). Therefore, an increase in the knowledge on the customer needs and wants and constant customer contact allows the service provider to tailor or customize the service to the customer's specifications (Berry, 1995). The benefits of relationship marketing include: increased customer retention and loyalty; higher customer profitability because customers buy more, lower costs to recruit new customers and reduced cost of sales since current customers are more responsive to marketing efforts (Stone et al., 1996). The benefits of a customer focus strategy promotes the retention of loyal customers which generate more revenues, but also the cost of retaining existing customers is lower than acquiring new ones (Berry, 1995). Potential benefits for the customer from a relationship marketing perspective include a proactive service attitude and customized service delivery (Berry, 1995). Finally, relationship marketing promotes a mutually beneficial relationship which allows customers to avoid transaction costs involved in changing service providers and suppliers to avoid unnecessary quality costs and new customer acquisition costs (Grönroos, 1994). A successful implementation of relationship marketing activities creates: increase customer retention and loyalty, higher customer profitability, increased value for the 
customer, customization of products and services, lower process, higher quality products and services (Kim et al., 2003; Stone, Woodcock, \& Wilson, 1996).

The development of technology has had tremendous impact on marketing strategies. Innovations in technology and information systems provide new ways to obtain, collect and analyze customer data and communicate with customers (Vesanen \& Raulas, 2006). Technology was viewed as a way to help manage customer information, maintaining records, personalizing the customer experience, and identifying cross-selling and up-selling opportunities (Dwyer et al., 1987). The use of technology to implement a relationship marketing strategy will be discussed in the next section.

\section{Relationship Marketing and Technology}

A company's marketing efforts have evolved over the years to demonstrate the importance of individual customers and the impact of technological advances on organizational strategies. Two major factors that have impacted the changes in marketing practices during this decade are technology developments and the globalization of the business world (Zineldin, 2000). In addition, major factors such as the need to handle increased product/service volumes while controlling costs, innovativeness and increased focus on consumers have promoted the use of technology by organizations (Zineldin, 2000). Technology has become a major part of an organization's strategy and a source of sustainable competitive advantage due to the increased importance of information to create and sustain relationships with customers (Main, 2002). Strategically all organizations will need to make creative and innovative changes in order to deal effectively with changes in technology that impact marketing (Martin \& Matlay, 2003). Due to 
the changing business environment the survival and sustainable competitive advantage of a firm may be dependent on its ability to undergo strategic changes (Martin \& Matlay, 2003).

Since personal interactions and relationship building are the most important core elements of relationship marketing, advances in technology allow organizations to communicate and do business easier in the national and international arena (Zineldin, 2000). Relationship marketing has evolved and entered a new era with advances in technology and the Internet (Luck \& Lancaster, 2003). Technology advances like the Internet and the WWW have dramatically changed the way business is conducted within an organization and the way business and customer relationships are formed (Zineldin, 2000).

Technology enables the implementation of relationship marketing and advances in technology will assist firms to better integrate relationship marketing and online functions (Luck \& Lancaster, 2003). An organization's use of technology will have an impact on the long-term relationships and long-term survival (Zineldin, 2000). Technology developments such as the Internet and websites are the most important factors in creating, developing and tightening relationships (Zineldin, 2000). However, companies that do not adapt to changing technologies will fall behind competitors that adopt new technologies at an earlier stage (Zineldin, 2000). Organizations that understand e-business functions and consumer needs will gain a larger segment of the market share and will become the winners of the new marketing era (Colby and Parasuraman, 2003).

An effective and efficient use of IT tools becomes an important factor to "create, develop and sustain mutual profitable business-to-business and business-to-customer long-term relationships" (Zineldin, 2000, p. 21). Due to the essential role information plays in the description, promotion, distribution, organization and delivery of tourism products and services, 
technology has become a strategic weapon and a main source of sustainable competitive advantage (Main, 2002). However, research has found that many tourism businesses use the internet to provide information rather than for acquiring information from customers, which leads to lost opportunities and misused resources (Luck \& Lancaster, 2003). The importance of technology implementation heightens when organizations that do not learn and adapt to changing technologies face difficult times because the competition switched strategies to "more technologically based relationships and advanced products and services" (Zineldin, 2000, p. 9).

Developments in IT and other technologies present opportunities for organizations to create new relationships with consumers (Zineldin, 2000). Programs like data mining tools and data warehousing techniques allow firms to identify and analyze consumer needs (Kim et al., 2003). These systems can be used to implement and support a relationship marketing strategy (Kim et al., 2003). Data collecting through new technology applications about customer's needs and behaviors enables organizations to identify key customer, calculate the value of each customer and estimate future investment opportunities (Luck \& Lancaster, 2003; Zineldin, 2000).

Computerizing relationships, through Internet presence, provides organizations with a powerful tool to profile existing customers and to create and retain stronger relationships, as well as to find new potential customers (Zineldin, 2000). O'Malley \& Mitussis (2000) explain the impact of new technologies, as systems were developed and implemented to help identify and quantify the loss of customers, the focus of marketing shifted from customer acquisition to customer retention (O’Malley \& Mitussis, 2000). IT advances like websites allows an organization to provide a consistent and integrative image to global consumers (Luck \& Lancaster, 2003; Martin \& Matlay, 2003; Zineldin, 2000). More specifically, the Internet should 
be used to obtain information, provide relationship building opportunities and respond to customer needs (Luck \& Lancaster, 2003; Zineldin, 2000). Therefore, advances in technology will allow an organization to better implement a relationship marketing strategy.

The free and seamless flow of information is crucial in creating, developing and enhancing long term relationships with customers in the IT era (Zineldin, 2000). Relationship marketing will not be successful if it is not supported by a quality information technology that is easily accessible to customers (Zineldin, 2000). Effective use of IT to create long-term and close partnerships allows an organization to reduce costs and improve quality of services offered thus improving the image of the organization (Luck \& Lancaster, 2003).

Implementing IT as part of a relationship marketing strategy allows organizations to create, develop, and sustain effective, efficient and profitable relationships with customers in the domestic and international markets (Zineldin, 2000). It is only through the effective use of IT in conjunction with other marketing efforts that a company can build successful relationships as part of their marketing strategies (Luck \& Lancaster, 2003). The interactivity of the Internet provides immense opportunities for relationship building with the audience (Van Niekerk, Berthon, and Davies, 1999). However, organizations cannot depend completely on the Internet and expect to retain customers, firms must continue to provide superior service and satisfy customer's needs to retain customers (Luck \& Lancaster, 2003).

Internet implementation is vital to an effective e-commerce presence on the domestics and international markets (Martin \& Matlay, 2003). Organizational websites are used to develop stronger and more effective links with customers as part of the relationship marketing strategy (Martin \& Matlay, 2003). In addition, advances in IT allow organizations to move from segmenting markets by groups to segmenting by individuals (Berry, 1995). Technology increases 
the practical value of relationship marketing by allowing the organization to efficiently perform relationship marketing tasks such as: tracking buying patterns; customizing services and promotions; coordinating and integrating delivery; providing two-way communication; minimizing the probability of service errors; augmenting service offerings; and personalizing service encounters appropriately (Berry, 1995).

Buhalis (1998) states that the strategic use of information technology has had a big impact on the tourism industry in several functions such as: communication (intra-organizational communication, inter-organizational communication), improved efficiency and the creation of a competitive advantage. These functions demonstrate that information technology and its advances are making relationship marketing more affordable, feasible and powerful (Berry, 1995). The Internet has been viewed as a marketing tool that can be used to focus marketing efforts and reach new markets and customers (Martin \& Matlay, 2003). Effective relationship marketing is positively impacted by the advances in technology and its decreasing costs (Berry, 1995; Zineldin, 2000).

The Internet has been viewed by many as a new marketing tool to develop stronger links with the customer (Martin \& Matlay, 2003). However, organizations will need to implement the use of the Internet as part of a new marketing strategy focused on the customer individual preferences (Martin \& Matlay, 2003). Since the Internet enables access to any online customer anytime and anywhere, companies need to focus on targeting the right customers to create profitable relationships (Luck \& Lancaster, 2003).

The relationship between relationship marketing and the Internet has been examined by many researchers (e.g. Contractor \& Bishop, 2000; Gummesson, 1994; Hanson, 2000). Relationship marketing has influenced the business community in several areas and research has 
been conducted to: 1) explain the additional relationships that emerge from internet transactions and activities (Gummesson, 1994); 2) examine the use of internet and websites for customer relationship building (Hanson, 2000); and 3) examine the use of the internet and other technology to substitute basic marketing functions (Contractor \& Bishop, 2000). However, regardless of the organization's specific use of the internet "the most important business goal for a website is to maximize user loyalty and the lifetime value of the user's future visits and purchases" (Smith, 2002, p. 149).

In order to understand the impact of the Internet, researchers have argued that there are five essential factors needed for successful implementation of digital marketing: attract, engage, retain, learn and relate (Gretzel et al., 2000; Parsons, Zeisser \& Waitman, 1998). These factors highlight the importance of attracting customer to the website; engage customer with interactive communication, retain customers by providing additional services and community functions; learn about your customers from alternate sources to better understand customer wants/needs; and relate to customers to obtain information to customize the online interaction. Another important factor to be considered when implementing the Internet as part of a relationship marketing strategy is the customer's use of the Internet as a decision making tool.

Previous research has tried to develop models to explain customer search and purchase behavior on the Internet (Blackwell, Miniard \& Engel, 2001; Crotts, 1999; Lexhagen, 2005; Mouthino, 1987). For example, Lexhagen (2005) investigated the importance of different valueadded services as perceived by the customer and found that most value-added services are designed to support the search and purchase process and that no services are designed to support the post-consumption process. Crotts' (1999) model proposed that there are different stages in the consumer decision process. The model suggests that the process starts with need recognition 
and continues with internal and external information search, evaluation, purchase and postpurchase evaluations. These models help understand the consumer perspective and their use of the Internet which helps organizations successfully use the Internet in their marketing strategies.

The marketing evolution from mass marketing to the ultimate goal of personalized and targeted marketing (Ahn et al., 2003; Gummesson, 1994) demonstrates the increased importance of the customer and their retention to the profitability of the organization. New technologies allow firms to understand and familiarize themselves with customers to implement a relationship marketing strategy (Kim et al., 2003). That is, advances in technology have helped organizations in the implementation of personalized and customized marketing (Ahn et al., 2003). A result of using technological advances, such as the internet and websites, is that organizations have achieved increased speed and efficiency in communications with customers and suppliers (Nour \& Fadlalla, 2000).

The Internet allows the customer to access information anytime and anywhere, and this fact has prompted many organizations to enter into web marketing hastily without a focused strategy, which in turn leads to wasting of valuable resources (Luck \& Lancaster, 2003). Organizations that decide to adopt the Web as part of their marketing strategy need to implement in conjunction of their overall organizational strategy (Martin \& Matlay, 2003). Since today's focus of marketing is creating and maintaining relationships with customers, a web-based marketing strategy focused on relationship marketing will allow a firm to reach this goal.

The Web has helped consumers in the search and selection of goods and services (Lexhagen, 2005). Moreover, the web has also helped organizations to target customers effectively and efficiently, and assist organizations to create long-lasting profitable relationships with consumers (Berry 1995; Kim et al., 2003; Vesanen \& Raulas, 2006). Walter and Lancaster 
(1999) state that the Web enables organizations to provide customers with: convenience, information, personalization and interactivity which provides an added value for the customer. In addition, the Web can be used to implement and support a relationship marketing strategy through data mining processes used in personalized and customized websites (Pierrakos, Paliouras \& Papatheodorou, 2003).

Tourism organizations, like CVBs, have realized the importance and impact the internet has on their marketing efforts. The internet has become a vital part of their marketing efforts (Wang \& Fesenmaier, 2006). Yuan et al. (2003) explain "the internet technology enables CVBs to enhance service abilities and, consequently, customer satisfaction" (p.241). Wang and Fesenmaier (2006) provide some guidelines that CVBs should follow in order to be successful in marketing destinations online:

provision of information about the destination; the promotion and publicity techniques for their destination Web sites, ... and the relationship building programs by which consumers can be engaged and retained to the sites (p. 2).

Technological advances can and have been used to assist in the marketing efforts of CVBs, the internet and websites can be used to provide customers with information, assist in customer information searches, provide capabilities to complete transactions and the postconsumption process (Lexhagen, 2005). Internet communication tools, such as e-mails, provide a flow of information from current, previous and prospective customers that can be collected and used to create a data warehouse for data mining purposes that can assist in creating customer profiles to create better marketing strategies to target customers (Nour \& Fadlalla, 2000). Nour 
and Fadlalla (2000) stated that the data collected can be used to "build strategic databases for use in planning and executing business and marketing strategies" (p. 40).

Many researchers have discussed the importance of the technological advances on the business world with a focus on service providers. The advancement of the Internet has helped organizations target customers by obtaining, storing and processing information to better manage customer relationships (Ahn et al., 2003). As mentioned earlier, the Web has become an essential part of a company's marketing efforts. Great importance has been placed on the websites and other technological advances which help manage and implement customization programs to assist organizations on the relationship building efforts (Ahn et al., 2003; Hanson, 2000; Zineldin, 2000). In addition, the use of specialized software makes it possible for an organization to deliver unique and dynamically personalized Web sites in real time (Hanson, 2000).

\section{Technology Implementation in CVBs}

In the tourism industry destination marketing organizations, such as CVBs, help develop and promote a destination to attract visitors to the area. A destination marketing organizations principal management function is marketing with increased focus on promotion, therefore budget allocation is focused towards those goals (Dore \& Crouch, 2003).

A CVB is a private, non-profit organization whose purpose is to help develop and market a destination and its services (Gartrell, 1988). CVBs have been established for destinations to become dynamic meeting places by attracting conventions, meetings, trade shows and visitor business to the area (Gartrell, 1988). A destination's promotional activities can be performed through different activities such as advertising, direct marketing, sales promotion, personal selling and publicity, and public relations (Dore \& Crouch, 2003). All these activities allow 
CVBs to perform their job and provide a comprehensive and unified marketing program that represents all components of the visitor industry at a destination (Gartrell, 1988). A destination's CVB is a community's single most important marketing organization, projecting an image for that destination into various targeted markets (Gartrell 1988). Per Gartrell (1988) CVBs have one fundamental mission:

to solicit and service conventions and other related group business and to engage in visitor promotions, which generate overnight stays for a destination, thereby enhancing and developing the economic fabric of the community (p. 10).

Since the creation of CVBs their responsibilities and purpose have evolved to include other functions that help market the destination. Yuan et al. (2003) formulated a definition that demonstrates the evolution of the responsibilities of a CVB. This definition provides a more comprehensive and updated definition of a CVB:

to promote tourism business and attract visitors to its region, with the ultimate goal of enhancing the economy and the region's image through deft coordination of the diverse components of the tourism industry (Yuan et al., p. 241).

Several activities and mediums have been used by CVBs to help perform their marketing functions. Some of the mediums used by CVBs to promote a destination include: radio and television commercials, print ads, promotional kits, poster campaigns, and websites (Buhalis, 2000; Dore \& Crouch, 2003; Gartrell, 1988). Since the focus of this study is the use of webbased marketing activities by CVBs it is imperative to discuss a CVB's use of technology and websites to perform their marketing activities. The importance of this aspect is highlighted by the fact that bureau directors perceive the use of IT, which is mainly focused on the internet, as being a valuable tool to deliver information to the consumer (Yuan et al., 2006). In addition, 
research has found that potential visitors who used a CVB's website to search for information on the destination were more likely to visit the destination and demonstrate a higher intention to return to the destination on future trips (So \& Morrison, 2003).

The Internet has become such an important medium of promotion and marketing because it seeks to simplify the consumer's choice by using a combination of intermediaries, trusted brand and established businesses (Palmer \& McCole, 2000). A CVB's website offers a potential visitor comprehensive information on the destination to provide a coherent picture of the destination to facilitate the travel planning and decision making process (So \& Morrison, 2003).

Furthermore, "many tourism destination marketing organizations have developed websites with different levels of interactivity" (Palmer \& McCole, 2000, p. 199). A CVB providing a website with interactive capabilities allows the visitor to customize their search and travel selections to fit their needs and wants (Yuan et al., 2006). Providing customization capabilities allows a CVB to perform better their marketing functions and gain a larger percentage of the market by creating relationships with customers and providing more customer service which can increase customer satisfaction (Gretzel et al., 2000; So \& Morrison, 2003).

Yuan et al. (2006) found that the WWW and email were the two Internet applications consistently being used by CVBs. However, bureaus are missing opportunities in creating relationships with customers through the web-marketing functions because they are mainly focused in the information and communication aspect of a website's functions (Luck \& Lancaster, 2003). Mainly bureaus perceived the WWW as a marketing tool with which to promote the image of their destination to potential visitors (Yuan et al., 2006). Research has shown that this is due to the lack of the critical organizational capabilities that would allow them to move forward in the implementation and use of IT functions (Yuan et al., 2006). Furthermore, 
most bureaus are uncertain about the marketing trends and this prevents them from taking full advantage of the potential provided by IT within their marketing functions (Yuan et al., 2006).

Bureaus use resources to run the organization and ensure maximum exposure of the destination and fulfill the needs of visitors (Gartrell, 1988). Since CVBs are not-for-profit organizations they do not obtain a financial gain from their activities, therefore effective and efficient use of resources is necessary. Therefore, continuous study of the effectiveness of the different promotional activities is imperative to allow efficient use of the resources.

As mentioned earlier, the functions of a CVB include the sales/marketing, operations/administration, and communications (Yuan et al., 2003). These functions assist in the marketing of the destination and the fulfillment of the needs of visitors to the area. American CVBs act as a liaison between prospective visitors to the area and the businesses that will interact with visitors when they arrive at the destination (Yuan et al., 2003). Technology has played an important role in the way CVBs performed their promotional activities. For example, internet technology enables CVBs to perform their duties more effectively and efficiently by aiding in the service delivery and provide better customer service (Yuan et al., 2003). Since the focus of this study is the use of web-based marketing functions by CVBs it is imperative to discuss the use and impact of technology by these organizations and how technology, more specifically websites, can be used to attract and retain customers and allow for effective use of promotional spending. 


\section{$\underline{\text { Stages of Web-based Technology Implementation }}$}

As previously discussed a paradigm shift is happening and a reengineering of the marketing approach is taking place with a focus towards relationship building. Different models have emerged to help marketers in the task to effectively and efficiently obtain and retain customers by using technology. The increased awareness of the importance of relationship marketing has made several researchers propose models that illustrate how to achieve a relationship with a customer; demonstrate its importance and benefits of relationship marketing.

Researchers propose different views of the evolution and use of technology. For example, Contractor and Bishop (2000) explained technology adoption occurs in three stages: substitution, enlargement and reconfiguration (Figure 1).

- Substitution stage: Technology is used to perform the same organizational activities; however, efficiency is achieved allowing the organization to expand activities. For example, e-mails requesting information are received and answered through the website instead of receiving postal mail.

- Enlargement stage: Organizations get acquainted and are comfortable utilizing technology, this process allows for the organization to expand the use of technology to other functional areas; however, the implementation of technology applications is not more sophisticated. For example, the use of e-mails as a communication tool promotes more frequent communication between the customer and the company.

- Reconfiguration stage: New technology is implemented and integrated into the business process of the organization; this means that completely new systems and technologies are implemented in the organization to accomplish new tasks in new 
ways. For example, a company uses a new system to manage customer accounts. This stage requires more skills and continuous learning to manage the change.

Contractor and Bishop (2000) explained the evolution of the use of technology, more specifically websites, for the implementation of web-based marketing activities. His view to the website implementation helps illustrate the scope and complexity of technological advances and its impact on marketing activities.

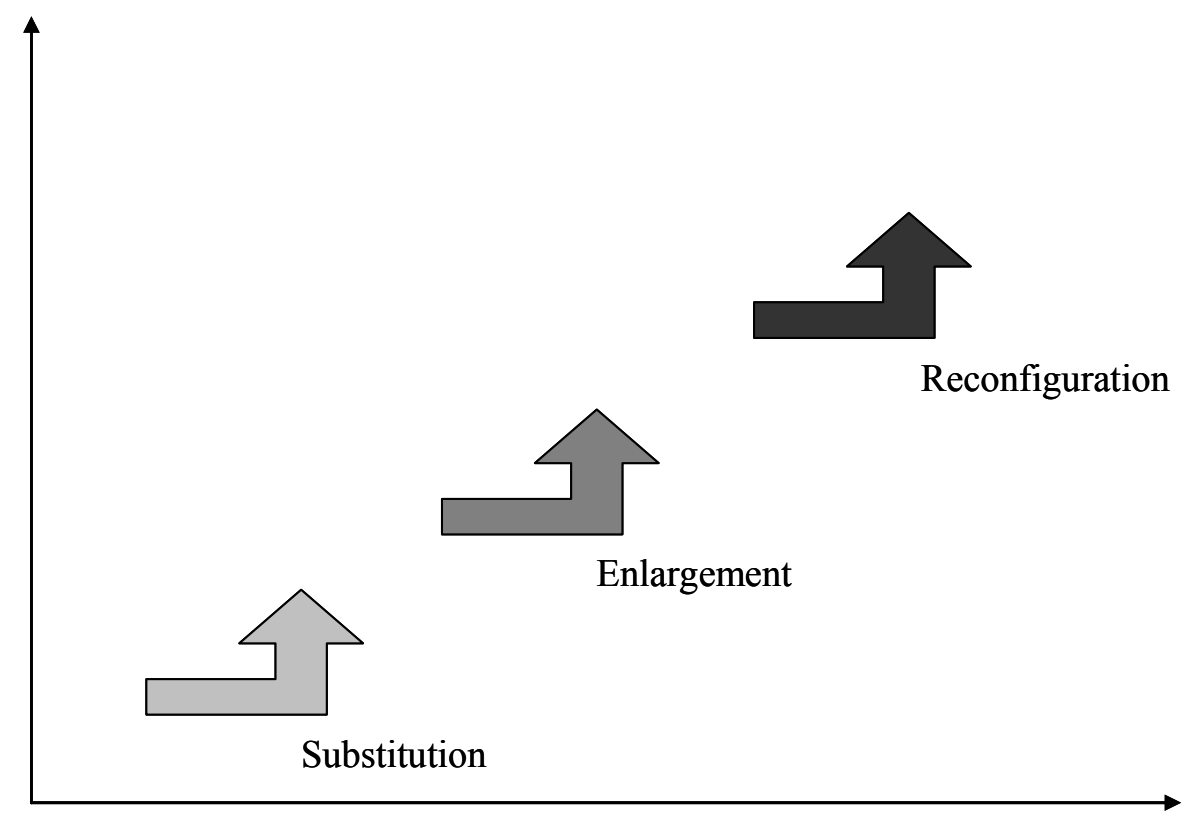

Source: Contractor (2002) as cited by Yuan, Gretzel and Fesenmaier (2003).

Figure 1: Web-based technology implementation model

There are different levels of implementation of technology applications in websites that assist in relationship marketing activities. Organizations show a pattern in internet applications. First, organizations implemented basic Internet applications, like the e-mail and the world wide 
web, that were relatively inexpensive to adopt (Forman, 2005). Hanson (2000) describes the stages of website development as follows:

- Stage 1: Publishing sites. This stage only provides information to the customer. The website is used as an information medium with limited interaction between customer and company. For example, the website only provides information as the customer clicks through the pages.

- Stage 2: Database and forms. This stage combines the ability to provide information and the ability to retrieve information in response to customer's request. For example, the website is used for basic e-commerce capabilities like buying and selling products/services.

- Stage 3: Personalization. The website creates a page catering to a specific individual preferences, the main focus of this stage is relationship building. This stage is the most challenging and least used. For example, the website obtains information from the user and caters the page and information to the user's preferences.

Hanson (2000) explains the evolution of website use as a tool for implementing webbased marketing activities. Most organizations begin their internet marketing efforts with a stage 1 website since it is inexpensive and easy to develop, many companies make the transition to stage 2 in which interaction and e-commerce activities are provided; however, very few companies achieve the personalization stage since it is more complicated to implement and additional information is required from the customer to provide a customized site. 


\section{e-Relationship Marketing Models}

Several researchers have proposed models to explain relationship marketing and its implementation on the web. Kotler, Bowen and Makens (2006) propose that there are five basic levels of relationship that can be formed with a customer online: basic, reactive, accountable, proactive and partnership. They define the terms as follows:

- Basic: The company sells the product but does not follow up in any way.

- Reactive: The company sells the product and encourages the customer to call at any time with questions or problems.

- Accountable: A company representative contacts the customer before and during the service encounter requesting suggestions for improvement. The continuous request for feedback facilitates the company's need to improve product or service offerings.

- Proactive: The salesperson or company representative contacts the customer from time to time with suggestions, improvements or creative suggestions for the future.

- Partnership: The company works closely with the customer and other customers to discover ways to deliver better value.

This relationship theory helps explain the focus of relationship marketing and the different levels which can be implemented within an organization. The goal of any company is to reach a partnership with their customers since it is at this stage where the relationship is most profitable (Grönroos 1990, 1994; Zablah, Bellenger \& Johnston 2004). CVBs should seek to create partnerships with customers in which the relationship becomes beneficial for both parties involved. This partnership can be achieved by the organization having systems in place to 
provide a customized experience for the customer (e.g. provide information catered to their needs) which can translate into increased customer satisfaction and customer retention.

Hanson (2000) proposes a model to explain the impact personalization has on relationship marketing. Hanson (2000) explains that different levels of personalization create a continuum. On one side of the continuum, there is homogeneity and no personalization in the marketing efforts or product/service offerings, as the organization places efforts to differentiate and customize product/service offerings and marketing efforts through choice assistance and design, the needs of the customer are satisfied. As the customer's needs are satisfied the customer experience progresses towards the relationship building side of the continuum, which is the opposite side of the continuum. The objective of personalization is to reach the relationship building side of the continuum, in which the marketing efforts and products/services are fully personalized by joint participation occurring over time. The goal of an organization striving to create relationships with their customers is to personalize services to retain customers and create profitable relationships. Personalization becomes a competitive advantage for a company when it is used to form a relationship (Hanson, 2000).

Sharma (2002) states that an organization's internet presence evolves in five stages: information, communication, transactions, relationships and e-commerce. The five stages demonstrate the progress and increased complexity of the internet functions and how they are used to create value for the customer (Figure 2). Sharma (2002) proposes that as an organization's internet functions evolve through the five stages they provide greater value to the customer. 


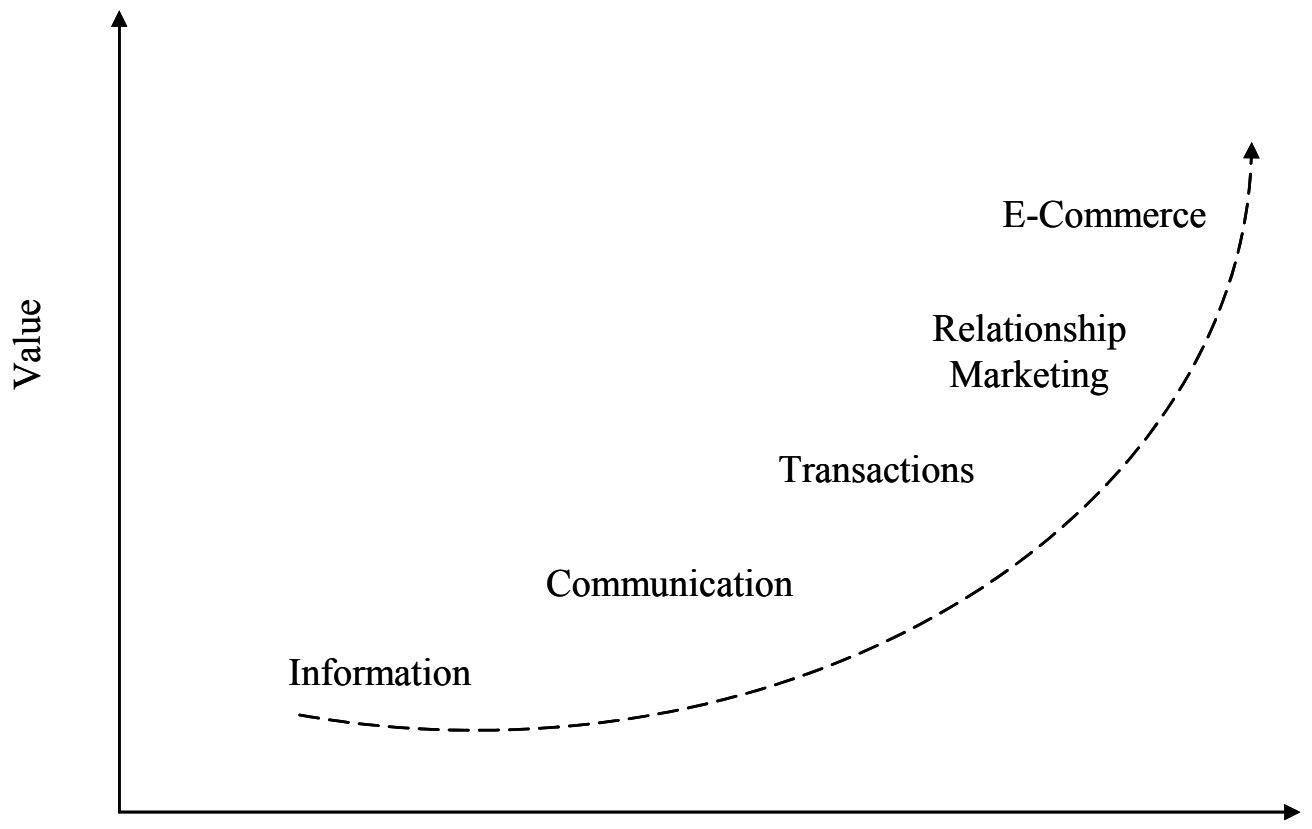

The Journey

Source: Sharma, 2002

\section{Figure 2: Evolution of internet presence}

The use of IT has become a major prerequisite in the formation of strategic alliances, development of innovative distribution methods and communication with consumers and partners, and satisfaction of consumer demands (Main, 2002). A review of the literature on internet applications and implementation reveals that organizations adopt website functions in various degrees of sophistication to provide different capabilities to the customer (Doolin, Burgess \& Cooper, 2002; Hanson, 2000). Websites are used by organizations for the following purposes: 1) to communicate with the customer and provide them with information to assist information search and decision making process (Buhalis, 1998; Doolin et al., 2002; Lexhagen, 2005; Sharma, 2002; Subramanian, Shaw \& Gardner, 2000); 2) to sell directly to the customer (Lexhagen, 2005; Doolin et al., 2002; Sharma, 2002; Subramanian et al., 2000) and, 3) post- 
transaction communication or customer service/support (Buhalis, 1998; Doolin et al., 2002;

Lexhagen, 2005; Sharma, 2002). The potential of the internet is appealing to many sectors of the tourism industry, which are dedicated to build relationships with customers and gather customer information, and they see this new media as a way to facilitate their job and execute their strategies (Main, 2002).

Research has been conducted by Buhalis (1998), Doolin et al. (2002) and Lexhagen (2005) on tourism related organizations that provide additional insight into the use of websites by these organizations. Buhalis (1998) states that there are three main functions for which organizations use websites: pre-travel arrangements, travel related documentation, post-travel arrangements. Doolin et al. (2002) states that organizations use websites at different stages ranging from broadcasting and providing links to useful information, providing interactive functions for the customer, providing online customer support, allowing online bookings to allow the consumer to complete secured transactions online. Further, Lexhagen (2005) states that websites are used to assist in the customer's search and evaluation process, purchase process and post-consumption process. A website's evolution and functions described on the literature provide the basis for the four stages of the proposed model for this research: information, communication, transaction and assurance.

The various models discussed previously help shed light on how tourism organizations use technology to conduct relationship marketing activities. Inspired by the arguments presented in these models and considering the unique responsibilities of DMOs in marketing and promoting destinations, this study proposes a four stage model DMOs should follow in their web-based relationship marketing efforts to reach a partnership with their customers (see Figure 3). 


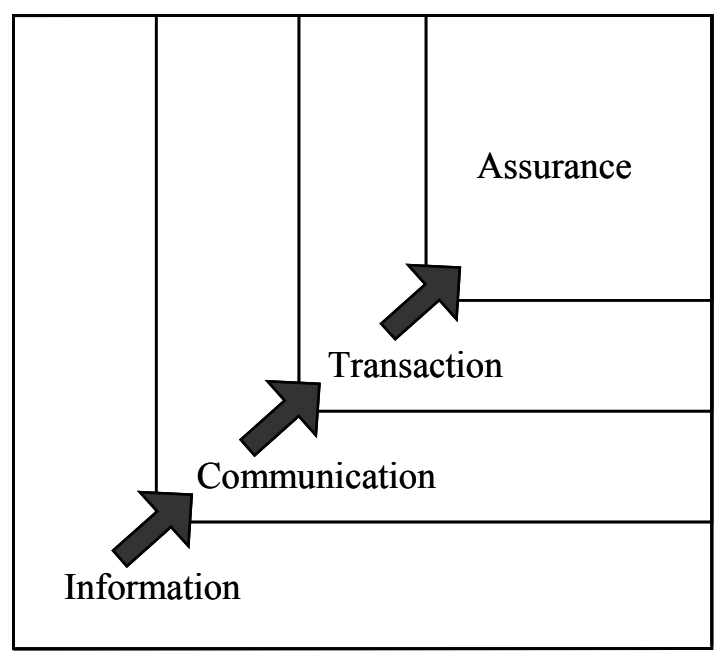

Source: Wang and Russo, 2006

Figure 3: Proposed stages of web-based relationship marketing activities

\section{Information}

Based on the literature on web-based technology implementation and relationship marketing four stages were proposed as important in the successful implementation of web-based marketing functions by CVBs. As previously discussed, the stages of web-based relationship marketing for the proposed model relate to Kotler et al.'s (2006) levels of customer-company relationship marketing and Hanson's (2000) stages of web-based relationship marketing. In the proposed model the first stage of web-based marketing involves the provision of information to the customer. In this stage, the web-based marketing strategy is aimed at providing the customer with basic information on the product or service but no transaction or interactive process is involved. This first stage relates to Kotler et al.'s (2006) first level of relationship which is the basic relationship. Also, the first stage of the proposed model relates to Hanson's (2000) first stage of the personalization continuum which is the mass market. An important aspect to 
consider is the end user or consumer since the utility and effectiveness of the functions are judged by the end-user.

From the perspective of the consumer the provision of information is the most basic function of the internet. A website should include product/services information. Information is still a valuable and most important function a website can provide since it allows customers from all over the world to search and compare products/services 24 hours a day, seven days a week. This gives the customer flexibility and convenience in their search process and does not limit their search to their geographic region.

\section{Communication}

The second stage of the proposed model involves the interactive communication with the customer. This stage involves interactive communication between the company and the customer. For example, if the customer has a question they can write an email or post a question on the website and the company will respond to their request. Also, this stage provides the customer with the capability of engaging in interactive functions within the website. The second stage of the proposed model relates to Kotler et al.'s (2006) second level of relationship which is the reactive relationship. In addition, the second stage of the proposed model relates to Hanson's (2000) second stage of the personalization continuum which is the differentiated stage.

Communication functions provided on a website allows the consumer to interact with the website to locate the information they want in order to make educated decisions. As a website provides additional functions it gives the consumer more choices and options tailored to their needs which makes the Internet a more powerful and effective marketing tool (Yuan et al., 2003). 


\section{Transaction}

The third stage of the proposed model involves the transaction capabilities provided on a website. This stage refers to the capabilities offered on a website to complete a transaction such as buying attraction tickets or making a hotel reservation. At this stage the company is perceived by the customer to be trustworthy to handle the customer's request. The third stage of the model relates to Kotler et al.'s (2006) third level of relationship which is the accountable relationship.

Transaction functions provide the customer with the capability to complete a transaction making the decision and buying process easier and more convenient for the consumer. Again, the benefit of the internet is that it is available to the consumer $24 / 7$ which allows them to buy products or services without time and place restrictions found in actual stores. In addition, transaction functions allow the customer to buy products from other countries or states which may be far from the customer, breaking down the time and space barrier when completing a transaction. From a tourism perspective transaction functions allow the customer to research and reserve/buy a product or service before customer arrives to their destination. This provides the customer with choices and peace of mind when planning a trip.

\section{Assurance}

The fourth stage of the proposed model involves the assurance functions implemented in the website. This stage involves constant activity from the company's side to personalize or customize website offerings for the customer needs. This stage is closely related to relationship marketing and its programs. For the company this stage entails engaging in constant communication with the customer to address their problems and/or needs before they happen or catering the service specifically for the customer's needs. The fourth stage of the proposed model relates to Kotler et al.'s (2006) fourth and fifth levels of relationships which are the proactive and 
partnership relationships. On the other hand, the fourth stage of the proposed model relates to Hanson's (2006) third (customized) and fourth (relationship) stage of the personalization continuum. Assurance functions allow the marketer to be more efficient in their marketing functions because it is a targeted strategy. Furthermore, from the consumer perspective it facilitates the search process since products and services can be recommended to the consumer based on previous choices or constant updates provided for their convenience. Assurance functions also give the consumer a sense of belonging and importance since relationships are being built between the company and the customer.

Organizations that seek to take advantage of the web and the Internet should provide functions in all four stages proposed. This will allow the consumer to have the information necessary to make decisions, complete transactions and have continuous contact with the company to complete future search and purchases. The company that successfully implements functions in the four stages will be able to market better their product/service, gain a competitive advantage in the market and retain customers.

\section{Organizational Factors}

There are many organizational characteristics that may impact the implementation of online relationship marketing activities within CVBs. Strategies, business processes, organizational culture, organizational goals/objectives, company size, technological expertise, financial resources, yearly budget for technology, management practices, technological support, management support and leadership style are some of the factors that have been identified as important for the successful implementation of web-based relationship marketing activities

(Goode and Stevens 2000; Gretzel et al 2000; O'Malley and Mitussis 2002; Wang and 
Fesenmaier 2006). Gummesson (1994) states the concept of relationship marketing is dependent on changes in organizational design. Since relationship marketing involves the implementation of new practices it entails a new type of management to support the process.

On regards to the service industry, a focus on a strong and well established corporate culture is necessary and important in helping enhance the customer focus and appreciation for good service (Grönroos, 1990). Developing a service culture provides an organization a means of creating and enhancing good interactive marketing performance needed for implementing a relationship marketing strategy (Grönroos, 1990). Organizational characteristics for relationship marketing implementation are important since effectively implementing a web-based marketing strategy requires the right combination of organization structure and culture, creative thinking, flexibility, and the ability to change and adapt quickly (Koch \& Steinhauser, 1983). Several researchers have studied the impact of organizational factors on the innovation adoption behavior (Tornatzky \& Fleischer, 1990), IS system adoption (Thong, 1999) and e-business use and value (Zhu \& Kraemer, 2005).

\section{Impact of Organizational Factors}

The research on innovation adoption and diffusion has been the focus of many researchers for decades. Previous research on innovation adoption and diffusion has been focused on the attributes of the innovation rather than on the characteristics of the organization (Damanpour, 1991; Frambach, 1993; Tornatzky \& Klein, 1982). In addition, organizational variables such as size, being receptive to change, competitive environment, strategic direction, management team's characteristics and government regulation have been the focus of innovation research (Damanpour, 1991; Davis, Bagozzi \& Warshaw, 1989; Frambach, 1993; Lefebvre \& 
Lefebvre, 1992; Lefebvre, Mason \& Lefebvre, 1997; Rogers, 1995; Thong, 1999; Tornatzky \& Fleischer, 1990; Zhu \& Kraemer, 2005).

These research studies have concluded that these variables have either a positive or negative impacts on the way organizations adopt technology innovations. Furthermore, studies have found that certain variables have contradictory results, which emphasizes the need and importance of additional research (Tornatzky \& Klein, 1982). For the purpose of this study focus will be placed on the organizational factors that impact information technology adoption and level of use. Tornatzky \& Fleischer's (1990) technological-organizational-environment framework was used as the guiding model for the proposed research. In addition, Thong (1999) and Zhu \& Kraemer (2005) have made adaptations to Tornatzky \& Fleischer's model to study additional organizational characteristics that impact the innovation implementation behavior of organizations. These studies were used to determine variable importance and selection for the proposed study.

Tornatzky and Fleischer (1990) developed a theoretical model to determine the impact three major factors have on the innovation adoption behavior of organizations. The authors developed the technological-organizational-environmental (TOE) framework in the early 90 s to explain the innovation adoption behavior by manufacturing firms. Technological context refers to the internal and external technologies relevant to the firm. The organizational context is typically defined in terms of a firm's descriptive measures: firm size; complexity of its managerial structure; the quality of its human resources; and the amount of resources available. The environmental context refers to the arena in which a firm conducts its business which includes competitors, industry and interactions with the government (Tornatzky \& Fleischer, 1990). The TOE framework helps explain the impact of organizational and environmental 
characteristics on the adoption and use of e-business functions like websites. The TOE framework has been used by various researches to explore the technology adoption behavior of organizations in different industries and countries.

On the other hand, Zhu and Kraemer (2005) developed a model for e-business use and value based on two theories: the technological, environmental and organizational environment (TOE) framework developed by Tornatzky and Fleischer (1990) and the resource-based theory. The study by Zhu and Kraemer (2005) focuses on the post-adoption stages or actual use of ebusiness functions as a point of value creation. As previously discussed, the TOE framework identified three elements of a firm's context that influence the process by which it adopts, implements and uses technological innovations: organizational, technological and environmental (Tornatzky \& Fleischer, 1990). The resource-based view (RBV) provides a theoretical basis for linking e-business use and value (Zhu and Kraemer, 2005, p. 64). The authors developed an integrative model for e-business use and value with six antecedents (based on the TOE framework) and two types of business capabilities (use and value) (p. 62).

Zhu and Kreamer's model (2005) seeks to understand the adoption and value of ebusiness. More specifically, their study examined the use and value of e-business measured on the post-adoption stages. The authors measure the influencing factors of e-business adoption by using the characteristics based on the TOE framework (technology context: technology competence; organization context: size, international scope and financial commitment; and environmental context: competitive pressure and regulatory support). Furthermore, the study also used the RBV to measure use and value of e-business. The RBV suggests that the greater the extent of a firm's IT use, the greater the value it provides to the organization. 
Zhu \& Kraemer (2005) found that technology competence, financial commitment, competitive pressure, and regulatory support have a significant influence on the extent of ebusiness use. Between all the TOE factors, technology competence is the strongest indicator of ebusiness use. Also, the study found that the firm's size is not an indicator of e-business use; however, it is an indicator of structural inertia (i.e. the bigger the organization the more time it takes to adjust and implement new technologies or processes). In addition, the study found that a higher degree of e-business use is associated with improved business performance which translates to added value to customers. The study provides insight on ways to obtain increased value of e-business functions through greater extent and depth of use. In addition, the authors propose that increased integration of e-business functions in all areas of the organization provides the company with a major source of e-business value because it is not easily copied by the competition. See Table 2 for a summary of the theoretical models and their results. 
Table 2: Theoretical models for innovation and technology adoption

$$
\text { Study }
$$

Tornatzky and Klein (1982)

Compatibility
Relative advantage
Complexity
Cost
Communicability
Divisibility
Profitability
Social approval
Trialability
Observability

Davis, Bagozzi \& Warshaw (1989)

Rogers (1995)

Lefebvre and Lefebvre (1992)

Affect

2. Social influence

Social norms

Relative advantage

Compatability

Complexity

Trialability

\section{Characteristics}

Results

\section{Innovation Characteristics}

1. Innovation attitudes

Perceived usefulness

Perceived ease of use

Observability

\section{Organizational Characteristics}

1. CEOs personal characteristics

Years in this sector

Years as CEO

Functional experience

In accounting/finances

In sales/marketing
Innovation adoption

$+$

?

Usage intentions

$$
\begin{aligned}
& + \\
& + \\
& + \\
& ?
\end{aligned}
$$

Innovation diffusion

$$
\begin{aligned}
& + \\
& + \\
& - \\
& + \\
& +
\end{aligned}
$$

Innovativeness 


\begin{tabular}{|c|c|c|c|}
\hline Study & Characteristics & \multicolumn{2}{|c|}{ Results } \\
\hline continued & In engineering/production & \multicolumn{2}{|c|}{+} \\
\hline Lefebvre and Lefebvre (1992) & In human resources & \multicolumn{2}{|c|}{-} \\
\hline & Level of education & \multicolumn{2}{|c|}{+} \\
\hline & 2. CEOs attitudes and personality traits & \\
\hline & Attitude towards risk & \multicolumn{2}{|c|}{+} \\
\hline & Proactive attitude & \multicolumn{2}{|c|}{+} \\
\hline & Locus of control & & \\
\hline & Internal & \multicolumn{2}{|c|}{+} \\
\hline & External & \multicolumn{2}{|c|}{-} \\
\hline & 3. Characteristics of CEOs decision-making process & \multirow{2}{*}{\multicolumn{2}{|c|}{+}} \\
\hline & Systematic external search for information & & \\
\hline & Systematic internal search for information & \multicolumn{2}{|c|}{+} \\
\hline & Futurity & \multicolumn{2}{|c|}{+} \\
\hline & Analytical ability & \multicolumn{2}{|c|}{+} \\
\hline & Strategic awareness & \multicolumn{2}{|c|}{+} \\
\hline & 4. Firms' characteristics & \\
\hline & Technocratization & \multicolumn{2}{|c|}{+} \\
\hline & Centralization & \multicolumn{2}{|c|}{ No relationship } \\
\hline & Formalization & \multicolumn{2}{|c|}{-} \\
\hline & 5. Size & \multicolumn{2}{|c|}{+} \\
\hline \multirow[t]{13}{*}{ Thong (1999) } & & Likelihood of IS Adoption & Extent of Adoption \\
\hline & 1. CEO characteristics & & \\
\hline & CEO's innovativeness & + & $\mathrm{n} / \mathrm{s}$ \\
\hline & CEO’s IS knowledge & + & $\mathrm{n} / \mathrm{s}$ \\
\hline & 2. IS characteristics & & \\
\hline & Relative advantage/compatibility of IS & + & $\mathrm{n} / \mathrm{s}$ \\
\hline & Complexity of IS & + & - \\
\hline & 3. Organizational characteristics & & \\
\hline & Business size & + & + \\
\hline & Employees' IS knowledge & + & + \\
\hline & Information intensity & - & + \\
\hline & 4. Environmental characteristics & & \\
\hline & Competition & - & $\mathrm{n} / \mathrm{s}$ \\
\hline
\end{tabular}




\begin{tabular}{|c|c|c|}
\hline Study & Characteristics & Results \\
\hline \multirow[t]{11}{*}{ Zhu and Kraemer (2005) } & & Extent of e-business use \\
\hline & 1. Technological context & \\
\hline & Organization's technological competence & + \\
\hline & 2. Organizational context & \\
\hline & Size & - \\
\hline & International scope & - \\
\hline & Financial commitment & + \\
\hline & 3. Environmental context & \\
\hline & Competitive pressure & + \\
\hline & Regulatory support & + \\
\hline & Innovation and Organizational Character & \\
\hline \multirow{13}{*}{$\begin{array}{l}\text { TOE model } \\
\text { (Tornatzky and Fleischer, 1990) }\end{array}$} & & Adoption \\
\hline & 1. Technological factors & \\
\hline & Availability & + \\
\hline & Characteristics & + \\
\hline & 2. Organizational factors & \\
\hline & Formal and informal linking structures & + \\
\hline & Communication processes & + \\
\hline & Size & + \\
\hline & Slack resources & + \\
\hline & 3. Environmental factors & \\
\hline & Government regulation & + \\
\hline & Technology support infrastructure & + \\
\hline & Industry characteristics and market structure & + \\
\hline \multirow[t]{12}{*}{ Frambach (1993) } & & Relation to diffusion \\
\hline & 1. Adopter characteristics & \\
\hline & Size & + \\
\hline & Complexity & + \\
\hline & Specialization & + \\
\hline & International relations & + \\
\hline & Formalization & - \\
\hline & Centralization & - \\
\hline & 2. Information & \\
\hline & Availability & + \\
\hline & Quality & + \\
\hline & Value & + \\
\hline
\end{tabular}




\begin{tabular}{|c|c|c|}
\hline Study & $\begin{array}{l}\text { Characteristics } \\
\end{array}$ & Results \\
\hline continued & 3. Information processing characteristics & \\
\hline \multirow[t]{25}{*}{ Frambach (1993) } & Absorption capacity & + \\
\hline & 4. Innovation characteristics & \\
\hline & Relative advantage & + \\
\hline & Compatibility & + \\
\hline & Complexity & - \\
\hline & Trialability & + \\
\hline & Observability & + \\
\hline & Uncertainty & - \\
\hline & Expectations technology & - \\
\hline & 5. Competitive environment & \\
\hline & Competitiveness industry & + \\
\hline & 6. Innovation development & \\
\hline & Management support & + \\
\hline & Incorporation in strategic posture & + \\
\hline & Innovation organizational climate & + \\
\hline & Superior product & + \\
\hline & Experience and synergy effects & + \\
\hline & Organization/execution of development & + \\
\hline & 7. Network participation & \\
\hline & Level of interaction & + \\
\hline & 8. Marketing strategy & \\
\hline & Co-operation with other suppliers & + \\
\hline & Positioning innovation in the market & + \\
\hline & Reducing the risk of adoption & + \\
\hline & Winning market support & + \\
\hline \multirow[t]{11}{*}{ Lefebvre, Mason and Lefebvre (1997) } & & Technology Policy adoption \\
\hline & 1. Structural characteristics & \\
\hline & Formalization & + \\
\hline & Technocratization & + \\
\hline & Centralization & + \\
\hline & 2. Scanning & \\
\hline & Scanning mechanisms & + \\
\hline & 3. Strategic orientation of business enterprise & \\
\hline & Aggressiveness & + \\
\hline & Analysis & - \\
\hline & Defensiveness & + \\
\hline
\end{tabular}




\begin{tabular}{lll}
\hline \multicolumn{1}{c}{ Study } & Characteristics & Results \\
\hline continued & Futurity & \\
Lefebvre, Mason and Lefebvre (1997) & Proactiveness & \\
& Riskiness & \\
& & + \\
\end{tabular}




\section{DMOs Online Relationship Marketing Activities - Determinant Factors}

Service industries, which are highly dependent on processing information and prompt access to information, depend on IS (Goode \& Stevens, 2000). The tourism industry is highly dependent on information and its effective and efficient delivery of information. Therefore, it is important to examine the factors that affect technology adoption and use. There are many organizational factors that affect the adoption and use of technology within an organization. Technological budget, size, CEOs characteristics, IT knowledge, type of industry, innovativeness and technological environment of the organizations are some of the factors that have been studied by many researchers because of their direct impact on the innovation adoption decision process (Goode \& Stevens, 2000; Scupola, 2003; Thong, 1999; Teo \& Tan, 1998; Zhu \& Kraemer, 2005; Zhu, Kraemer \& Xu, 2003).

These factors have been identified by the above authors as being important and at times vital for the adoption of technology and e-business functions within an organization. However, opposing views of the importance of some of the variables have been found among the studies; therefore, further examination of the variables is needed. For the purpose of this research the organizational factors to be examined are: technological environment, organizational characteristics and technological competence and their impact on technology adoption and use, more specifically of online relationship marketing activities. See figure 4 for the proposed conceptual model. 


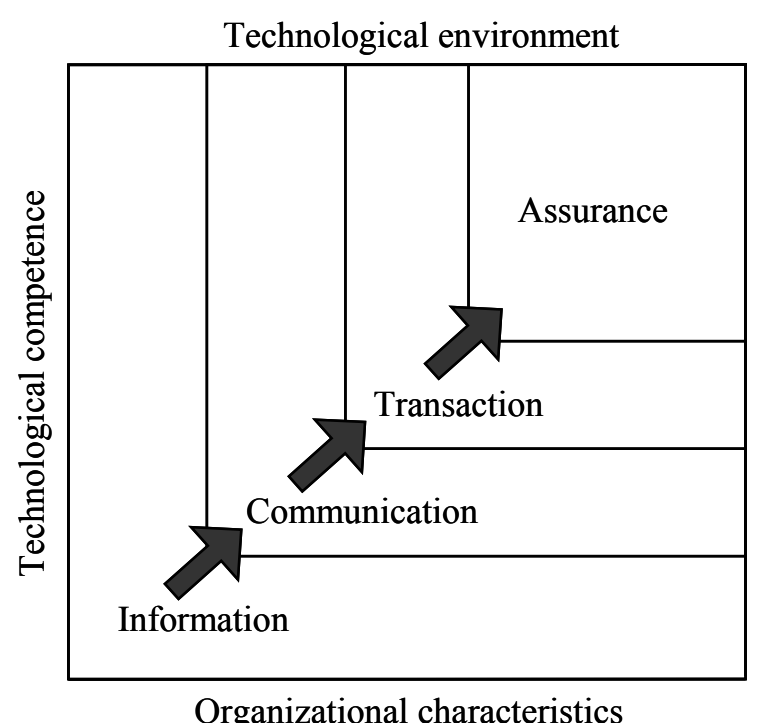

\section{Figure 4: Proposed conceptual model of DMOs web-based relationship marketing implementation and the impact of organizational factors}

\section{Technological Environment}

An organization's overall technological environment entails the management support, management involvement, financial support, and the resources to implement and maintain technology systems. More specifically, an organization's technological environment can be defined by factors such as: IT training (Frambach \& Schillewaert, 2002; Main, 2002; Wöber \& Gretzel, 2000), financial resources (Goode \& Stevens, 2000; Tornatzky \& Fleischer, 1990; Zhu $\&$ Kraemer, 2005), management involvement (Lefebvre, Mason \& Lefebvre, 1997) and management support (Frambach, 1993; Frambach \& Schillewaert, 2002). As part of the overall technological environment studies have found that development of technical and management skills are vital to the successful implementation of web-based solutions (Adebanjo, 2003). The technological environment of an organization is an important factor to examine since it has been 
found that a company's technology competence is significant to adoption facilitation (Zhu, Kraemer and Xu, 2003). Furthermore, Scupola (2003) found that the organization's overall technology environment is a necessary condition for the adoption and implementation of ecommerce activities.

Training has been found to be a crucial factor for technology acceptance (Frambach \& Schillewaert, 2002) and use success (Main, 2002; Wöber \& Gretzel, 2000). The development of training programs and knowledge management strategies are necessary for the effective implement, use and support of the new technologies (Martin \& Matlay, 2003). Even thought technology training has been identified as a predictor to technology implementation and its success, this area has been largely ignored.

Certain sectors of the tourism industry have been slow to implement technology innovations for various reasons (Main, 2002). Main (2002) found that lack of training continues to plague the industry which impedes the effective use of technology applications. Main (2002) also found that informal training through family and friends has helped the progression of use of technology; however, formal training should not be disregarded since it allows for the maximization and exploitation of the full range of functions that technology has to offer. The importance of technology training is demonstrated in a study by Yuan et al. (2003) which found that educating and training personnel promotes the use of Internet applications by American CVBs.

Another important organizational characteristic that needs additional investigation is an organization's financial commitment or resources dedicated for IT. Studies have found that an organization's financial commitment is a major predictor to technology adoption and use (Goode \& Stevens, 2000; Grover \& Teng, 1992; Scupola, 1990; Thong 1999; Tornatzky \& Fleischer, 
1990; Zhu \& Kraemer, 2005). The first step toward the decision to adopt information systems (IS) is having adequate financial resources (Thong, 1999). Earlier studies have suggested that firms that budget for information technology acquisition and maintenance are likely to be technology adopters (Goode \& Stevens, 2000). Budget existence indicates that the business considers information technology to be important for their operations (Grover \& Teng, 1992). Implementing e-business functions within an organization requires investment to obtain hardware, software, system integration and employee training (Zhu \& Kraemer, 2005). Sufficient financial resources committed to e-business allow the organization to obtain the necessary resources and develop them into superior e-business functions (Zhu \& Kraemer, 2005). Therefore, only those businesses that have adequate financial (i.e. budget allocations and resources for IT) and organizational resources (i.e. management support and involvement) should consider IS adoption as a viable undertaking (Thong, 1999). Firms with greater resources and greater financial commitment towards e-business are more likely to achieve successful ebusiness implementation and in turn tend to achieve a greater extent of usage (Zhu \& Kraemer, 2005).

In addition, a study by Goode and Stevens (2000) found that IT budgets were good indicators of technology adoption behavior. Furthermore, the same study found that IT budget is associated with World Wide Web adoption which demonstrates its importance to the operation (Goode \& Stevens, 2000). However, contradictory results in regards to the importance of technological budget have been reported. Scupola (1999) states financial resources are important but not a determinant for e-commerce adoption. The importance of this aspect in the tourism industry is demonstrated in a study by Gretzel et al. (2000) which found that an organization's limited resources are a barrier to technology implementation and adoption on American CVBs. 
Due to the importance financial resources play on the acquisition and implementation of technology innovations and conflicting results of previous studies further investigation of this variable is important to shed more light onto the impact of budget on technology adoption and implementation.

The central role of the CEO in an organization suggests that their involvement and support are even more critical in the decision making process of a small business to adopt IS (Frambach, 1993; Frambach \& Schillewaert, 2002; Lefebvre, Mason \& Lefebvre, 2002; Thong, 1999). Moreover, CEOs who perceive new information systems as "beneficial, compatible, and relatively easy to use will be more likely to adopt them" (Thong, 1999, p. 205). Further investigation of this aspect finds that the CEOs' support involves the allocation of financial resources and sufficient budget allocations for innovations and technology adoptions (Thong, 1999; Zhu \& Kraemer, 2005). Since technology adoption involves financial investment only an organization with a knowledgeable and innovative CEO will be willing to take the risk (Thong, 1999).

Management's involvement in technology and e-commerce adoption and implementation has been found critical to its success (Gretzel et al., 2000; Yuan et al., 2003). Management support has been found to be important to the adoption and implementation decision of ecommerce functions (Scupola, 2003). Scupola (2003) found that the CEO or project champion has the most important role in initiating and promoting the e-commerce project. A study by Gretzel et al. (2000) found that lack of management support is a barrier to technology implementation within American CVBs. Furthermore, Yuan and Fesenmaier (2000) identified leadership's understanding of the potential of technology implementations to be one of the main 
factors that have an impact on the adoption and implementation behavior of internet/intranet technology.

Furthermore, in regards to website adoption and leadership Wang and Fesenmaier (2006) found that management support of IT was found to be an important factor to American CVBs web marketing strategies. More specifically, Yuan et al. (2003) found that management support is needed to promote the use of Internet technology by American CVBs. A better understanding of the technological environment of the organization will provide a better support system and increased success rate of new technology implementations.

\section{Organizational Characteristics}

The impact of organizational characteristics on innovation and technology adoption has been one of the most researched factors since the increased use of technology on daily operations (Tornatzky \& Klein, 1982). Organizational characteristics include the organization's size, budget, number of employees and industry sector, among others. Since size and organizational innovativeness have been heavily researched as major predictors to technology adoption and use, many times with different results, this research will focus on these two factors.

Size has been the most studied organizational characteristic on studies related to innovation and technology adoption (Tornatzky \& Klein, 1982). Rogers (1995) found that there is a positive relationship between organization size and innovativeness. Several studies have found that an organization's size has been identified as an influencing factor to technology adoption (Frambach \& Schillewaert, 2002; Goode \& Stevens, 2000; Main, 2002; Thong, 1999; Tornatzky \& Fleischer, 1990; Tornatzky \& Klein, 1982; Wang \& Fesenmaier, 2006; Zhu \& Kraemer, 2005). 
Previous studies have found that size is positively related to innovation and technology adoption (Frambach, 1993; Goode \& Stevens, 2000; Lefebvre \& Lefebvre, 1992; Tornatzky \& Klein, 1990). More specifically, previous studies among small businesses have found that business size is the most significant discriminator between adopters and non-adopters of information systems (Thong, 1999). Also, Thong (1999) found that business size is the most significant organizational characteristic that determines extent of IS adoption. The reasoning behind the impact of business size on technology adoption and use is that larger businesses have more resources available (Thong, 1999).

However, other studies have found that organizational size is negatively or not related to technology adoption and use (Main, 2002; Zhu \& Kraemer, 2005). Main (2002) conducted the first stage of a study in 1994 which indicated that firm size was found to be statistically significant in the use of technology. However, there was no statistical evidence in the most recent surveys conducted in 2000 and 2001 (Main, 2002) that indicated that these factors have a significant impact on the use of technology. Zhu \& Kraemer (2005) explain that larger organizations experience structural inertia due to fragmented decision making and implementation process.

On regards to web marketing strategies size has been found to be a contributing factor to their implementation (Wang \& Fesenmaier, 2006). However, Goode and Stevens (2000) found that company size was not significantly related to World Wide Web technology adoption. In addition, a study conducted by Wang \& Fesenmaier (2006) on American CVBs web-marketing strategies found that size of the organization was identified as important to the implementation of web-marketing strategies. These results provide good supporting evidence that further 
investigation is needed to explore the effects of company size on technology and more specifically World Wide Web technology implementation (Goode \& Stevens, 2000).

Organizational innovativeness is defined as the inherent desire to experiment with technology, learn about it and influence others (Colby \& Parasuraman, 2003). Innovativeness is a permanent trait exhibited by truly innovative organizations over a period of time (Subramanian $\&$ Nilakanta, 1996). Therefore, truly innovative organizations are those that over time consistently exhibit innovative behavior (Subramanian \& Nilakanta, 1996). Previous research has found that organizational characteristics facilitate and influence organizational innovativeness (Subramanian \& Nilakanta, 1996).

A firm's innovation level supports or deters the adoption and implementation of innovations such as new technology applications. New technologies present potential adopters with new means of solving problems and exploiting opportunities (Thong, 1999). Innovative organizations create a climate conducive to innovation in the whole organization (Damanpour, 1991). Since the adoption of innovations by an organization is the result of the strategic direction of the organization a proactive and innovative organization will be more likely to adopt new technologies (Subramanian \& Nilakanta, 1996). In addition, Frambach (1993) found that an innovative organizational climate is positively related to innovation adoption and diffusion.

Innovative organizations understand the desires of consumers and their use of e-business functions (Colby \& Parasuraman, 2003). These same organizations will continue to obtain technology innovations that will keep them competitive in the business world and capture a larger percentage of the market (Colby \& Parasuraman, 2003; Subramanian \& Nilakanta, 1996). In addition, Wang and Fesenmaier (2006) found that innovativeness was an important factor to web-based marketing strategies implemented by American CVBs. Research in this topic within 
the hospitality industry is limited; this fact prompted the inclusion of this variable as an important factor to examine in this research.

\section{Technological Competence}

An organization's technological competence is defined by management's technological expertise (Main, 2002; Scupola, 2003; Thong, 1999) and employees' technological expertise (Scupola, 1999; Thong, 1999; Zhu \& Kraemer, 2003; Zhu, Kraemer \& Xu, 2005). Zhu and Kraemer (2005) explain that technological competence is defined by an organization's information technology human resources (i.e. technology proficient employee's and IT personnel). Zhu \& Kraemer (2005) explain that IT human resources are important to the organization since they provide knowledge and skills to develop e-business/internet related applications.

Management's technological knowledge has been found to be a major influencing factor to innovation adoption and technology implementation. Wöber and Gretzel (2000) found that managers who have better knowledge about technology and tourism will have fewer cognitive difficulties in using information technology. Thong (1999) found that the likelihood of IS adoption was associated with management information system (IS) knowledge. Management's IS knowledge may influence initial decision to adopt IS; however, it does not affect the extent of IS adoption (Thong, 1999).

A study by Martin and Matlay (2003) found that owners/managers who possess relevant skills and knowledge on technology applications would be able to recognize the Internet's potential and build on it. Therefore, firms must keep in mind that technology competence constitutes both internet skills and e-business know-how (Zhu \& Kraemer, 2005). The development of technical and management skills are vital to the successful implementation of 
web-based solutions (Adebanjo, 2003). The importance of management's knowledge within the hospitality industry is highlighted in a study conducted by Main (2002). The author states that lack of management skills continues to plague the hospitality industry, which impedes the effective use of technology applications.

Since the technology environment within the organization is influenced by the employee's competence level it is important to address employees' IT knowledge. Employees who are more knowledgeable about IS are more likely to adopt IT functions (Thong, 1999). Moreover, Scupola (2003) states that once a firm adopts e-commerce, the employee's IT knowledge and resistance to change is considered key to e-commerce diffusion and in turn its use within the company. In order to successfully implement technology applications technological support is needed within the organization. Technological support includes the skills of the labor force and access to suppliers of technology related services (Scupola, 2003). In addition, it has been found that small businesses with employees with greater IS knowledge are likely to use IS more extensively (Thong, 1999).

Furthermore, an organization's technology competence, which is largely defined by the employee's technology knowledge and competence, has been found to have significant influence on the extent of use of e-business (Zhu \& Kraemer, 2005). More specifically, Scupola (2003) found that employees' IS knowledge is the second most significant organizational characteristic that determines extent of use. Previous studies have found that organizations with "higher levels of technology competence tend to achieve a greater extent of e-business use" (Zhu \& Kraemer, 2005, p. 77). Zhu \& Kraemer's (2005) study found that it is important for an organization to build up technology competence which entails having resources like managerial skills and IT 
knowledgeable employees in order to implement technology and e-business functions and achieve better business value.

On regards to the use of the World Wide Web, technology knowledge and experience was associated with World Wide Web adoption and use (Goode \& Stevens, 2000). More specifically, management's insufficient knowledge is a barrier to technology implementation and adoption on American CVBs (Gretzel et al., 2000; Yuan \& Fesenmaier, 2000). A study of American CVBs (Wang \& Fesenmaier, 2006) found internet literacy of the organization as important in the implementation of web-marketing strategies. Furthermore, Yuan and Fesenmaier (2000) identified two main factors that have an impact on the adoption and implementation behavior of internet/intranet technology by CVBs: (1) leadership understanding of the potential of technology implementations; and, (2) employee intellectual sufficiency to work and manage the new systems.

As an organization's internet technology spreads and becomes a necessity to stay in business, technology and managerial skills for e-business management become more significant. The necessity of managerial and technology skills urges top managers to promote the retention of employees and staff with managerial and technological e-business skills (Zhu et al., 2003).

Based on the review of the literature, firms with a higher degree of technology competence tend to enjoy greater readiness to use e-business and e-commerce activities in their processes (Zhu \& Kraemer, 2005). As a result, these organizations would be more likely to achieve a greater extent of e-business use (Zhu \& Kraemer, 2005). This is an important aspect CVBs must consider when deciding to implement technology innovations within the organization. 
The literature demonstrates that there are several characteristics that impact the successful implementation of web-based relationship marketing efforts. For the purpose of this study organizational factors will be divided into three main groups: 1) technological environment, 2) organizational characteristics and 3) technological competence. The study will measure the impact these characteristics have on the implementation of web-based relationship marketing activities. Under technological environment four factors will be measured: IT training, financial resources, management involvement, and management support. From the organizational characteristics perspective two characteristics will be examined: size and organizational innovativeness. Finally, from the technological competence perspective management technological expertise and employee technological expertise will be studied.

The conceptual model for this research is based on Tornatzky \& Fleischer (1990) TOE theoretical framework of technological innovation, with adaptations made to reflect factors investigated by Frambach (1993), Lefebvre and Lefebvre (1992), Thong (1999), Zhu and Kraemer (2005). Previous research explores the impact of technological, organizational and leadership characteristics of the organization and their impact on the adoption of e-commerce activities. However, this research will focus on the technological environment, organizational characteristics and technological competence of a CVB and their impact on the level of adoption of web-based relationship marketing activities. More specifically, this research will examine the CVBs web-based relationship marketing functions and the extent of their applications (i.e. information, communication, transaction or assurance). 


\section{Model of the Study}

Businesses use their websites for different marketing activities such as provide customers with information; answer questions through interactive communication; complete a transaction like buying an airline tickets, car rental reservations, hotel reservations; and relationship building activities like newsletters and customization of webpage. All these functions are affected by the organizational characteristics of the individual organizations within which web-based marketing activities are implemented. The proposed model (see Figure 5 for testing model) seeks to determine the impact of the firm's characteristics (technological environment, organizational characteristics and technological competence) have on the stage of implementation of the webmarketing activities (information, communication, transaction and assurance). 
Technological environment

-IT training

- Financial resources

-Management involvement

-Management support

\section{Organizational characteristics}

-Size

- Organizational innovativeness

\section{Technological competence}

-Management team's technological expertise

-Employee's technological expertise

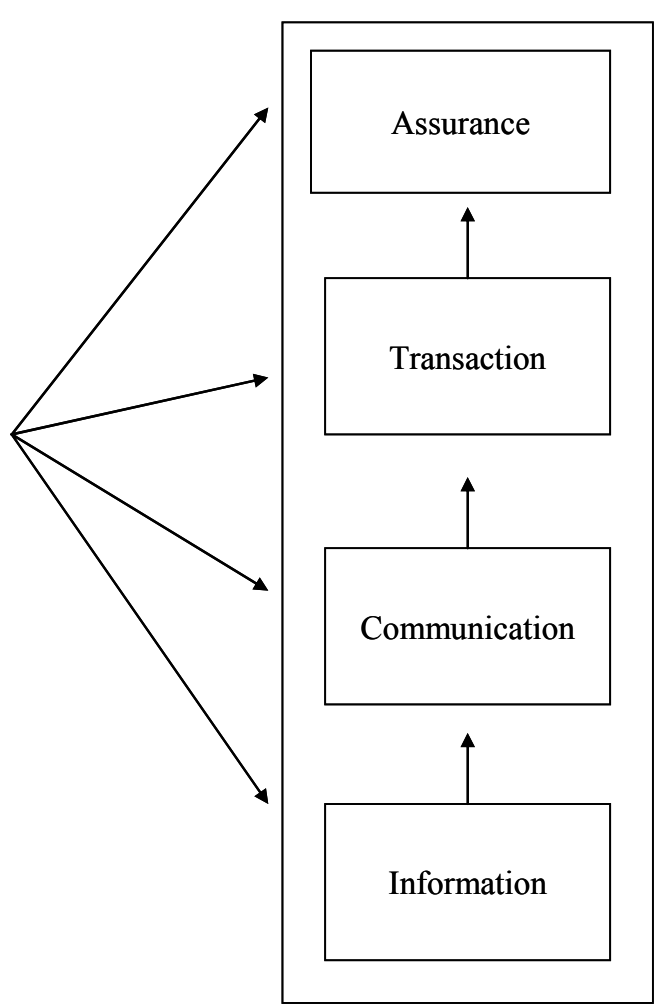

\section{Figure 5: Testing model for impact of organizational factors on DMOs web-based relationship marketing activities.}

This model seeks to demonstrate the impact of organizational characteristics on webmarketing functions implementation levels. A proactive organization will have all the sufficient resources and favorable organizational characteristics (e.g. innovativeness and technology expertise) and will adopt more sophisticated levels of web-based marketing functions. This same organization will implement functions to support all four stages of web-based marketing, progressively moving from information to the assurance stage. Using web-based marketing functions will allow CVBs to use their websites as a retention tool to support their relationship marketing strategy. 
The model proposed in this study is an adaptation of Hanson's (2000) and Kotler's (2006) models on the stages of relationship building. In addition, the proposed model seeks to examine the degree of impact organizational characteristics may have on the implementation of web-based relationship marketing activities. The aspect of the impact of organizational characteristics is based on the TOE framework (Tornatzky and Fleischer, 1990) of innovation adoption.

\section{$\underline{\text { Summary }}$}

Innovation adoption research shows that organizational factors greatly impact an organization's decision to adoption technology innovations (Tornatzky \& Klein, 1982). This chapter provided an overview on previous literature on relationship marketing, innovation adoption, web based marketing activities and organizational factors that impact information technology adoption and implementation. Factors to be examined were identified and discussed. 


\section{CHAPTER THREE: RESEARCH METHODOLOGY}

The primary objective of this study is to examine the web-based marketing functions of American CVBs from a relationship marketing perspective. Specifically this study will: 1) Evaluate web-based marketing activities used by CVBs from a relationship marketing perspective, 2) Measure the effectiveness of web-based marketing activities implemented by CVBs, and 3) Identify and determine the impact CVBs organizational characteristics have on the implementation of web-based marketing activities. This chapter presents the research design, questionnaire and statistical procedures used to analyze the data and examine the objectives of this study. The questionnaire, data collection and sampling procedures are also discussed in this chapter.

\section{Survey Instrument}

This study seeks to evaluate the web-based marketing activities used by CVBs and examine the impact different organizational characteristics have on the level of implementation of web-based marketing activities. The survey used for this study was designed and developed in 2002 by the National Laboratory for Tourism and eCommerce of the University of Illinois at Urbana-Champaign. The survey was specifically developed to collect data regarding the web marketing strategies of CVBs, an area largely under researched in the tourism industry. Limited research in this area makes this survey a pioneer in the attempts in this field of research.

The questionnaire was developed based on previous literature regarding the impact of organizational characteristics, organizational technology climate and web marketing strategy. All of these areas have been studied in the tourism industry however the importance lies in the target 
sample group, CVB. A survey is the preferred method of data collection for this kind of topic because it allows for the exploration of various areas within the same instrument. In addition, a survey allows data to be collected from large sample groups and allows for the examination of multiple aspects or variables. Data collected through surveys allows for the examination of relationships between variables and allows patterns to emerge and examined on the analysis process.

Secondary data was selected for this study to allow for in-depth examination of the data previously collected. The data has been used to examine the relative importance of organizational components on the web marketing strategies. However, the data has not been used to examine the web marketing strategies from the relationship marketing perspective.

The proposed study seeks to identify the organizational descriptors that have the most impact on the level of web-based marketing functions implemented by a CVB. In addition, further examination of the data will allow the investigation of the effectiveness of the web-based marketing activities implemented by the CVBs. Furthermore, a more in-depth examination of the data will allow for a better understanding of American CVBs and their web marketing strategies.

\section{Sampling Frame and Data Collection}

Convention and visitors bureaus in the United States at the regional, county and city level were the population used for the study. The sample was selected from a database built to integrate CVB information collected from different sources. More specifically, the names of the CVBs were obtained from general searches on the Internet and from the 2002 membership list provided by the International Association of Convention and Visitors Bureaus. The researchers identified a total of 1,200 regional, county and city CVBs in the United States. The CVBs 
identified were then contacted with a brief telephone call to verify the address and the director/CEO's name. After the information was verified the list was randomly divided into two groups using Statistical Package of Social Sciences (SPSS) randomization procedure. This research project's sample is one of the randomly selected groups. The sample size is 600 CVBs.

A three-step mailing process was used to maximize the response rate. The survey packet was mailed to CEOs/Directors of the $600 \mathrm{CVBs}$ previously identified. The packet included a cover letter which explained the purpose and provided an incentive (i.e. a free copy of the executive summary of the results) to participate in the study. Non-respondents were sent two follow up mailings in two week intervals. The researchers received a total of 268 questionnaires out of which 260 were found usable, representing a $43 \%$ response rate.

\section{Review of the Survey}

The survey was divided into four sections: 1) the organization and its use of the Internet; 2) Web applications and strategies; 3) the organization's general technological environment; and 4) the organizational and director's demographics (See Appendix). The survey included closeended questions with options provided and open ended questions requesting the participant to input their answer.

Section one of the survey gathered information on the organizational characteristics and general technological climate of the organization. These questions helped measure: 1) the organization's demographics such as size, budget and number of full time employees; and 2) technological climate of the organization such as the number of computers in use at the organization and the percentage of computers connected to the internet. Section two of the 
survey gathered information on the CVBs web-based marketing strategies, use of web applications; and perceived importance and effectiveness of the web applications.

Section three of the survey gathered specific information on the organization's technological climate. These questions measured the level of management's support to technological implementations, management's and employee's technological knowledge level. Section four of the survey gathered information on the director's characteristics, innovation levels and decision making process. These questions will help measure leadership's style and characteristics that may affect technology implementation behavior.

\section{Dependent Variables}

The dependent variable in this study is the various levels of web-based marketing activities implemented by the CVBs: information, communication, transaction and assurance. A list of the web applications for each function was prepared and verified with a panel of experts. The applications were divided by functions as follows: 12 applications for the information function, 5 applications for the communication function, 7 applications for the transaction function and 8 applications for the assurance function. See Table 3 for a summary of the web functions and applications. 
Table 3: List of web functions and applications

\section{Functions and Applications}

\begin{tabular}{ll}
\hline Information & Transaction \\
Activities/attraction information & Online reservations \\
Accommodation information & Themed products \\
Events calendar & Secure transactions \\
Restaurant information & Event tickets \\
Shopping information & Attraction tickets \\
Links to regional/city/area pages & Shopping carts \& payment system \\
Maps/driving directions & Web seal certification \\
Travel guides/brochures & \\
Tour operator information & Assurance \\
Frequently asked questions & Email newsletters \\
Banner advertisements & Highlight special offers/best buys \\
Virtual tours & Direct email campaign \\
& Privacy policy \\
Communication & Personalization/Customization \\
Brochure request capabilities & Incentive programs \\
Search functions & Cross-selling/up selling opportunities \\
Interactive tools & Customer loyalty programs \\
Trip/vacation planner & \\
Community functions & \\
& \\
\hline
\end{tabular}

After the applications were divided by function the variables were recoded to convert the Likert scale part the question into dichotomous data as follows: 1 through 3 were recoded as not important; 4 through 7 were recoded as important. After the new variable was created an effectiveness index was calculated by using the extent of use and importance score of each application. The effectiveness index was calculated based on an effectiveness matrix.

Wang and Fesenmaier (2006) developed an effectiveness matrix that will be used to calculate the effectiveness scores of the web applications. Wang and Fesenmaier (2006, p. 243) describe the matrix as a tool constructed to reflect the degree to which the Web marketing efforts match the perceived importance of these efforts. This is done by providing weights to the different quadrants to reflect the importance and utilization of each of the applications (see Figure 6). The matrix consists of four quadrants to demonstrate the four possible scenarios of 
director's perceptions of importance and actual utilization. Quadrant I (missing opportunities) describes a CVB that perceives the web application as important but has not implemented the application in their web-based marketing activity; the weight assigned for this quadrant is -1 (missing opportunity). Quadrant II (effective) describes a CVB that perceives the web application as important and has implemented the application in their web marketing; the weight assigned for this quadrant is +1 (effective).

Quadrant III (wasting resources) identifies CVB's that perceive the web application as not important but have implemented the application in their web marketing; the weight assigned for this quadrant (wasting resources) is -1. Quadrant IV (indifference) describes the CVB that do not perceive the web application as important and has not implemented the application on their web marketing effort; the weight assigned for this quadrant is 0 (indifference). The weight values of the web-marketing applications will be added up to determine the effective use of each function.

Source: Wang and Fesenmaier, 2006

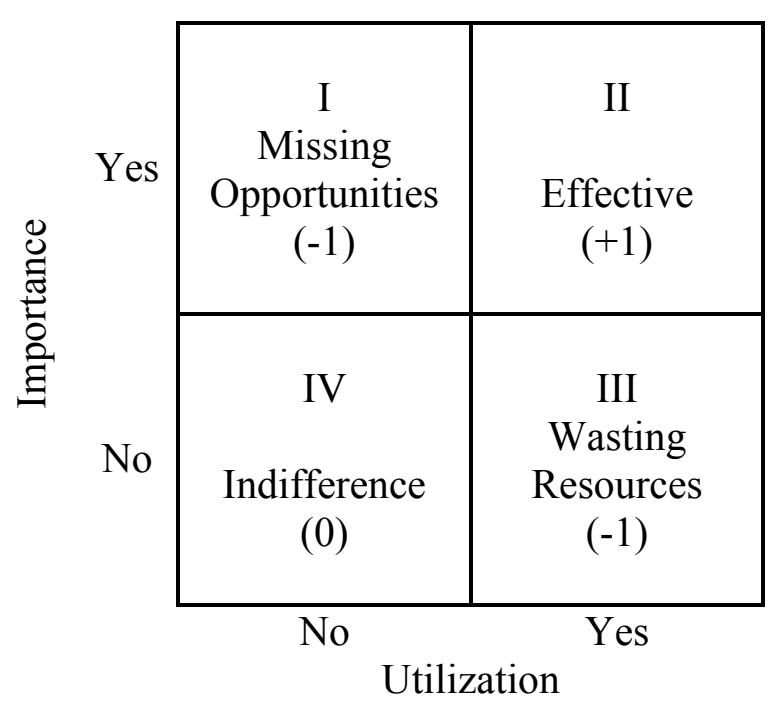

Figure 6: Effectiveness evaluation matrix for web marketing activities 
Finally, once the effectiveness index was calculated for all the applications under each function the effectiveness scores were calculated by adding the effectiveness indexes for the applications. For example, once an effectiveness index was calculated for all the 12 applications for the information function then the indexes were added to calculate the total effectiveness score for the information function. This same process was followed for all the applications in the other three functions. The effectiveness scores for each function (information, communication, transaction, assurance and sophistication) are used as the dependent variables of the study.

\section{Independent Variables}

The independent variables being studied are the three organizational characteristics: the technological environment of the organization, organizational characteristic and the organizational technological competence. The first group of variables, the technological environment, includes the availability of technology training programs, website budget, management involvement and support for technology operations. The second group of variables, the organizational characteristics, includes organizational size measured by the CVBs yearly budget and number of full time employees; and the organizational innovativeness determined by the director's level of innovativeness. This measure was selected based on previous studies which show that an organization's innovativeness is mostly defined by its management team, CEO or director (Thong, 1999). Several studies have found that an organization's management or leadership team has great impact on their strategic direction, innovation adoption and system implementation (Frambach, 1992; Main, 2000; Scupola, 2003; Thong, 1999). The third group of variables, the organizational technological competence, includes management's and employees' technological knowledge measured by their level of knowledge/skills with Internet technology. 
The independent variables will be measured utilizing related questions from the survey.

Table 4 shows the independent variable to be measured with the corresponding questions in the survey. A 7 point Likert scale was used with different anchors as noted in the table.

\section{Table 4: Independent variables}

\begin{tabular}{|c|c|}
\hline Independent Variables & Measure \\
\hline \multicolumn{2}{|l|}{ Technology Environment } \\
\hline \multirow[t]{2}{*}{ IT training } & Level of Training (Question 30) \\
\hline & $1=$ No training at all $7=$ Regular training \\
\hline \multirow[t]{2}{*}{ Financial Resources } & Size of Website budget (Question 14) \\
\hline & Total amount of Website budget \\
\hline \multirow[t]{2}{*}{ Management Involvement } & Level of management involvement (Question 29) \\
\hline & $1=$ Not at all involved $7=$ Extremely involved \\
\hline \multirow[t]{2}{*}{ Management Support } & Level of management support (Question 28) \\
\hline & $1=$ Not at all supportive $7=$ Extremely supportive \\
\hline \multicolumn{2}{|l|}{ Organizational characteristics } \\
\hline \multirow[t]{2}{*}{ Size } & Size of yearly budget (Question 4) \\
\hline & Number of full time employees (Question 5) \\
\hline \multirow[t]{8}{*}{ Organizational innovativeness } & Level of risk involved in project (Question 37a) \\
\hline & $1=$ Low risk $7=$ High risk \\
\hline & Level of reaction to outside changes (Question 37b) \\
\hline & $1=$ Gradual and moderate $7=$ Aggressive and far reaching \\
\hline & Timing of introduction of changes (Question 37c) \\
\hline & $1=$ After competitors $7=$ Before competitors \\
\hline & Methods/Innovations (Question 37d) \\
\hline & $1=$ Time tested methods $7=$ Innovation \\
\hline \multicolumn{2}{|l|}{ Technological competence } \\
\hline \multirow{2}{*}{$\begin{array}{l}\text { Management team's technological } \\
\text { expertise }\end{array}$} & Level of management team's expertise (Question 26) \\
\hline & $1=$ Novice $7=$ Expert \\
\hline \multirow[t]{2}{*}{ Employee's technological expertise } & Level of employee's technological expertise (Question 27) \\
\hline & $1=$ Novice $7=$ Expert \\
\hline
\end{tabular}




\section{Data Analysis}

The 260 usable surveys were analyzed by Statistical Package of Social Sciences (SPSS). First, descriptive statistics were performed on selected variables to obtain ranges, frequencies and means. Second, standard multiple regression analysis was applied to examine the statistical significance of the independent variables, determine how much of the variance in the dependent variable is explained by the model, and examine the contribution of each independent variable on the prediction of the dependent variable.

Multiple regression analysis requires the use of continuous dependent and independent variables therefore additional data transformation was needed. Three independent variables had to be transformed: financial resources, size and organizational innovativeness. The variable for financial resources was website budget which required the respondent to provide budget amounts. To allow for this variable to be included in the analysis the variable was transformed using log transformation of the original variable which allows to be normalized in this case since actual budget amounts were provided.

Organizational size was measured based on a single index constructed taking into account the total number of full time employees and CVB yearly budget. However, organizational innovativeness was measured by a single item in the survey with 4 sub-questions that measured CEOs/directors project risk levels, reactions to outside changes, introduction of changes compared to competitors, and innovations. The answers to these questions were added to create a new variable to measure organizational innovativeness.

Finally, standard multiple regression analysis was used to investigate the impact of the independent variables on the dependent variables. Five regression models were developed to examine the impact of the technological environment, organizational characteristics and 
technological competence on each function of the web-based relationship marketing activities (information, communication, transaction, assurance and sophistication). The formula used for the study is as follows:

Web marketing function $=f(\mathrm{TP}, \mathrm{FR}, \mathrm{MI}, \mathrm{MS}, \mathrm{S}, \mathrm{OI}, \mathrm{MKNOW}, \mathrm{EKNOW})$

Sophistication $=f(\mathrm{TP}, \mathrm{FR}, \mathrm{MI}, \mathrm{MS}, \mathrm{S}, \mathrm{OI}, \mathrm{MKNOW}, \mathrm{EKNOW})$

where

Web function $=$ information $(\mathrm{IN})$, communication $(\mathrm{CM})$, transaction $(\mathrm{TR})$, assurance $(\mathrm{AS})$

Sophistication $=$ Sophistication of web-based marketing (SOP)

$\mathrm{TP}=$ Training programs

$\mathrm{FR}=$ Financial resources

MI = Management involvement

$\mathrm{MS}=$ Management support

$\mathrm{S}=$ Size

$\mathrm{OI}=$ Organizational innovativeness level

MKNOW = Management knowledge level

EKNOW = Employee knowledge level

\section{$\underline{\text { Summary }}$}

This chapter describes the methodology and research framework of the study. This study is based on data collected by the National Laboratory for Tourism and eCommerce of the University of Illinois at Urbana-Champaign in 2002. The population used for the study was CVBs at the regional, county and city level. The areas analyzed were the technology 
environment, organizational characteristics, and technological competence and their impact on the effectiveness of the web-based relationship marketing activities. 


\section{CHAPTER FOUR: RESEARCH RESULTS}

This chapter presents the results of the data analysis performed using SPSS to test the proposed model. The model consisted of the organizational characteristics and their impact on the effectiveness of each of the web-based relationship marketing functions implemented by the CVB, as well as on the level of sophistication of web marketing activities. The independent variables are the eight organizational factors: IT training, financial resources, management involvement, management support, size, organizational innovativeness, management team's technological expertise and employee's technological expertise. The dependent variables include four web marketing functions (information, communication, transaction, assurance) and the sophistication of web-based marketing (sophistication) of the web-based relationship marketing activities implemented by the CVB.

\section{$\underline{\text { CVB Profiles }}$}

The first step of the analysis was to examine the profile of the participating CVBs and the findings are presented in Table 5. Three levels of tourism offices were represented in the sample group. The majority of the CVBs represented the county offices (46\%), followed by city level offices $(45.6 \%)$ and the least represented category was the regional level offices $(8.4 \%)$. The majority of the CVBs identified themselves as independent tourism organizations $(51.6 \%)$, followed by a division of the Chamber of Commerce (22\%).

In regards to the most important markets for the participating CVBs, the leisure market obtained the highest percentage (90.3\%) followed by the meetings/conventions market $(63.7 \%)$; and festival and special events (55.2\%). In terms of the organization's yearly budget, $28.8 \%$ of 
the CVBs reported having a yearly budget of $\$ 1,000,001$ and above; $23.1 \%$ of CVBs reported having a budget of $\$ 100,000-250,000$, representing the second highest percentage.

In regards to the number of full time employees the majority of the CVBs (76.9\%) had 19 full time employees while only $0.8 \%$ reported having 201 and more full time employees. More than half $(52.7 \%)$ of the CVBs reported using 1 to 5 computers in their organization.

In terms of the percentage of computers connected to the Internet almost $80 \%$ of the CVBs reported having $96 \%$ or more of the computers connected. In regards to the use of the organizational website $88.6 \%$ of the CVBs reported using their website to broadcast information; $51.8 \%$ of them provided interactive capabilities, $21.1 \%$ provided online booking and payment functions, and only 14\% provide personalization and recommendation functions in their website. 
Table 5: CVB profiles

\begin{tabular}{|c|c|c|}
\hline Organization Characteristics & Count & Percent (\%) \\
\hline \multicolumn{3}{|l|}{ Level of tourism office } \\
\hline Regional level & 21 & 8.4 \\
\hline County level & 115 & 46.0 \\
\hline City level & 114 & 45.6 \\
\hline \multicolumn{3}{|l|}{ Type of tourism office } \\
\hline Independent organization & 129 & 51.6 \\
\hline Part of county government & 29 & 11.6 \\
\hline Division of economic development & 4 & 1.6 \\
\hline Part of city government & 24 & 9.6 \\
\hline Division of the Chamber of commerce & 55 & 22.0 \\
\hline Other & 9 & 3.6 \\
\hline \multicolumn{3}{|l|}{ Important market } \\
\hline Leisure travel & 234 & 90.3 \\
\hline Sports & 111 & 42.9 \\
\hline Business travel & 106 & 40.9 \\
\hline Festival/special events & 143 & 55.2 \\
\hline Meetings/conventions & 165 & 63.7 \\
\hline Other & 38 & 14.7 \\
\hline \multicolumn{3}{|l|}{ Yearly budget } \\
\hline Under $\$ 100,000$ & 33 & 12.7 \\
\hline$\$ 100,001-250,000$ & 60 & 23.1 \\
\hline$\$ 250,001-500,000$ & 58 & 22.3 \\
\hline$\$ 500,001-750,000$ & 19 & 7.3 \\
\hline$\$ 750,001-1,000,000$ & 15 & 5.8 \\
\hline$\$ 1,000,001$ and above & 75 & 28.8 \\
\hline \multicolumn{3}{|l|}{ Number of full time employees } \\
\hline 1 to 9 & 200 & 76.9 \\
\hline 10 to 19 & 35 & 13.5 \\
\hline 20 to 49 & 16 & 6.2 \\
\hline 50 to 99 & 7 & 2.7 \\
\hline 201 and more & 2 & 0.8 \\
\hline \multicolumn{3}{|l|}{ Number of computers } \\
\hline 1 to 5 & 136 & 52.7 \\
\hline 6 to 10 & 57 & 22.1 \\
\hline 11 to 20 & 38 & 14.7 \\
\hline 21 to 50 & 18 & 7.0 \\
\hline 51 to 100 & 6 & 2.3 \\
\hline 101 and more & 3 & 1.2 \\
\hline \multicolumn{3}{|l|}{$\begin{array}{l}\text { Percentage of computers connected } \\
\text { to the Internet }\end{array}$} \\
\hline $5 \%$ or less & 10 & 3.9 \\
\hline 6 to $25 \%$ & 2 & 0.8 \\
\hline 26 to $50 \%$ & 10 & 3.9 \\
\hline 51 to $75 \%$ & 8 & 3.1 \\
\hline 76 to $95 \%$ & 23 & 8.9 \\
\hline $96 \%$ or more & 206 & 79.5 \\
\hline \multicolumn{3}{|l|}{ Organizational use of website } \\
\hline Broadcast information & 202 & 88.6 \\
\hline Interactive capabilities & 118 & 51.8 \\
\hline Online booking and payment & 48 & 21.1 \\
\hline Personalization and recommendation & 32 & 14.0 \\
\hline
\end{tabular}




\section{Popularity and Importance of Web Applications}

The second step on the analysis involved the popularity and importance of the applications under each of the four web functions. Popularity was measured by the extent of use of the applications and importance was measured by the CEOs/director's perceived importance of the applications. Analysis of the data revealed several trends. Table 6 presents the findings. The results of the descriptive statistics are organized in the table in decreasing order based on the popularity percentage.

In terms of popularity (extent of use), the majority of the applications under the information function were found to be frequently used by CVBs. Seven out of the twelve applications were found to have a popularity percentages between $99 \%$ to $80 \%$. The applications for the provision of activities/attraction information, accommodation information, events calendar and restaurant information all have reported percentages between $94 \%$ to $99 \%$. The applications representing the provision of shopping information, links to regional/city/area pages and maps/driving directions reported percentages between $89 \%$ to $81 \%$. The least frequently used applications were banner advertisements and virtual tours both, of which attained less than $20 \%$ of use.

In terms of the popularity (extent of use) of the communication applications the highest percentage was achieved by the brochure request capabilities. Almost $90 \%$ of the CVBs reported the use of this application. On the other hand, the least frequently used application under the communication function was the community functions (i.e. chat rooms), less than $1 \%$ of the CVBs reported using this application.

The percentages for popularity (extent of use) of the applications under the transaction function reveal that these applications are the least frequently used among the CVBs. 
Applications under the transaction function reported percentages of use of less than $20 \%$. The highest reported percentage was for the online reservations applications where $20.8 \%$ of CVBs reported using this application in their website. The analysis found that the least popular application was the Web seal certification which was found to be used by only $2.3 \%$ of the CVBs.

In terms of the popularity (extent of use) of the applications under the assurance function the results demonstrate that applications for the assurance function received higher percentages than applications under the transaction function. This is an interesting finding since these functions require a higher sophistication level as discussed in the literature review. The highest percentages of use were reported for the following applications: email newsletters (34.6\%), highlight special offers/best buys (33.1\%) and direct email campaign (30\%). The least used application, customer loyalty programs, was reported to be used by less than $4.2 \%$ of the CVBs.

In regards to the importance of the applications (based on the 7 point Likert scale, 7 being extremely important and 1 being not at all important), the means demonstrate that the majority of the applications under the information and communication functions were perceived to be important to the web marketing strategy. The most significant findings are those of the information function where eight out of the twelve applications were reported to be perceived as important. This demonstrates the increased attention and importance CVBs place on the applications geared towards providing information to the customer. Furthermore, applications under the transaction and assurance functions reported lower means demonstrating lower perceived importance. This finding is supported by the main function of a CVB which is to provide information to potential visitors rather than sell or create long lasting relationships with customers. 
Table 6: Popularity and perceived importance of web technology application by functions

\begin{tabular}{|c|c|c|c|}
\hline Functions and Applications & $\begin{array}{c}\text { Popularity } \\
\text { (\%) }\end{array}$ & $\begin{array}{c}\text { Importance } \\
\text { (Mean) }\end{array}$ & (SD) \\
\hline \multicolumn{4}{|l|}{ Information } \\
\hline Activities/attraction information & 99.2 & 6.66 & 0.74 \\
\hline Accommodation information & 99.2 & 6.74 & 0.71 \\
\hline Events calendar & 97.3 & 6.42 & 1.01 \\
\hline Restaurant information & 94.2 & 5.74 & 1.34 \\
\hline Shopping information & 89.6 & 5.58 & 1.35 \\
\hline Links to regional/city/area pages & 88.1 & 5.36 & 1.37 \\
\hline Maps/driving directions & 81.2 & 5.86 & 1.15 \\
\hline Travel guides/brochures & 77.3 & 5.48 & 1.66 \\
\hline Tour operator information & 50.8 & 4.92 & 1.46 \\
\hline Frequently asked questions & 21.5 & 3.66 & 1.43 \\
\hline Banner advertisements & 19.2 & 3.27 & 1.32 \\
\hline Virtual tours & 13.8 & 4.08 & 1.27 \\
\hline \multicolumn{4}{|l|}{ Communication } \\
\hline Brochure request capabilities & 89.2 & 6.25 & 1.13 \\
\hline Search functions & 51.5 & 5.39 & 1.41 \\
\hline Interactive tools & 28.5 & 4.43 & 1.43 \\
\hline Trip/vacation planner & 23.5 & 4.44 & 1.40 \\
\hline Community functions & 0.8 & 2.28 & 1.16 \\
\hline \multicolumn{4}{|l|}{ Transaction } \\
\hline Online reservations & 20.8 & 4.32 & 1.55 \\
\hline Themed products & 18.8 & 3.44 & 1.40 \\
\hline Secure transactions & 10.4 & 3.40 & 1.71 \\
\hline Event tickets & 9.6 & 3.31 & 1.46 \\
\hline Attraction tickets & 8.8 & 3.34 & 1.44 \\
\hline Shopping carts \& payment system & 8.5 & 3.15 & 1.43 \\
\hline Web seal certification & 2.3 & 3.00 & 1.26 \\
\hline \multicolumn{4}{|l|}{ Assurance } \\
\hline Email newsletters & 34.6 & 4.71 & 1.43 \\
\hline Highlight special offers/best buys & 33.1 & 4.01 & 1.86 \\
\hline Direct email campaign & 30.0 & 4.62 & 1.68 \\
\hline Privacy policy & 22.3 & 3.75 & 1.70 \\
\hline Personalization/Customization & 23.8 & 4.29 & 1.39 \\
\hline Incentive programs & 18.5 & 4.33 & 1.54 \\
\hline Cross-selling/up selling opportunities & 15.8 & 3.54 & 1.61 \\
\hline Customer loyalty programs & 4.2 & 3.90 & 1.54 \\
\hline
\end{tabular}

Some interesting findings were revealed by the discrepancy between the use and importance of applications under the communication, transaction and assurance functions. Certain applications under the communication, transaction and assurance functions demonstrate low popularity percentages (extent of use) and high levels of perceived importance which indicates that CVBs think of the applications as important but are choosing not to implement the 
application within their web marketing strategy owing to certain reasons. This trend demonstrates that management will need to take action and increase the use of applications that are perceived important to the success of the web marketing strategy.

\section{Effectiveness of Web Applications}

The third step of the data analysis involved the effectiveness of the applications under each of the four functions which was calculated using the $2 \times 2$ effectiveness matrix discussed on Chapter 3. The effectiveness matrix provided four possible scenarios: missing opportunities (not used but important); effective (used and important); wasting resources (used but not important); and indifference (not used and not important). See Figure 6 on Chapter 3 for a visual representation of the effectiveness matrix. Table 7 presents the effectiveness percentages per quadrant for each application, the results are organized based on the effective quadrant (II) in decreasing order. 
Table 7: Assessment of effectiveness of web technology applications based on functions

\begin{tabular}{|c|c|c|c|c|}
\hline Functions and Applications & $\begin{array}{c}\text { I } \\
\text { Missing } \\
\text { opportunities } \\
\text { (\%) }\end{array}$ & $\begin{array}{c}\text { II } \\
\text { Effective } \\
(\%)\end{array}$ & $\begin{array}{c}\text { III } \\
\text { Indifference } \\
(\%)\end{array}$ & $\begin{array}{c}\text { IV } \\
\text { Wasting } \\
\text { resources } \\
(\%)\end{array}$ \\
\hline \multicolumn{5}{|l|}{ Information } \\
\hline Activities/attraction information & 0.8 & 98.8 & 0 & 0.4 \\
\hline Accommodation information & 0.8 & 98.5 & 0 & 0.8 \\
\hline Events calendar & 2.3 & 96.2 & 0.4 & 1.2 \\
\hline Restaurant information & 5.4 & 87.7 & 0.4 & 6.5 \\
\hline Shopping information & 8.1 & 86.9 & 2.3 & 2.7 \\
\hline Links to regional/city/area pages & 10.0 & 82.7 & 1.9 & 5.4 \\
\hline Maps/driving directions & 17.3 & 79.6 & 1.5 & 1.5 \\
\hline Travel guides/brochures & 6.2 & 70.0 & 16.5 & 7.3 \\
\hline Tour operator information & 41.5 & 48.8 & 7.7 & 1.9 \\
\hline Frequently asked questions & 21.5 & 20.0 & 56.9 & 1.5 \\
\hline Banner advertisements & 12.7 & 14.6 & 68.1 & 4.6 \\
\hline Virtual tours & 67.7 & 11.5 & 18.5 & 2.3 \\
\hline \multicolumn{5}{|l|}{ Communication } \\
\hline Brochure request capabilities & 9.2 & 87.3 & 1.5 & 1.9 \\
\hline Search functions & 41.5 & 48.1 & 6.9 & 3.5 \\
\hline Interactive tools & 56.2 & 28.1 & 15.4 & 0.4 \\
\hline Trip/vacation planner & 61.2 & 23.1 & 15.4 & 0.4 \\
\hline Community functions & 11.9 & 0.4 & 87.3 & 0.4 \\
\hline \multicolumn{5}{|l|}{ Transaction } \\
\hline Online reservations & 60.8 & 20.0 & 18.5 & 0.8 \\
\hline Themed products & 13.1 & 17.3 & 68.1 & 1.5 \\
\hline Secure transactions & 19.6 & 9.6 & 70.0 & 0.8 \\
\hline Event tickets & 16.5 & 9.2 & 73.8 & 0.4 \\
\hline Attraction tickets & 18.1 & 8.5 & 73.1 & 0.4 \\
\hline Shopping carts \& payment system & 18.5 & 7.3 & 73.1 & 1.2 \\
\hline Web seal certification & 16.5 & 1.9 & 81.2 & 0.4 \\
\hline \multicolumn{5}{|l|}{ Assurance } \\
\hline Email newsletters & 53.8 & 33.5 & 11.5 & 1.2 \\
\hline Highlight special offers/best buys & 13.1 & 30.4 & 53.8 & 2.7 \\
\hline Direct email campaign & 54.2 & 28.8 & 15.8 & 1.2 \\
\hline Personalization/Customization & 58.5 & 22.7 & 17.7 & 1.2 \\
\hline Privacy policy & 18.5 & 18.8 & 59.2 & 3.5 \\
\hline Incentive programs & 64.6 & 17.7 & 16.9 & 0.8 \\
\hline Cross-selling/up-selling opportunities & 20.0 & 13.8 & 64.2 & 1.9 \\
\hline Customer loyalty programs & 70.8 & 3.8 & 25.0 & 0.4 \\
\hline
\end{tabular}

\section{Information}

In the information function, 8 of the 12 applications were found to be relatively effective (used and important): activities/attraction information (98.8\%), accommodation information (98.5\%), events calendar (96.2\%), restaurant information (87.7\%), shopping information 
$(86.9 \%)$, links to regional/city/area pages $(82.7 \%)$, maps/driving directions $(79.6 \%)$ and travel guides/brochures (70\%). However, the tour operator application was found to be split between effective (48.8\%) and missing opportunities (41.5\%). On the other hand, the virtual tours (67.7\%) application was found to be missing opportunities since the application is not being provided in the website but is considered to be important to the success of the web marketing strategy. Furthermore, the analysis found CVBs are indifferent to providing banner advertisements (68.1\%) and frequently asked questions (56.9\%) in their websites.

\section{Communication}

In the communication function, only the brochure request capabilities $(87.3 \%)$ application was found to be effective. Furthermore, the search functions application received split results between the effective (48.1\%) and missing opportunities (41.5\%) quadrants which demonstrates that CVBs have mixed feelings and perceptions about the use and importance of the application. However, trip vacation planner (61.2\%) and interactive tools $(56.2 \%)$ were found as missing opportunities. An application which received a high percentage on the indifference quadrant was the community functions $(87.3 \%)$. This means that CVBs are indifferent (not used and not important) towards this function and not implementing the application in their website will not be detrimental to their web marketing strategy.

\section{Transaction}

The results for the transaction function provide some alarming results since most applications fall under the indifference quadrant. Only one application, online reservations, was found to be a missing opportunity with $60.8 \%$ of the CVBs stating that it is not used but is important. The finding is important since it demonstrates the CVBs' have an increased awareness of the missed opportunities by not providing this very popular travel related web application. On 
the other hand, CVBs stated that they were indifferent to the remaining six applications. Under the indifference quadrant the web seal certification received the highest percentage $(81.2 \%)$, followed by five applications: event tickets (73.8\%), attraction tickets (73.1\%), shopping carts and payment center $(73.1 \%)$, secure transactions $(70 \%)$, and themed products $(68.1 \%)$. These functions are not used by the CVBs but perceived not important to the web marketing strategy. The results in this section are in line with the mission of CVBs in that they position themselves as destination marketing organizations not sales focused organizations.

\section{Assurance}

The results for the assurance function also reveal some areas of concern. Under the assurance function, 5 out of the 8 functions were found to be missing opportunities. The customer loyalty programs application was identified a missing opportunity for $70.8 \%$ of the CVBs, followed by the incentive programs application with $64.6 \%$ of the CVBs stating they are missing an opportunity by not providing this application on their website. This is an important observation, since the majority of the CVBs recognize that they are missing opportunities by not providing these important applications in their websites. Furthermore, CVBs were indifferent (not used and not important) to the remaining three applications.

\section{$\underline{\text { Regression Analysis }}$}

As stated earlier the third and final goal of the study is to determine the impact of CVBs organizational factors on the implementation of web-based marketing activities. Therefore, the fourth step of the data analysis entailed the execution of multiple regression analysis. A standard multiple regression will allow for investigation of the relationships between the dependent and independent variables. Standard multiple regression was selected for the study since it allows for 
a more sophisticated exploration of the interrelationships among a set of variables (Pallant, 2001).

Five regression models were formulated to examine the impact of the organizational factors on the web-based marketing activities, with the following dependent variables for each model: Model I (effectiveness of the information function = IN); Model II (effectiveness of the communication function $=\mathrm{CM}$ ); Model III (effectiveness of the transaction function $=\mathrm{TR}$ ); Model IV (effectiveness of the assurance function = AS); and Model V (sophistication of webbased marketing $=$ SOP). The same set of the independent variables were used in each of the five regression models: IT training (TP), financial resources (FR), management involvement (MI), management support (MS), organizational size (S), organizational innovativeness (OI), management team's technological expertise (MKNOW), and employee's technological expertise (EKNOW). The multiple regression yielded some interesting results. Table 8 presents the findings.

Model I: The influence of organizational factors on the effectiveness of the information function.

$$
\mathrm{IN}=f(\mathrm{TP}, \mathrm{FR}, \mathrm{MI}, \mathrm{MS}, \mathrm{S}, \mathrm{OI}, \mathrm{MKNOW}, \mathrm{EKNOW})
$$

Results for Model I revealed that $18.1 \%$ of the variance of the effectiveness of the information function is explained by the eight independent variables. The results of the standardized coefficients and significance levels revealed that the size of the organization $(\beta=.232$; Sig. $=.016)$ has the greatest impact and makes the strongest and most significant unique contribution explaining the dependent variable, followed by management team's technological expertise $(\beta=.218 ;$ Sig. $=.021)$. The results show that CVBs that seek to effectively implement 
the information function as part of their web marketing strategy will need to be aware of the importance of organizational factors such as organizational size and management team's technological expertise in the successful implementation of the information function.

Model II: The influence of organizational factors on the effectiveness of the communication function.

$$
\mathrm{CM}=f(\mathrm{TP}, \mathrm{FR}, \mathrm{MI}, \mathrm{MS}, \mathrm{S}, \mathrm{OI}, \mathrm{MKNOW}, \mathrm{EKNOW})
$$

Results for Model II representing the communication function revealed that $29.8 \%$ of the variance of the function is explained by the independent variables. Three organizational factors (independent variables) were found to provide more information and help explain the relationship between the independent and dependent variables.

The results of the standardized coefficients and significance levels revealed that financial resources $(\beta=.254 ;$ Sig.= .005), size $(\beta=.210 ;$ Sig.=.018) and management team's technological expertise $(\beta=.182 ; \mathrm{Sig} .=.037)$ were found to make a significant unique contribution to explaining the communication function (dependent variable). Furthermore, significance level show that the variable representing financial resources makes a more significant and unique contribution to the prediction of the communication function (dependent variable) than any of the other variables.

This results show that three organizational factors (financial resources, size and management team's technological expertise) have the greatest impact on the effective use of the communication function on the web marketing strategy. This means that CVBs that seek to effectively implement the communication function in their web marketing strategies will need to be aware of the importance of financial resources, size and management team's technological 
expertise in the successful implementation of the communication function. In addition, special attention must also be placed to the impact of the sufficient allocation of financial resources on the communication function.

Model III: The influence of organizational factors on the effectiveness of the transaction function.

$$
\mathrm{TR}=f(\mathrm{TP}, \mathrm{FR}, \mathrm{MI}, \mathrm{MS}, \mathrm{S}, \mathrm{OI}, \mathrm{MKNOW}, \mathrm{EKNOW})
$$

Results of Model III representing the transaction function revealed that only $7.7 \%$ of the variance of the function is explained by all the independent variables, which means that this model provides very little explanation on the predictive power of the independent variables as they relate to the transaction function (dependent variable). The results of the standardized coefficients revealed that none of the independent variables were found to make a significant contribution to explaining the dependent variable (transaction function). Consequently, this model provides no significant information on the importance of organizational factors (independent variable) related to the transaction function (dependent variable).

Model IV: The influence of organizational factors on the effectiveness of the assurance function.

$$
\mathrm{AS}=f(\mathrm{TP}, \mathrm{FR}, \mathrm{MI}, \mathrm{MS}, \mathrm{S}, \mathrm{OI}, \mathrm{MKNOW}, \mathrm{EKNOW})
$$

Results for Model IV representing the assurance function revealed that $21.6 \%$ of the variance of this function is explained by the independent variables. The model found that two variables were found to be important to the assurance function (dependent variable). 
The results of the standardized coefficients and significance levels revealed that financial resources $(\beta=.249$; Sig.= .009) and size $(\beta=.156$; Sig.= .096) were found to make the most statistically significant unique contribution to explaining the assurance function (dependent variable). The significance levels reveal that the variable representing financial resources makes a more unique and stronger contribution to the prediction of the assurance function (dependent variable). This means that CVBs that seek to effectively implement the assurance function within their web marketing strategies will need to be aware of the importance organizational size and financial resources in the successful implementation of the assurance function. More importantly, sufficient allocation of financial resources is found to have a greater impact on the assurance function, therefore more attention must be paid to this factor.

Model V: The influence of organizational factors on the sophistication of web-based marketing function.

$$
\mathrm{SOP}=f(\mathrm{TP}, \mathrm{FR}, \mathrm{MI}, \mathrm{MS}, \mathrm{S}, \mathrm{OI}, \mathrm{MKNOW}, \mathrm{EKNOW})
$$

The results of Model V representing sophistication of web-based marketing revealed that $33.9 \%$ of the variance of this function is explained by the independent variables. Three variables were found to be important to sophistication of the web-based marketing strategy (dependent variable).

The results of the standardized coefficients and significance levels revealed that size $(\beta=$ .254 ; Sig.= .003), financial resources $(\beta=.241$; Sig. $=.006)$ and management team's technological expertise $(\beta=.186$; Sig.=.028) were found to make the most statistically significant contribution to explaining the sophistication (dependent variable). The significance levels reveal that financial resources and organizational size make the strongest contribution to 
the prediction of the sophistication (dependent variable). This means that CVBs that seek higher sophistication levels in their web marketing strategy will need to be aware of the importance of sufficient allocation of financial resources, organizational size and management team's technological expertise in the successful implementation of a sophisticated web marketing strategy.

The results of the multiple regression analyses revealed that of all the independent variables the most significant organizational factors are size, management team's technological expertise and financial resources. In addition, financial resources made the most significant impact among the variables. It can be concluded from the analysis that bigger organizations with more financial resources and management with technological expertise are important to the adoption and successful implementation of the different functions on the web-marketing. The results of the study were found to be similar to previous research in that bigger organizations have more financial resources available to implement technology innovations and that technology savvy leadership is helpful and sometimes imperative to support and effectively implement new technology innovations. 
Table 8: Results of standard multiple regression analyses on the impact of organizational factors on the effectiveness and sophistication of web marketing functions

\begin{tabular}{|c|c|c|c|c|c|c|c|c|c|c|}
\hline \multirow[t]{2}{*}{ Independent Variables } & \multicolumn{2}{|c|}{$\begin{array}{c}\text { Model I } \\
\text { Information }\end{array}$} & \multicolumn{2}{|c|}{$\begin{array}{c}\text { Model II } \\
\text { Communication }\end{array}$} & \multicolumn{2}{|c|}{$\begin{array}{c}\text { Model III } \\
\text { Transaction }\end{array}$} & \multicolumn{2}{|c|}{$\begin{array}{l}\text { Model IV } \\
\text { Assurance }\end{array}$} & \multicolumn{2}{|c|}{$\begin{array}{c}\text { Model V } \\
\text { Sophistication }\end{array}$} \\
\hline & Betas & Sig. & Betas & Sig. & Betas & Sig. & Betas & Sig. & Betas & Sig. \\
\hline IT Training & .082 & .248 & .101 & .125 & .019 & .805 & .051 & .464 & .087 & .172 \\
\hline Financial resources & .061 & .524 & .254 & $.005^{* * *}$ & .138 & .176 & .249 & $.009 * * *$ & .241 & $.006^{* * *}$ \\
\hline Management involvement & .096 & .305 & .093 & .287 & .056 & .575 & -.036 & .694 & .065 & .444 \\
\hline Management support & -.068 & .475 & -.135 & .123 & .012 & .905 & .017 & .858 & -.053 & .532 \\
\hline Size & .232 & $.016^{* *}$ & .210 & $.018 * *$ & .131 & .196 & .156 & $.096^{*}$ & .254 & $.003 * * *$ \\
\hline Organizational innovativeness & .090 & .230 & .076 & .271 & -.022 & .785 & .066 & .365 & .078 & .246 \\
\hline $\begin{array}{l}\text { Management team's technological } \\
\text { expertise }\end{array}$ & .218 & $.021 * *$ & .182 & $.037 * *$ & -.028 & .781 & .138 & .132 & .186 & $.028 * *$ \\
\hline \multirow[t]{2}{*}{ Employee's technological expertise } & -.078 & .355 & -.001 & .994 & .057 & .523 & .027 & .747 & -.002 & .975 \\
\hline & & $\mathrm{R}^{2}=18.1 \%$ & & $\mathrm{R}^{2}=29.8 \%$ & & $7.7 \%$ & & $\mathrm{R}^{2}=21.6 \%$ & & $\mathrm{R}^{2}=33.9 \%$ \\
\hline
\end{tabular}

Note: ${ }^{*} \mathrm{p}<.10, * * \mathrm{p}<.05, * * * \mathrm{p}<.01$ 


\section{Summary}

Multiple regression was used to examine the impact of organizational factors on the effectiveness of the web based marketing functions (information, communication, transaction, assurance and sophistication) implemented by CVBs. In all five models the effects of the IT training programs, financial resources, management involvement, management support, size, organizational innovativeness, management team's technological expertise and employee's technological expertise were used to see the effects on the different levels of web based marketing functions. The results of the multiple regression found that financial resources, organizational size and management team's technological expertise are important and have the greatest impact on most of the web functions (information, communication, assurance and sophistication). 


\section{CHAPTER FIVE: CONCLUSION AND IMPLICATIONS}

This chapter focuses on the discussion and implications of the data analyses. Conclusions are drawn from research findings. Limitations of the study and suggestions for further research in the destination marketing field are provided.

\section{$\underline{\text { Discussion }}$}

Previous research has demonstrated that many organizational factors impact the way organizations adopt and implement information technology innovations (Thong, 1999; Tornatzky \& Fleischer, 1990; Zhu \& Kraemer, 2005). This study provides additional information to better understand the use of website applications for the successful execution of web marketing strategies from a relationship marketing perspective. The study examined the use and effectiveness of web applications by American CVB and the impact of organizational factors on the level of web functions implemented. Multiple regression analyses found that size, financial resources and management team's technological expertise have the most impact on the different levels of web functions implemented by CVBs.

First, the study examined the use of web applications by CVBs. The results of the study showed that most CVBs use their websites mainly for information provision purposes with less focus placed on the communication, transaction and assurance applications. This finding supports the findings of previous research that show that organizational websites are used mainly to provide information to the consumer and not for transaction or relationship building purposes (Dore \& Crouch, 2003; Gretzel et al., 2000; Palmer \& McCole, 2000; Yuan et al., 2006). The significance of this finding is highlighted by the fact that CVBs need to understand the 
importance of the Internet and the purpose of their own websites and establish its potential value compared to more traditional promotional activities (So \& Morrison, 2003).

Second, the study examined the effectiveness of the web applications. The CVBs reported that applications categorized under the information function are perceived to be the most effective. These applications are categorized as effective since they are used and perceived to be important for the successful implementation of web marketing strategies. On the other hand, CVBs reported that applications under the communication, transaction and assurance functions were found to be either lost opportunities or indifferent to the overall success of the web-based marketing agenda. These results show that there are many opportunities within the web marketing plan for CVBs to implement web applications to create and retain relationships with consumers.

Third, the findings of the multiple regression both support and contradict the results of previous studies. This study focuses on one specific type of organization, CVBs, which are a unique organization in that their job is to promote a destination and its services without any monetary gain for the organization. The organization's size, financial resources and management team's technological expertise were found to have an impact on the web functions implemented by a CVB.

Four of the models found the same organizational factors having an impact on the effectiveness of the web functions. Model I showed that size and management's team technological expertise are the only two functions having an impact on the effectiveness of the information function. Model II found that financial resources, size and management team's technological expertise all have an impact, in different degrees, on the effectiveness of the communication function. Model III found that none of the variables identified have an impact on 
the effectiveness of the transaction function. Model IV found that allocation of financial resources and size have an impact on the effectiveness of the assurance function. Finally, Model $\mathrm{V}$ which represents the sophistication of web-based marketing found that financial resources, size and management team's technological expertise all have the greatest impact on the sophistication of web-based marketing strategy.

\section{IT Training}

In regards to the presence of IT training programs the study found that it does not have an impact on the level of web function implemented by a CVB. This finding is different from previous studies in which training was found to be a crucial factor for technology acceptance (Main, 2002). In addition, another study found that training programs are necessary for the effective implementation, use and support of new technologies (Martin \& Matlay, 2003). Furthermore, Main (2002) found lack of training was identified as a factor that impedes the effective use of technology applications. It can be argued that training programs are not as necessary or critical because most people are familiar with the basic functions of the Internet and its use.

\section{Financial Resources}

In regards to financial resources the study found that it has a strong impact on the effectiveness of the web-based marketing functions. This study found that the allocation of financial resources was the variable that has the most significant impact on the web functions implemented by CVBs. Financial resource variable was found to be the most statistically significant variable at the .01 level for the communication, assurance and sophistication of webbased marketing. 
Thong (1999) states that having adequate financial resources is the first step in the decision to adopt IT functions. In addition, previous studies have found that the allocation of financial resources for IT adoption and implementation has a positive impact on innovation adoption behavior (Yuan et al., 2003). The results of this study support the findings of previous research stating that organizations that have more resources will be more likely to implement IT innovations and have a higher level of sophistication in their implementations (Zhu \& Kraemer, 2005). Gretzel et al. (2000) demonstrate the importance of this variable for the tourism industry, stating that limited resource is a barrier to technology adoption and implementation. Based on the findings of this study and previous research it can be concluded that financial resources is the most important variable in relation to the adoption and use of web-based marketing functions.

\section{Management Involvement}

In regards to influence of management involvement on the level of web-based marketing the study found that there were no significant findings on any of the web functions. This may be because even though management is involved in the decision to adopt the function or application, management involvement is not necessary for the implementation and use of the functions.

However, previous research demonstrates that management involvement is critical to technology and e-commerce success (Gretzel et al., 2000; Yuan et al., 2003). Furthermore, another study found that management involvement is critical in initiating and promoting ecommerce projects (Scupola, 2003). Previous research argues that management that is involved in the research, decision making process and implementation of innovations has great influence on the success of the use of the applications (Yuan et al., 2000). The findings of this study 
challenge those of previous research which indicates that further examination of this aspect is needed especially in the tourism and destination marketing field.

\section{Management Support}

The influence of management support was not found to be significant on the effectiveness of the web-based marketing functions. The lack of impact of the management support variable may be a part of the little direct influence upper management plays on the day to day operations. That is, upper management is not directly involved on the front line operation which ultimately influences the need and implementation of the web functions. However, previous studies have fond that lack of management support is a barrier to technology implementation (Gretzel et al., 2000). Furthermore, other studies have found that management support is needed to promote the use of the technology innovation (Yuan et al., 2003). The significance of this variable is demonstrated in previous research and highlights the importance of further investigation needed on this factor in the CVB arena.

\section{Organizational Size}

Size has been the most investigated organizational characteristics on regards to technology adoption and implementation (Tornatzky \& Klein, 1982). Previous studies have found that the size of the organization has both a positive and negative impact to the adoption, implementation and extent of use of information technology applications (Tornatzky \& Fleischer, 1990; Zhu \& Kraemer, 2005). However, this study found that size makes the most significant impact on most of the functions (information, communication, assurance and sophistication of web-based marketing). Size was found to make a contribution to the most number of web functions, four out of the five functions, however the most statistically significant level was found on the sophistication of web-based marketing at the .001 level. 
Tornatzky \& Fleischer (1990), Lefebvre \& Lefebvre (1992), Frambach (1993), Thong (1999) found that size has a positive impact on the adoption, diffusion and extent of use of innovations, more specifically IT innovations. In line with this research, a research study by Wang \& Fesenmaier (2006) found that size is positively related to the implementation of web marketing strategies. However, Main (2002) and Zhu \& Kraemer (2005) found that size has a negative impact on the extent of e-business use. Furthermore, Goode and Stevens (2000) found that size is not related to WWW technology adoption.

\section{Organizational Innovativeness}

The influence of organizational innovativeness as measured on this study, by the CEOs innovativeness was not found to have an impact on any of the web functions. The lack of significant relationship between the variables may be due to several aspects used to determine innovativeness: management's risk aversion, reaction to outside changes or innovation adoption behavior. The various variables that impact CEO innovativeness are critical to the overall strategy therefore making innovativeness a complicated variable to examine. The findings do not support to previous research in which organizational innovativeness was found to facilitate innovation adoption and diffusion (Frambach, 1993). In addition, research in the destination marketing field concluded that organizational innovativeness is important for the web-based marketing strategies (Wang \& Fesenmaier, 2006).

Due to the findings of this study, further investigation of this variable is recommended to deepen the understanding of the impact of innovativeness (CEOs innovativeness) on the overall organization and their marketing strategies. 


\section{Management Team's Technological Expertise}

The study found that this variable has a strong impact on the level of web functions implemented. Management's expertise was found to make the most significant contribution at the .05 level to the following web functions: the information, communication and sophistication of web-based marketing. The results support the argument that a more knowledgeable and technology savvy management team will recognize the potential to implement technology innovations (Martin \& Matlay, 2003).

In addition, the results of this study support the findings of previous studies that management's knowledge and expertise is extremely important to the likelihood to adopt and implement IT innovations (Thong, 1999; Wang \& Fesenmaier, 2006; Yuan et al., 2003). This finding supports the argument that a more knowledgeable management team will recognize the benefits and support the decision to adopt innovations (Thong, 1999, Yuan et al., 2003). The findings highlight the importance of having and developing technical skills vital to the successful implementation of web-based solutions (Adebanjo, 2003).

\section{Employee’s Technological Expertise}

The study found that employee's technological expertise does not have an impact on the level of web-based marketing functions. This may be due to the little or no influence employees play on the decision to adopt applications that support the different web functions. Since the main decision to adopt an application is made by upper management, employee's technological expertise is not going to be a variable that has an impact on the decision to ultimately include the application on the web marketing strategy.

This findings do not support those of previous research in which employee's technological expertise was found to positively impact likelihood to adopt IT functions (Thong, 
1999). Furthermore, previous research found that employee's expertise is a critical factor to technology use and diffusion within the organization (Scupola, 2003). In regards to the extent of use previous research has found that organizations with higher technology competence levels achieve greater extent of use of e-business functions (Zhu \& Kraemer, 2005). This is an area of concern since this study found that employee technological expertise was not found to have an impact on the level of web use. Further examination of this variable is needed to assess the effect of employee's technological expertise especially in the tourism field.

The findings of this study may not support the findings of previous studies. This demonstrates that more research is needed in this field to provide a better understanding of the organizational factors of this kind of organization. Highlighting the importance of continuing with the research efforts in this field is necessary.

\section{$\underline{\text { Implications }}$}

The findings of this study will be of interest to CVB directors/CEOs. The findings help shed some light into the use, importance and effectiveness of web applications. A better understanding of the use of web applications will allow CVB directors to appropriately allocate resources to support those applications which are found to be important and effective for the overall web marketing strategy.

The results demonstrate that the transaction and assurance functions are not being frequently used in the web-based relationship marketing efforts. This is an interesting fact for CVB directors to keep in mind when deciding to implement an application. Implementing applications that support all the web-based relationship marketing functions will allow for the organization to attract and retain customers. In addition, since the main purpose of a CVB is not 
to complete transactions, providing applications that support the assurance function will allow CVBs still create relationships with customer to help retain them. Implementing the applications deemed important by the consumer will provide CVBs with a competitive advantage over other organizations.

In addition, the findings of the study will help explain the impact of organizational factors on the different web functions. The findings suggest that three main factors are of great importance to web based marketing. Financial resources, size and management team's technological expertise have the most impact and make the most contribution to the effectiveness of the various web functions.

Special attention must be paid to those factors that have the strongest impact on the effectiveness of the web functions. The study found that financial resources variable has the strongest impact on the effectiveness of web functions. Therefore sufficient allocation of resources and critical decision making regarding which applications to implement will help assure the successful implementation of the web marketing activities.

This study contributes to the body of literature relating to web-based marketing not only on the use of the web applications but also on the overall importance and effectiveness of those functions. In addition, it highlights the importance of certain organizational factors on the overall web marketing strategy implemented by a CVB. The results of the study provided a comprehensive view of the organizational factors that may impact technology implementation, more specifically web functions and their applications.

The study confirms that certain organizational factors have a more significant impact on the adoption and level of web activities implemented by an organization. However, interesting results were discovered on several variables. The financial resource variable was found to have 
the most significant impact; however this impact was only recorded in three of the five functions investigated.

As mentioned earlier, organizational size has been the most studied characteristics on the innovation adoption studies. The results of this study continue to support the theory that size is one of the most important variables related to technology implementation and use. The results show that organizational size makes a significant contribution on four out of the five web functions. The results demonstrate that even though size has been the most studied organizational factor it should be included in future research studies as an important factor to investigate.

From a practical standpoint, this study may help destination marketing organizations to use more effectively their web marketing activities. CVB directors that have a better understanding of the organizational factors and their impact on the web-marketing activities will allocate resources accordingly and take action to positively impact the level web presence they desire.

The results will help CVB directors better understand the factors that may impact negatively the overall web marketing strategy. A better understanding of the factors that have the greatest impact will help CVB directors make appropriate decisions regarding the allocation of resources, increase their knowledge of IT and innovations, and the impact of size on the overall web marketing strategy.

The strength of this study is that is examines the effects of the specific aspects (technological environment, organizational characteristics and technological competence) of the organization in predicting the level of web-based marketing strategies implemented by CVBs. This study is one of few that examines CVBs and their web activities, especially from a 
relationship marketing perspective. The findings of the study suggest that three major factors are important to the prediction of the level of web use.

First, management will need to allocate sufficient resources for the adoption and development of the web applications which in turn impact the web marketing strategy. Second, since size is the most frequently studied variable in regards to technology adoption behavior, understanding its impact is important. Understanding the impact of size on the web-marketing activities is needed especially since management has little or no impact on this aspect. Previous research has concluded that size and financial resources are directly related (Tornatzky \& Fleischer, 1990). Research has found that big organizations will have more resources to allocate to IT innovations, which can translate into higher sophistication levels of the applications implemented.

Finally, management's technological expertise is important since knowledge will help management realize the potential and benefits of technology applications. Management that does not posses good knowledge of systems and technology should take action by either hiring people that fill that gap and support them in this role or increase their knowledge through training and classes.

These findings should help top management realize the influence and importance of understanding all the factors that affect web-based marketing and their applications. A greater understanding of the influencing factors can help destination marketing organization better allocate resources, avoiding the investment of resources in fruitless actions. In addition, a better understanding of the influencing factors will provide organizations with a more efficient decision making process when determining which web applications to implement. 


\section{$\underline{\text { Conclusion }}$}

The study highlights the importance of organizational factors on the web-based relationship marketing activities implemented by CVBs. The results of the study provided a comprehensive view of the organizational factors that may impact technology implementation, more specifically web functions and their applications. The study confirms that certain organizational factors have a more significant impact on the adoption and level of web activities implemented by CVBs.

The results of the study show that three organizational factors have the most impact on the effective use of web-based marketing functions. Financial resources, size and management team's technological expertise were found to make the most significant contribution to the effectiveness of different functions of web-based marketing. CVBs need to pay close attention to these factors when implementing web-based marketing activities that support relationship marketing.

The results support previous research which states that organizations that have more resources to adopt and implement technology innovations tend to implement more sophisticated innovations (Tornatzky \& Fleischer, 1990). In turn, implementing more sophisticated webmarketing functions such as transaction and assurance functions provides a competitive advantage and allows CVBs to provide greater value to customers.

Another finding of this study is the impact organizational size has on the web-based marketing functions. Since size is a factor which can not be really controlled and most CVBs are small organizations, an increased awareness of this factor and its impact will allow for the correct allocation of resources. A better understanding of this factor will reduce the amount of 
wasted resources on applications and functions that are not really useful for what the organization is trying to achieve.

In addition, the results help shed some light onto the management impact in small organizations. Management team's technological expertise was found to have an affect on the effective implementation of web marketing functions. This finding supports previous research stating that directors and CEOs of small organizations have a direct impact on the strategic direction of the organization. Therefore, management in small organizations such as CVBs need to be aware of the technology areas in which they lack skills or knowledge. Identifying those areas and developing knowledge will prepare them nurture a more innovative organization where proactive strategies can be implemented.

\section{Limitations and Suggestions for Future Research}

As with any research this study has several limitations that need to be addressed. First, the research is based on self reported responses to the questions. CVB directors may not be completely honest about the website budget or their expertise of technology.

Second, in the data collection process, mailed surveys have some inherent disadvantages. In a mailing method any misunderstandings or confusions on the items of the survey will translate in erroneous answers to the questions since clarification is not possible.

Third, even though the questionnaire was addressed to the CEO/director of the CVB office, the person responding to the survey may not be the CEO/director but the marketing director, accounting or research department director, which may translate into iconsistent answers to the questions. 
Research in this topic within the CVB arena is very limited. Further research in this field is needed to have better understanding of this type of organization and its special needs. In addition, the topic of relationship marketing in the CVB field is extremely under researched since these organizations are not focused on creating long-term relationships with customers. However, the literature demonstrates that relationship building is an important aspect that organizations should consider implementing due to its benefits (i.e. customer retention, decreased advertising costs, etc). More research in this topic will create a better understanding of the activities involved, its benefits and provide practical suggestions to implement in daily operations. A better understanding of the use of web applications to create customer relationships will make their web marketing strategies more effective and efficient.

Further research is needed to understand the impact of those organizational factors which were not supported by the previous research (i.e. importance of training, management involvement, management support, organizational innovativeness, employee technological expertise). This will provide more clarity on the organizational factors needed for the successful implementation of a web based marketing strategy focused on relationship building.

Based on the specific characteristics of this type of organization further research should include the examination of management characteristics and their impact on web technology adoption, implementation and effective use. In addition, since most destination marketing organizations are non-profit organizations, the aspect of financial resources warrants further investigation. Also, since the mission of the organization plays an important role on the strategies implemented, further examination on the aspect of the mission of a CVB and its impact on relationship marketing would be an interesting topic to examine. 
In addition, further research should include the consumer's perspective in understanding their use of a destination's websites. This will provide a comprehensive view and understanding of relationship marketing strategies through web applications. For example, research examining the consumer's perspective on the aspect of web-based relationship marketing can be conducted to identify the differences between consumers and organizations in terms of what is relevant. This comparison will provide CVBs with valuable information on what applications are important and how a CVB can adjust its Web-based marketing strategies to fit the needs and preferences of the consumers.

Another interesting perspective to examine would be the differences in use of a destination's website between the leisure market and convention and meetings market. This will provide a better understanding of the two most important markets for the CVBs. A deeper understanding of the use and importance of web applications will allow the CVB to implement applications that are important for the specific needs of the different markets.

\section{$\underline{\text { Summary }}$}

This chapter discusses the results of the study and its implications for CVBs. The results of the study provide an explanation to the impact of the different organizational factors on the web based marketing functions and strategies. Three major factors are found to be significant to the implementation of web functions: financial resources, size and management team's technological expertise. 


\section{APPENDIX: NATIONAL SURVEY ON WEB MARKETING STRATEGIES}


This section contains questions about your organization and its Internet use.

1. What level of tourism office/convention and visitor bureau (CVB) do you work for? (Please $\sqrt{ }$ one)

$\begin{array}{ll}\square \text { Tourism office/CVB at the state level } & \square \text { Tourism office/CVB at the county level } \\ \square \text { Tourism office/CVB at the regional level } & \square \text { Tourism office/CVB at the city level }\end{array}$

2. Please identify the type of tourism office/convention and visitor bureau (CVB) you work for. (Please $\sqrt{ }$ one)
$\square$ Other:

3. Please identify the most important markets for your organization. (Please $\sqrt{ }$ all that apply)

$\begin{array}{lll}\square \text { Leisure travel } & \square \text { Business travel } & \square \text { Meetings/Convention } \\ \square \text { Sports } & \square \text { Festival/Special events } & \square \text { Other: }\end{array}$

4. Please indicate the approximate yearly budget of your organization. (Please $\sqrt{ }$ one)

$\begin{array}{lll}\square \text { Under } \$ 100,000 & \square \$ 250,001-\$ 500,000 & \square \$ 750,001-\$ 1,000,000 \\ \square \$ 100,001-\$ 250,000 & \square \$ 500,001-\$ 750,000 & \square \$ 1,000,001 \text { and above }\end{array}$

5. Please indicate the number of full time employees in your organization. (Please $\sqrt{ }$ one)
7 to 9
20 to 49
100 to 200
10 to 19
50 to 99
201 and more

6. What is the approximate number of computers currently in use in your organization? (Please $\sqrt{ }$ one)
1 to 5
11 to 20
51 to 100
$\square 6$ to 10
$\square 21$ to 50
100 and more

7. Please estimate the percentage of the computers that are connected to the Internet. (Please $\sqrt{ }$ one)

$\begin{array}{lll}\square 5 \% \text { or less } & \square 26 \text { to } 50 \% & \square 76 \text { to } 95 \% \\ \square \text { to } 25 \% & \square 51 \text { to } 75 \% & \square 6 \% \text { or more }\end{array}$

8. Please estimate the percentage of employees who have Internet access in your organization. (Please $\sqrt{ }$ one)
$5 \%$ or less
26 to $50 \%$
76 to $95 \%$
6 to $25 \%$
51 to $75 \%$
$\square 96 \%$ or more

National Laboratory for Tourism and eCommerce

University of Illinois at Urbana-Champaign 
9. On average, how long have employees in your organization been using the Internet?(Please $\sqrt{ }$ one)
One month or less
$\square 7$ to 11 months
$\square 3$ to 4 years
$\square 2$ to 6 months
$\square 1$ to 2 years
$\square 5$ years or more

10. Does your organization have a Website?

$\square$ No (please skip to question 32) $\square$ Yes, our Website address is:

The following questions are related to your organization's Web applications and strategies.

11. Please indicate whether or not you are currently providing the following contents on your organization's Website. Then, rate the importance of each to your organization's Website marketing strategy.

\begin{tabular}{|c|c|c|c|c|c|c|c|c|}
\hline Contents & $\begin{array}{l}\text { Currently } \\
\text { Provide } \\
\text { (Please } \sqrt{ } \text { ) }\end{array}$ & $\begin{array}{l}\text { Not : } \\
\text { Impc }\end{array}$ & & cil & Im & $\tan$ & & $\begin{array}{l}\text { mely } \\
\text { tant }\end{array}$ \\
\hline Activities/Attraction information & $\square$ Yes $\square$ No & 1 & 2 & 3 & 4 & 5 & 6 & 7 \\
\hline Events Calendar & $\square$ Yes No & 1 & 2 & 3 & 4 & 5 & 6 & 7 \\
\hline Restaurant information & $\square$ Yes $\square$ No & 1 & 2 & 3 & 4 & 5 & 6 & 7 \\
\hline Accommodation information & $\square$ Yes $\square$ No & 1 & 2 & 3 & 4 & 5 & 6 & 7 \\
\hline Shopping information & $\square$ Yes $\square$ No & 1 & 2 & 3 & 4 & 5 & 6 & 7 \\
\hline Maps/Driving directions & $\square$ Yes No & 1 & 2 & 3 & 4 & 5 & 6 & 7 \\
\hline Online reservations & $\square$ Yes $\square$ No & 1 & 2 & 3 & 4 & 5 & 6 & 7 \\
\hline Shopping carts \& Payment system & Yes No & 1 & 2 & 3 & 4 & 5 & 6 & 7 \\
\hline Trip/Vacation planner & $\square$ Yes $\square$ No & 1 & 2 & 3 & 4 & 5 & 6 & 7 \\
\hline Virtual tours & Yes $\backsim$ No & 1 & 2 & 3 & 4 & 5 & 6 & 7 \\
\hline Brochure request capabilities & $\square$ Yes $\square$ No & 1 & 2 & 3 & 4 & 5 & 6 & 7 \\
\hline Search functions & Yes No & 1 & 2 & 3 & 4 & 5 & 6 & 7 \\
\hline Links to Regional/City/Area pages & $\square$ Yes $\square$ No & 1 & 2 & 3 & 4 & 5 & 6 & 7 \\
\hline Tour operator information & $\square$ Yes - No & 1 & 2 & 3 & 4 & 5 & 0 & 7 \\
\hline Industry news & $\square$ Yes $\square$ No & 1 & 2 & 3 & 4 & 5 & 6 & 7 \\
\hline Classified ads & Yes $=$ No & 1 & 2 & 3 & 4 & 5 & 6 & 7 \\
\hline Frequently asked questions & $\square$ Yes $\square$ No & 1 & 2 & 3 & 4 & 5 & 6 & 7 \\
\hline Research \& travel-related statistics & Yes No & 1 & 2 & 3 & 4 & 5 & 6 & 7 \\
\hline Education materials & $\square$ Yes $\square$ No & 1 & 2 & 3 & 4 & 5 & 6 & 7 \\
\hline
\end{tabular}

National Laboratory for Tourism and eCommerce

University of Illinois at Urbana-Champaign 
12. If your organization has a Website, what source do you use for the design, content development, and maintenance of your Website? (Please $\sqrt{ }$ one for each category)

\begin{tabular}{|lll|}
\hline Categories In-house Both \\
\hline
\end{tabular}

Design

$\square \quad \square$

Content development

Maintenance

13. Please indicate whether or not your organization is currently using the following marketing strategies on its Website. Then, rate the importance of each of these strategies to your organization's marketing efforts.

\begin{tabular}{|c|c|c|c|c|c|c|c|c|}
\hline Marketing Strategies & $\begin{array}{c}\text { Currently } \\
\text { Provide } \\
\text { (Please } \sqrt{ } \text { ) }\end{array}$ & \multicolumn{7}{|c|}{ Perceived Importance? } \\
\hline News & $\square$ Yes $\square$ No & 1 & 2 & 3 & 4 & 5 & 6 & 7 \\
\hline Email newsletters & Yes $\sqsubset$ No & 1 & 2 & 3 & 4 & 5 & 6 & 7 \\
\hline Personalization/Customization & $\square$ Yes $\square$ No & 1 & 2 & 3 & 4 & 5 & 6 & 7 \\
\hline Interactive tools & [Yes $\sqsubset$ No & 1 & 2 & 3 & 4 & 5 & 6 & 7 \\
\hline Community functions like chat rooms & $\square$ Yes $\square$ No & 1 & 2 & 3 & 4 & 5 & 6 & 7 \\
\hline Secure transactions through SSL & $\square$ Yes $\square$ No & 1 & 2 & 3 & 4 & 5 & 6 & 7 \\
\hline Privacy policy & $\square$ Yes $\square$ No & 1 & 2 & 3 & 4 & 5 & 6 & 7 \\
\hline Web seal certification (i.e., Truste) & $\square$ Yes $\square$ No & 1 & 2 & 3 & 4 & 5 & 6 & 7 \\
\hline Cross-selling/up-selling opportunities & $\square$ Yes $\square$ No & 1 & 2 & 3 & 4 & 5 & 6 & 7 \\
\hline Highlight special offers/best buys & Yes $\_$No & 1 & 2 & 3 & 4 & 5 & 6 & 7 \\
\hline Direct email campaign & $\square$ Yes $\square$ No & 1 & 2 & 3 & 4 & 5 & 6 & 7 \\
\hline Incentive programs to attract new customers & $\square$ Yes $\sqsubset$ No & 1 & 2 & 3 & 4 & 5 & 6 & 7 \\
\hline Customer loyalty programs & $\square$ Yes $\square$ No & 1 & 2 & 3 & 4 & 5 & 6 & 7 \\
\hline
\end{tabular}

National Laboratory for Tourism and e Commerce University of Illinois at Urbana-Champaign 
14. Please estimate your organization's Website related expenditures for the fiscal year 2001-2002.

\begin{tabular}{|l|l|}
\hline Overall Website budget & Total Amount (\$) \\
\hline Expenditure categories & \% of your Total Budget \\
\hline Design & $\begin{array}{c}\text { \% of your } \\
\text { Total Web budget }\end{array}$ \\
\hline Content development & $\%$ \\
\hline Technology & $\%$ \\
\hline Research & $\%$ \\
\hline Personnel & $\%$ \\
\hline Other, please specify: & $\%$ \\
\hline
\end{tabular}

15. Which of the following strategies is your organization currently using to promote your Website? Also, please rate the importance of these strategies to your organization's marketing efforts.

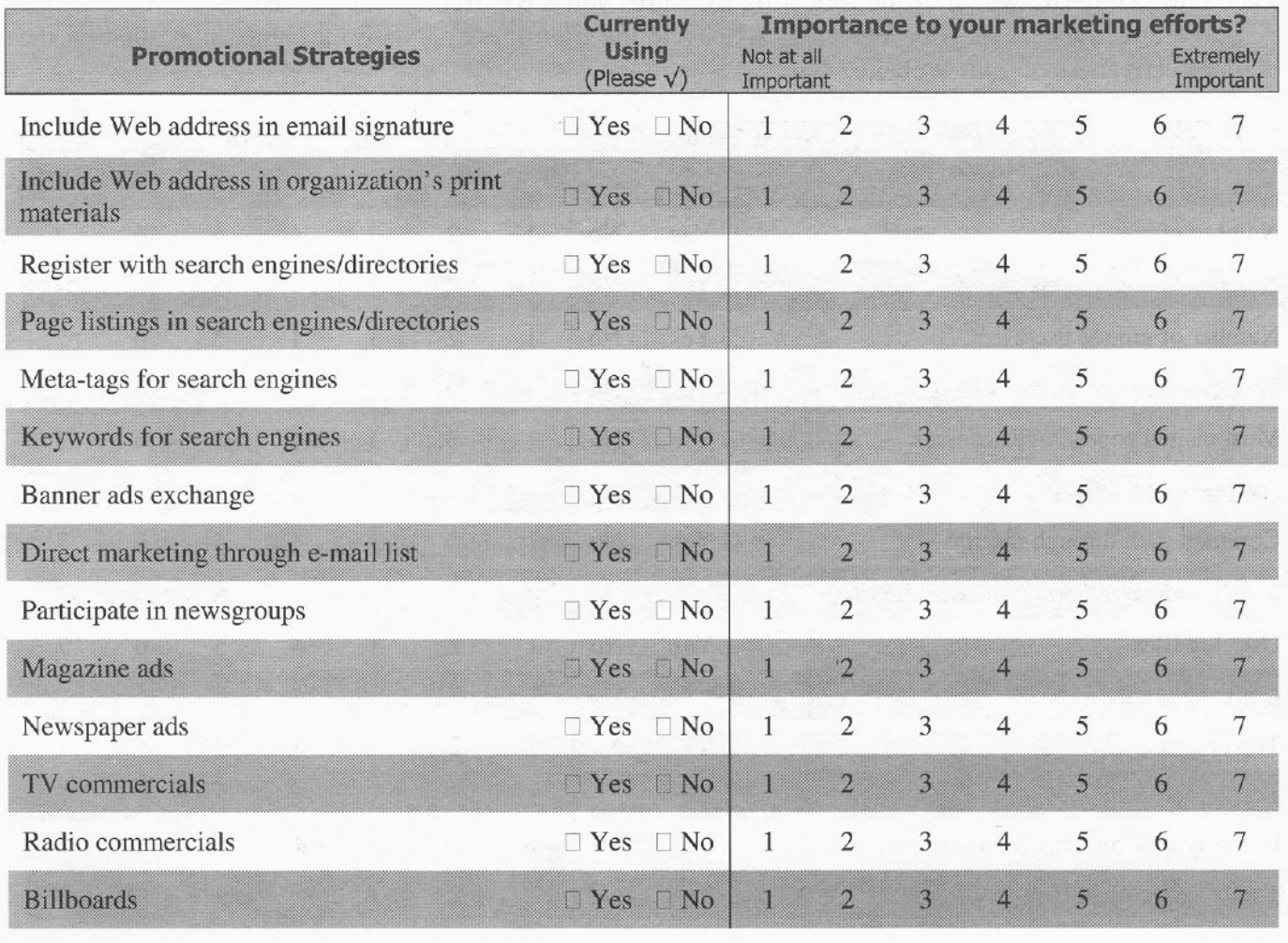

National Laboratory for Tourism and eCommerce

University of Illinois at Urbana-Champaign 
16. Please indicate the types of e-commerce activities you are providing on your Website. Then, rate the effectiveness of these activities in helping reach your marketing goals.

\begin{tabular}{|lc|c|c|c|c|ccc|}
\hline \multicolumn{1}{|c}{ E-commerce activities } & $\begin{array}{l}\text { Currently } \\
\text { Providing } \\
\text { (Please } \sqrt{\text { ) }}\end{array}$ & $\begin{array}{l}\text { Effectiveness in reaching marketing goals? } \\
\text { Not at all } \\
\text { Efective }\end{array}$ & $\begin{array}{c}\text { Extremely } \\
\text { Effective }\end{array}$ \\
\hline Online reservation & $\square$ Yes $\square$ No & 1 & 2 & 3 & 4 & 5 & 6 & 7 \\
\hline Banner advertisements & Yes $\square$ No & 1 & 2 & 3 & 4 & 5 & 6 & 7 \\
\hline Publications/Reports & $\square$ Yes $\square$ No & 1 & 2 & 3 & 4 & 5 & 6 & 7 \\
\hline Themed products & $\square$ Yes $\square$ No & 1 & 2 & 3 & 4 & 5 & 6 & 7 \\
\hline Attraction tickets & $\square$ Yes $\square$ No & 1 & 2 & 3 & 4 & 5 & 6 & 7 \\
\hline Event tickets & $\square$ Yes $\square$ No & 1 & 2 & 3 & 4 & 5 & 6 & 7 \\
\hline Travel guides/Brochures & $\square$ Yes $\square$ No & 1 & 2 & 3 & 4 & 5 & 6 & 7 \\
\hline Others, please specify: & $\square$ Yes $\square$ No & 1 & 2 & 3 & 4 & 5 & 6 & 7 \\
\hline
\end{tabular}

17. Please indicate which of the following measures you are currently using to assess and/or evaluate the effectiveness of your Website. Also, rate the usefulness of these measures in evaluating the effectiveness of your Website.

\begin{tabular}{|c|c|c|c|c|c|c|c|c|}
\hline Website Measures & $\begin{array}{c}\text { Currently } \\
\text { Using } \\
\text { (Please } \sqrt{ } \text { ) }\end{array}$ & $\begin{array}{l}\text { Not at all } \\
\text { Useful }\end{array}$ & & & uln & & & $\begin{array}{l}\text { mely } \\
\text { seful }\end{array}$ \\
\hline Number of hits & $\square$ Yes $\square$ No & 1 & 2 & 3 & 4 & 5 & 6 & 7 \\
\hline Number of page views & Yes $\square$ No & 1 & 2 & 3 & 4 & 5 & 6 & 7 \\
\hline Number of unique users & $\square$ Yes $\square$ No & 1 & 2 & 3 & 4 & 5 & 6 & 7 \\
\hline Sessions per user & Yes $\square$ No & 1 & 2 & 3 & 4 & 5 & 6 & 7 \\
\hline Most visited pages/Page accesses & $\square$ Yes $\square$ No & 1 & 2 & 3 & 4 & 5 & 6 & 7 \\
\hline Average number of pages per visitor & $\square$ Yes $\square$ No & 1 & 2 & 3 & 4 & 5 & 6 & 7 \\
\hline Common path through the site & $\square$ Yes $\square$ No & 1 & 2 & 3 & 4 & 5 & 6 & 7 \\
\hline \# of spiders attempting to index the site & Yes - No & 1 & 2 & 3 & 4 & 5 & 6 & 7 \\
\hline User log files & $\square$ Yes $\square$ No & 1 & 2 & 3 & 4 & 5 & 6 & 7. \\
\hline Conversion rate/ROI & $\square$ Yes $\square$ No & 1 & 2 & 3 & 4 & 5 & 6 & 7 \\
\hline Top entry pages & $\square$ Yes $\square$ No & 1 & 2 & 3 & 4 & 5 & 6 & 7 \\
\hline Top exit pages & Yes No & 1 & 2 & 3 & 4 & 5 & 6 & 7 \\
\hline Users by time and day of visit & $\square$ Yes $\square$ No & 1 & 2 & 3 & 4 & 5 & 6 & 7 \\
\hline Top referencing URLs & $\square$ Yes No & 1 & 2 & 3 & 4 & 5 & 6 & 7 \\
\hline
\end{tabular}


18. Some Websites collect user information through various means. Please indicate whether or not your organization collects the following kinds of information. If YES, rate the usefulness of this information in supporting your marketing efforts.

\begin{tabular}{|c|c|c|c|c|c|c|c|c|}
\hline \multirow{3}{*}{$\begin{array}{l}\text { Sources of User Information } \\
\text { Email inquiries }\end{array}$} & \multirow{3}{*}{$\begin{array}{c}\begin{array}{c}\text { Currently Using } \\
\text { (Please } \sqrt{ })\end{array} \\
\square \text { Yes } \square \text { No }\end{array}$} & \multicolumn{7}{|c|}{ Usefulness in supporting marketing efforts? } \\
\hline & & \multicolumn{2}{|c|}{$\begin{array}{l}\text { Not at all } \\
\text { Useful }\end{array}$} & \multirow[b]{2}{*}{3} & \multirow[b]{2}{*}{4} & \multirow[b]{2}{*}{5} & \multicolumn{2}{|c|}{$\begin{array}{r}\text { Extremely } \\
\text { Useful }\end{array}$} \\
\hline & & 1 & 2 & & & & 6 & 7 \\
\hline Online information request forms & 7 Yes No & 1 & 2 & 3 & 4 & 5 & 6 & 7 \\
\hline Online brochure order forms & $\square$ Yes $\square$ No & 1 & 2 & 3 & 4 & 5 & 6 & 7 \\
\hline Online sign-up for coupons/giveaway & $\square$ Yes $\square$ No & 1 & 2. & 3 & 4 & 5 & 6 & 7 \\
\hline Online lottery/sweepstakes & $\square$ Yes $\square$ No & 1 & 2 & 3 & 4 & 5 & 6 & 7 \\
\hline Online reservations/transactions & Yes No & 1 & 2 & 3 & 4 & 5 & 6 & 7 \\
\hline Registration/personalization forms & $\square$ Yes $\square$ No & 1 & 2 & 3 & 4 & 5 & 6 & 7 \\
\hline Surveys & Yes $\perp$ No & 1 & 2 & 3 & 4 & 5 & 6 & 7 \\
\hline Log files & $\square$ Yes $\square$ No & 1 & 2 & 3 & 4 & 5 & 6 & 7 \\
\hline Online chat rooms & - Yes ¿ No & 1 & 2 & 3 & 4 & 5 & 6 & 7 \\
\hline Bulletin boards/ discussion forums & $\square$ Yes $\square$ No & 1 & 2 & 3 & 4 & 5 & 6 & 7 \\
\hline
\end{tabular}

19. Do you analyze the user information/feedback you collect?

$\square$ No (Please skip to Question 20)

Yes

If YES, what kind(s) of user information do you collect and analyze? (Please $\sqrt{ }$ all that apply)

$\square$ Geographic information including zip code, country of residence, etc.

$\square$ Demographics including gender, education, age, etc.

Psychographics including hobbies, interests, etc.

$\square$ Contact information including e-mail address, phone number, etc.

20. How frequently do you update the following aspects of your Website?

\begin{tabular}{|lcccccc|}
\hline Type of material & Daily & Weekly & Monthly & $\begin{array}{c}\text { Every } 6 \\
\text { months }\end{array}$ & Yearly & $\begin{array}{c}\text { Bi- } \\
\text { yearly }\end{array}$ Seldom \\
\hline Web design & $\square$ & $\square$ & $\square$ & $\square$ & $\square$ & $\square$ \\
Web content & $\square$ & $\square$ & & & $\square$
\end{tabular}

Search engine registration

National Laboratory for Tourism and e Commerce

University of Illinois at Urbana-Champaign 
National Survey on Web Marketing Strategies

21. Please rate the importance of the following sources of knowledge or expertise used for developing your Web strategy.

\begin{tabular}{|lccccccc|}
\hline \multicolumn{1}{c}{ Information sources } & \multicolumn{3}{c}{$\begin{array}{c}\text { Not at all } \\
\text { Important }\end{array}$} & & & & \multicolumn{3}{c|}{$\begin{array}{c}\text { Extremely } \\
\text { Important }\end{array}$} \\
\hline Own marketing/sales persons & 1 & 2 & 3 & 4 & 5 & 6 & 7 \\
\hline Own technical staff & 1 & 2 & 3 & 4 & 5 & 6 & 7 \\
\hline Vendor technical/marketing staff & 1 & 2 & 3 & 4 & 5 & 6 & 7 \\
\hline Customers & 1 & 2 & 3 & 4 & 5 & 6 & 7 \\
\hline Competitors & 1 & 2 & 3 & 4 & 5 & 6 & 7 \\
\hline Consultants & 1 & 2 & 3 & 4 & 5 & 6 & 7 \\
\hline Universities/Other research institutions & 1 & 2 & 3 & 4 & 5 & 6 & 7 \\
\hline Government organizations & 1 & 2 & 3 & 4 & 5 & 6 & 7 \\
\hline Industry/Trade associations & 1 & 2 & 3 & 4 & 5 & 6 & 7 \\
\hline Professional conference/meetings & 1 & 2 & 3 & 4 & 5 & 6 & 7 \\
\hline Technical/Trade press, Internet & 1 & 2 & 3 & 4 & 5 & 6 & 7 \\
\hline Fairs/Exhibitions & 1 & 2 & 3 & 4 & 5 & 6 & 7 \\
\hline Journal ads & 1 & 2 & 3 & 4 & 5 & 6 & 7 \\
\hline
\end{tabular}

22. Please indicate the extent to which your website has decreased (or increased) your total printing cost of promotional material including brochures, paper-based advertising, etc. over the past year. (Please $\sqrt{ }$ one)

\footnotetext{
$\square$ Increased by $26 \%$ or more

$\square$ Increased 10 to $25 \%$

$\square$ Has stayed about the same
}

Decreased by $10 \%$ or less

Decreased by 11 to $25 \%$

Decreased by $26 \%$ or more

23. Please indicate the extent to which your website has decreased (or increased) the volume of calls you have received over the past year. (Please $\sqrt{ }$ one)

\footnotetext{
$\square$ Increased by $26 \%$ or more

$\square$ Increased 10 to $25 \%$

$\square$ Has stayed about the same
}

Decreased by $10 \%$ or less

Decreased by 11 to $25 \%$

Decreased by $26 \%$ or more

24. Organizations use Web-based technologies in different ways and with varying intensity. Please indicate which of the following capabilities are integrated into your website. (Please $\sqrt{ }$ all that apply)

$\square$ Our Website is used to broadcast information by providing brochure-like information.

$\square$ Our Website includes advanced capabilities offering interactive queries and requests forms.

$\square$ Our Website includes personalization and recommendation capabilities.

$\square$ Our Website offers online booking and payment capabilities. 
The following questions are related to your organization's general technological environment.

25. How would you rate the success of your organization's Web marketing strategies?

$\begin{array}{lllllllll}\begin{array}{l}\text { Not at all } \\ \text { successful }\end{array} & 1 & 2 & 3 & 4 & 5 & 6 & 7 & \begin{array}{c}\text { Extremely } \\ \text { successful }\end{array}\end{array}$

26. How would you rate your management team's knowledge/skills with Internet technology?

$$
\begin{array}{lllllllll}
\text { Novice } & 1 & 2 & 3 & 4 & 5 & 6 & 7 & \text { Expert }
\end{array}
$$

27. How would you rate your employees' knowledge/skills with Internet technology?

$$
\begin{array}{lllllllll}
\text { Novice } & 1 & 2 & 3 & 4 & 5 & 6 & 7 & \text { Expert }
\end{array}
$$

28. How would you rate your management team's support of Internet technology adoption and implementation?
Not at all
supportive
12
$\begin{array}{lll}4 & 5 & 6\end{array}$
$7 \begin{aligned} & \text { Extremely } \\ & \text { supportive }\end{aligned}$

29. How would you evaluate your management team's direct involvement related to Internet technology operations?

$\begin{array}{lllllllll}\begin{array}{c}\text { Not at all } \\ \text { involved }\end{array} & 1 & 2 & 3 & 4 & 5 & 6 & 7 & \begin{array}{c}\text { Extremely } \\ \text { involved }\end{array} \\ \end{array}$

30. To what extent does your organization provide Internet technology related training programs to employees?
No training at all
2
4
56
$7 \begin{aligned} & \text { Regular } \\ & \text { training }\end{aligned}$

31. Who mainly decides on your organization's Internet strategy?
$\square$ CEO/Director/President/General manager
$\square$ Marketing/Sales Director
$\square$ Webmaster/Web designer
Others (please specify):
$\square$ External agency/consultant 
The following questions ask about the characteristics of the CEO/Director of your organization.

32. How long has the CEO/Director been working in your organization? (Please fill in number) Years

33. How long has he/she been CEO/Director of your organization? (Please fill in number) Years

34. How long has your CEO/Director been working in this industry? (Please fill in number) Years

35. How frequently does your CEO/Director travel for business purposes such as attending conferences, meeting with industry leaders and customers, etc?

$$
\begin{array}{lllllllll}
\begin{array}{l}
\text { Very } \\
\text { Rarely }
\end{array} & 1 & 2 & 3 & 4 & 5 & 6 & 7 & \begin{array}{c}
\text { Very } \\
\text { Frequently }
\end{array}
\end{array}
$$

36. Please indicate your CEO/Director's level of expertise in the following areas:

\begin{tabular}{|lccccccccc|}
\hline \multicolumn{1}{r}{ Area of Expertise } & Low & & & & & & High \\
\hline Accounting/Finance & 1 & 2 & 3 & 4 & 5 & 6 & 7 \\
\hline Sales/Marketing & 1 & 2 & 3 & 4 & 5 & 6 & 7 \\
\hline Management & 1 & 2 & 3 & 4 & 5 & 6 & 7 \\
\hline Computer Systems & 1 & 2 & 3 & 4 & 5 & 6 & 7 \\
\hline
\end{tabular}

37. Your CEO/Director prefers:

\begin{tabular}{|lllllllllll|}
\hline Low risk projects & 1 & 2 & 3 & 4 & 5 & 6 & 7 & High risk projects \\
\hline $\begin{array}{l}\text { Gradual and moderate } \\
\text { reactions to outside changes }\end{array}$ & 1 & 2 & 3 & 4 & 5 & 6 & 7 & $\begin{array}{l}\text { Aggressive and far } \\
\text { reaching reactions to } \\
\text { outside changes }\end{array}$ \\
\hline $\begin{array}{l}\text { Introduce changes after } \\
\text { competitors }\end{array}$ & 1 & 2 & 3 & 4 & 5 & 6 & 7 & $\begin{array}{l}\text { Introduce changes } \\
\text { before competitors }\end{array}$ \\
\hline Time-tested methods & 1 & 2 & 3 & 4 & 5 & 6 & 7 & Innovation \\
\hline
\end{tabular}




\section{National Survey on Web Marketing Strategies}

38. How regularly does your CEO/Director ask for opinions and seek advice from the following groups?

\begin{tabular}{|lcccccccc|}
\hline \multicolumn{1}{c}{ Groups } & \multicolumn{1}{c}{ Never } & & & & Regularly \\
\hline Organization's upper level mgt. & 1 & 2 & 3 & 4 & 5 & 6 & 7 \\
\hline Employees other than mgt. & 1 & 2 & 3 & 4 & 5 & 6 & 7 \\
\hline Customers & 1 & 2 & 3 & 4 & 5 & 6 & 7 \\
\hline Competitors & 1 & 2 & 3 & 4 & 5 & 6 & 7 \\
\hline Consultants & 1 & 2 & 3 & 4 & 5 & 6 & 7 \\
\hline
\end{tabular}

This last section of the survey asks for information about you and will be kept in the strictest confidence and used for statistical purposes only.

39. Please indicate your CEO/Director's level of education. (Please $\sqrt{ }$ one)

$\begin{array}{ll}\square \text { High school } & \square \text { Some college } \\ \square \text { Vocational training } & \square \text { Undergraduate degree }\end{array}$

40. Please provide your current position title:

41. Your age category. (Please $\sqrt{ }$ one)

$\begin{array}{ll}\square 30 \text { years and below } & \square 41 \text { to } 50 \text { years } \\ \square 31 \text { to } 40 \text { years } & \square 51 \text { to } 60 \text { years }\end{array}$

42. Your gender. (Please $\sqrt{ }$ one)

$$
\checkmark \text { Female } \quad \square \text { Male }
$$

Please provide your name and email address if you would like to receive a free copy of the study results.

Name:

Email: 
National Survey on Web Marketing Strategies

Do you have any comments you wish to share?

Thank you again for your time and contribution to this important study!

Daniel R. Fesenmaier, Director

National Laboratory for Tourism and eCommerce

University of Illinois at Urbana-Champaign 


\section{LIST OF REFERENCES}

Adebanjo, D. (2003). Classifying and selecting e-CRM applications: an analysis-based proposal. Management Decision, 41(6), 580-577.

Ahn, J. Y., Kim, S. K., \& Han, K. S. (2003). On the design concepts for CRM system. Industrial Management \& Data Systems, 103(5), 324-331.

Bauer, H. H., Grether, M., \& Leach, M. (2002). Building customer relations over the Internet. Industrial Marketing Management, 31(2), 155-163.

Berry, L. L. (1995). Relationship marketing of services: growing interest, emerging perspectives. Journal of the Academy of Marketing Science, 23(4), 236-245.

Berry, L. L., \& Parasuraman, A. (1993). Building a new academic field- The case of services marketing. Journal of Retailing, 69(1), 13-60.

Buhalis, D. (1998). Strategic use of information technologies in the tourism industry. Tourism Management, 19(5), 409-421.

Buhalis, D. (2000). Marketing the competitive destination of the future. Tourism Management, 21(1), 97-116.

Colby, C. L., \& Parasuraman, A. (2003). Technology still matters. Marketing Management, 12(4), 28-33.

Contractor, N., \& Bishop, A. P. (2000). Reconfiguring Community Networks: The case of PrairieKNOW. In T. Ishida \& K. Isbister, Digital cities: Technologies, experiences and future perspectives (151-164). Berlin: Springer-Verlag.

Cross, R., \& Smith, J. (1995). Customer bonding. Chicago: NTC Business Books.

Crotts, J. C. (1999). Consumer decision making and prepurchase information search. In Mansfield and Pizam (Eds.), Consumer behaviour in travel and tourism (pp. 149-168). Binghamton, NY: Haworth Press.

Damanpour, F. (1991). Organizational innovations: a meta-analysis of effects of determinants and moderators. Academy of Management Journal, 34(3), 555-590.

Davis, F. D., Bagozzi, R. P., \& Warshaw, P. R. (1989). User acceptance of computer technology: A comparison of two theoretical models. Management Science, 35(8), 982-1003.

Davis, R., Oliver-Buchanan, M., \& Brodie, R. (1999). Relationship marketing in electronic commerce environments. Journal of Information Technology, 14(4), 319-331. 
Doolin, B., Burgess, L., \& Cooper, J. (2002). Evaluating the use of the web for tourism marketing: a case study from New Zealand. Tourism Management, 23(5), 557-561.

Dore, L., \& Crouch, G.I. (2003). Promoting destinations: An exploratory study of publicity programs used by national tourism organizations. Journal of Vacation Marketing, 9(2), $137-151$.

Dwyer, F. R., Schurr, P. H., \& Oh, S. (1987). Developing buyer-seller relationships. Journal of Marketing, 51(2), 11-27.

Forman, C. (2005). The corporate digital divide: Determinants of internet adoption. Management Science, 51(14), 641-654.

Frambach, R. T. (1993). An integrated model of organizational adoption and diffusion innovations. European Journal of Marketing, 27(5), 22-41.

Frambach, R. T., \& Schillewaert, N. (2002). Organizational innovation adoption: A multi-level framework of determinants and opportunities for future research. Journal of Business Research, 55(2), 163-176.

Gartrell, R. B. (1988). Destination Marketing for Convention and Visitor Bureaus. Dubuque: Kendall/Hunt Publishing Company.

Gilbert, D., \& Powell-Perry, J. (2003). Exploring developments in web based relationship marketing within the hotel industry. Journal of Hospitality and Leisure Marketing, $10(3 / 4), 5-24$.

Goode, S., \& Stevens, K. (2000). An analysis of the business characteristics of adopters and nonadopters of world wide web technology. Information and Technology Management, $1(1 / 2), 129-154$.

Gretzel, U., Yuan, Y., \& Fesenmaier, D. R. (2000). Preparing for the new economy: Advertising strategies and change in destination marketing organizations. Journal of Travel Research, 39(2), 146-156.

Grönroos, C. (1990). Relationship approach to marketing in service contexts: the marketing and organizational behavior interface. Journal of Business Research, 20(1), 3-11.

Grönroos, C. (1991). The marketing strategy continuum: A marketing concept for the 1990s. Management Decision, 29(1), 7-13.

Grönroos, C. (1994). From marketing mix to relationship marketing: towards a paradigm shift in marketing. Management Decision, 32(2), 4-20. 
Grönroos, C. (1996). Relationship marketing: strategic and tactical implications. Management Decision, 43(4), 5-14.

Grover, V., \& Goslar, M. D. (1993). The initiation, adoption, and implementation of telecommunications technologies in U.S. organizations. Journal of Management Information Systems, 10(1), 141-163.

Grover, V., \& Teng, J. T. C. (1992). An examination of DBMS adoption and success in American organizations. Information \& Management, 23(5), 239-248.

Gummesson, E. (1994). Making relationship marketing operational. International Journal of Service Industry Management, 5(5), 5-20.

Gummesson, E. (1997). Collaborate or compete: Conflicting trends plague service marketers. Marketing Management, 6(3), 17-20.

Hanson, W. (2000). Principles of Internet Marketing. South-Western College Publishing, Ohio: Thomson Learning.

Kim, J., Suh, E., \& Hwang, H. (2003). A model for evaluating the effectiveness of CRM using the balanced scorecard. Journal of Interactive Marketing, 17(2), 5-19.

Koch, D. L., \& Steinhauser, D. W. (1983). Changing corporate culture. Datamation, 29(10), 247256.

Kotler, P., Bowen, J., \& Makens, J. (2003). Chapter 11: Building customer loyalty through quality. In Marketing For Hospitality and Tourism ( $3^{\text {rd }}$ ed., pp.380-440). Upper Saddle River, NJ: Prentice Hall, Inc.

Lefebvre, E., \& Lefebvre, L. A. (1992). Firms innovativeness and CEO characteristics is small manufacturing firms. Journal of Engineering and Technology Management, 9(3/4), 243277.

Lefebvre, L., Mason, R., \& Lefebvre, E. (1997). The influence prism in SMEs: The power of CEO perceptions on technology policy and its organizational impacts. Management Science, 43(6), 856-878.

Lexhagen, M. (2005). The importance of value-added services to support the customer search and purchase process on travel websites. Information Technology and Tourism, 7(2), 119135.

Luck, D., \& Lancaster, G. (2003). E-CRM: Customer relationship marketing in the hotel industry. Managerial Auditing Journal, 18(3), 213-231. 
Main, H. C. (2002). The expansion of technology in small and medium hospitality enterprises with a focus on net technology. Information Technology and Tourism, 4(3/4), 167-174.

Martin, L. M., \& Matlay, H. (2003). Innovative use of the Internet in established small firms: The impact of knowledge management and organizational learning in accessing new opportunities. Qualitative Market Research, 6(1), 18-26.

McCarthy, E. J. (1960). Basic Marketing. Illinois: Homewood.

Nour, M. A., \& Fadlalla, A. (2000). A framework for web marketing strategies. Information Systems Management, 17(2), 41-50.

O’Malley, L., \& Mitussis, D. (2002). Relationship and technology: strategic implications. Journal of Strategic Marketing, 10(3), 225-238.

Pallant, J. (2001). SPSS survival manual: A step by step guide to data analysis using SPSS for Windows. United Kingdom: Open University Press.

Palmer, A., \& McCole, P. (2000). The role of electronic commerce in creating virtual tourism destination marketing organizations. International Journal of Contemporary Hospitality Management, 12(3), 198-204.

Parsons, A., Zeisser, M., \& Waitman, R. (1998). Organizing today for the digital marketing of tomorrow. Journal of Interactive Marketing, 12(1), 31-46.

Payne, A. (Ed.) (1995). Advances in Relationship Marketing. London: Kogan Page.

Rogers, E. M. (1995). Diffusion of Innovations (fourth ed.). New York: The Free Press.

Rogers, E. M., \& Shoemaker, F. F. (1971). Communication of innovations: A cross cultural approach. New York: Free Press.

Rothman, J. (1974). Planning and organizing for social change: Action principles from social research. New York: Columbia University Press.

Scupola, A. (2003). The adoption of internet commerce by SMEs in the South of Italy: An environmental, technological and organizational perspective. Journal of Global Information Technology Management, 6(1), 52-71.

Sharma, A. (2002). Trends in internet-based business-to-business marketing. Industrial Marketing Management, 31(2), 77-84.

Sisoda, R. S., \& Wolfe, D. B. (2000). Information technology: its role in building, maintaining, and enhancing relationships. Thousand Oaks, CA: Sage Publications, Inc. 
Smith, A. D. (2002). Loyalty and e-marketing issues: customer retention on the web. Quarterly Journal of Electronic Commerce, 3(2), 149-161.

So, S., \& Morrison, A.M. (2003). Destination marketing organizations' web site users and nonusers: A comparison of actual visits and revisit intentions. Information Technology and Tourism, 6(2), 129-139.

Stone, M., Woodcock, N., \& Wilson, M. (1996). Managing the change from marketing planning to customer relationship management. Long Range Planning, 29(5), 675-683.

Storbacka, K., Strandvik, T., \& Grönroos, C. (1994). Managing customer relationships for profit: The dynamics of relationship quality. International Journal of Service Industry Management, 5(5), 21-38.

Subramanian, A., \& Nilakanta, S. (1996). Organizational innovativeness: exploring the relationship between organizational determinants of innovation, types of innovations, and measures of organizational performance. Omega, 24(6), 631-647.

Subramanian, C., Shaw, M. J., \& Gardner, D. M. (2000). Product marketing and channel management in electronic commerce. Information Systems Frontier, 1(4), 363-378.

Sussmann, S., \& Baker, M. (1996). Responding to the electronic marketplace: Lessons from destination management systems. International Journal of Hospitality Management, 15(2), 99-112.

Teo, T. S., \& Tan, M. (1998). An empirical study of adopters and non-adopters of the internet in Singapore. Information \& Management, 34(6), 339-345.

Thong, J. Y. L. (1999). An integrated model of information systems adoption in small businesses. Journal of Management Information Systems, 15(4), 187-214.

Tornatzky, L. G., \& Fleischer, M. (1990). The process of technological innovation. Massachusetts: Lexington Books.

Tornatzky, L. G., \& Klein, K. J. (1982). Innovation characteristics and innovation adoptionimplementation: A meta-analysis of findings. IEEE Transactions on Engineering Management, 29(1), 28-45.

Van Niekerk, D. N. R., Brethon, J. P., \& Davies, T. (1999). Going with the flow. Internet Research: Electronic Networking Applications and Policy, 9(2).

Varki, S., \& Wong, S. (2003). Consumer involvement in relationship marketing of services. Journal of Service Resesarch, 6(1), 83-91. 
Vesanen, J., \& Raulas, M. (2006). Building bridges for personalization: A process model for marketing. Journal of Interactive Marketing, 20(1), 5-20.

Walters, D., \& Lancaster, G. (1999). Using the Internet as a channel for commerce. Management Decision, 37(10), 800-816.

Wang, Y., \& Fesenmaeir, D. R. (2006). Identifying the success factors of web-based marketing strategy: an investigation of convention and visitors bureaus in the United States. Journal of Travel Research, 44(3), 239-255.

Wang, Y., \& Russo, S. (June 2006). Conceptualizing and evaluating the functions of destination marketing systems. ISTT Conference, Las Vegas.

Wöber, K., \& Gretzel, U. (2000). Tourism managers' adoption of marketing decision support systems. Journal of Travel Research, 39(2), 172-181.

Yuan, Y., \& Fesenmaier, D. R. (2000). Preparing for the new economy: the use of the internet and intranet in American convention and visitors bureaus. Information Technology and Tourism, 3(2), 71-86.

Yuan, Y., Gretzel, U., \& Fesenmaier, D. R. (2003). Internet technology use by American convention and visitors bureaus. Journal of Travel Research, 41(3), 240-255.

Yuan, Y., Gretzel, U., \& Fesenmaier, D. R. (2006). The role of information technology use in American convention and visitors bureaus. Tourism Management, 27(2), 326-341.

Zablah, A. R., Bellenger, D. N., \& Johnston, W. J. (2004). An evaluation of divergent perspectives on customer relationship management: towards a common understanding of an emerging phenomenon. Industrial Marketing Management, 33(6), 475-489.

Zhu, K., Kraemer, K., \& Xu, S. (2003). Electronic business adoption by European firms: A cross-country assessment of facilitators and inhibitors. European Journal of Information Systems, 12(4), 251-268.

Zhu, K., \& Kraemer, K. L. (2005). Post-adoption variations in usage and value of e-business by organizaions: Cross-country evidence from the retail industry. Information Systems Research, 16(1), 61-84.

Zineldin, M. (2000). Beyond relationship marketing: technologicalship marketing. Marketing Intelligence \& Planning, 18(1), 9-23. 